\title{
The Wishbone Ridge at the Chatham Rise Intersection: Structural Characteristics and Tectonic Implications
}

\author{
by \\ Rachel Siân Barrett
}

A thesis submitted to Victoria University of Wellington in partial fulfilment of the requirements for the degree of Master of Science in Geophysics

School of Geography, Environment and Earth Sciences

Victoria University of Wellington

April, 2017 


\section{Abstract}

Geophysical data show that the West Wishbone Ridge, offshore of eastern New Zealand, is best described as having previously been a crustal transform fault, which first propagated along the eastern margin of the Hikurangi Plateau as subduction along the New Zealand sector of the Gondwana margin began to slow and reorientate between 105 and 101 Ma. Variation in the strike of the West Wishbone Ridge has resulted in contrasting compressional and extensional zones along the ridge. These regimes reflect the direction of strike offset from the direction of fault propagation, and constrain the sense of motion along the West Wishbone Ridge as having been dextral.

We find evidence that Cretaceous subduction along the Chatham Rise margin extended east of the margin offset at $174^{\circ} \mathrm{W}$ that marks the edge of Hikurangi Plateau subduction beneath the margin. Rotation of the Chatham Rise margin between 105 and 101 Ma was accommodated by westward broadening of the extensional zone of deformation associated with the West Wishbone Ridge near its intersection with the Chatham Rise. The amount of offset along the ridge indicates that significant transform motion along the West Wishbone Ridge south of $\sim 40.5^{\circ} \mathrm{S}$ ceased ca. $101 \mathrm{Ma}$, coeval with the cessation of spreading of the Osbourn Trough, and of subduction of the Hikurangi Plateau.

Additionally, we find anomalously thick oceanic crust adjacent to the WWR and north of the Hikurangi Plateau ( $>12 \mathrm{~km}$ thick). This is attributed to the proximity of this crust to the Hikurangi Plateau Large Igneous Province.

The results of this study are based on seismic reflection and magnetic data recently collected during the 2016 R/V Sonne survey SO-246, as well as previously collected seismic reflection profiles and satellite gravity data. 


\section{Acknowledgements}

Firstly, I would like to thank my supervisors Bryan Davy and Tim Stern for their guidance and for generously giving of their time during this project. Thank you for challenging me to think more critically and for helping to shape me into a better scientist.

I wish to thank the Alfred Wegener Institute for Marine and Polar Research (Bremerhaven, Germany) for making seismic lines AWI-20160004 and AWI-20160006 available for this research. I also wish to thank the crew and scientific party of the R/V Sonne SO-246 survey, and in particular the cruise leader Karsten Gohl, for making me so welcome on the 2016 survey of the eastern Chatham Rise region. I also would like to thank GNS Science for making seismic lines CHAT-3 and CHAT-4 available for this research, for making resources available for me to use at GNS Science, Avalon, and for giving me the opportunity to join voyages SO-246 and TAN-1611 (of R/V Tangaroa to the Colville Ridge in Spring 2016). I would also like to thank the GLOBE Claritas support team (particularly Keleigh Jones and Guy Maslen) for their assistance with applying Surface Related Multiple Elimination to the seismic data processed here.

Thank you to the Westergaard family for their financial support and encouragement over the past year. It is so appreciated.

I also wish to extend my thanks to the Geophysics and technical staff at Victoria, especially Huw Horgan for patiently answering my questions about seismic processing in the early stages of this project; and Rupert Sutherland and Simon Lamb for helpful conversations during the course of the thesis.

Thanks to my officemates and friends, Merijn Thornton, Sam Taylor-Offord, Andy McNab and Nicolas Oestreicher: it has been great to work alongside you all this year. Thanks also to Ari Luecker, Shani Meyer, Daniel Herring, Jerome de Vries, Ping Lim and Hannah Brightley. Thanks to Ping Lim and Jiten Patel for proofreading final versions of chapters of this thesis. 
And finally, thanks to my family, to Mum, Dad and Jenni. Thanks for your endless support, encouragement, and belief in me. 


\section{Contents}

Abstract iii

Acknowledgements $\quad$ V

Contents vii

List of Figures $\quad$ xiv

List of Tables $\quad$ XV

1 Introduction $\quad 1$

1.1 Project Overview . . . . . . . . . . . . . . . . 1

1.2 Geological Setting . . . . . . . . . . . . . . . . . . . 3

1.2.1 The Hikurangi Plateau . . . . . . . . . . . . . . . . . . . . 3

1.2.2 The West Wishbone Ridge . . . . . . . . . . . . . . 6

1.2.2.1 An extinct spreading ridge, a region of strike-slip faulting or a former intra-oceanic arc? . . . . . . . 7

1.2.2.2 Crustal age on either side of the West Wishbone Ridge . . . . . . . . . . . . . . . . 8

1.3 Research Voyage SO-246 . . . . . . . . . . . . . . . . . . . 10

1.4 Project Objectives . . . . . . . . . . . . . . . . . . . 11

1.5 Thesis Structure . . . . . . . . . . . . . . . . . . 13

2 Multi-Channel Seismic Reflection Data 15

2.1 Theory . . . . . . . . . . . . . . . . . . 16

2.2 Data Acquisition . . . . . . . . . . . . . . . . . . . 19

2.3 Seismic Processing _. . . . . . . . . . . . . . . . . . . 21

2.3.1 Quality Control . . . . . . . . . . . . . . . 21

2.3.2 Preliminary Processing . . . . . . . . . . . . . . . 23

2.3.3 Pre-Stack Processing . . . . . . . . . . . . . . . . . . 24

2.3.3.1 Brute Stack . . . . . . . . . . . . . . 26 
2.3.3.2 Amplitude Recovery . . . . . . . . . . . . 26

2.3.3.3 Trace Edits . . . . . . . . . . . . . . 26

2.3.3.4 Swell Noise Removal . . . . . . . . . . . . . . . 27

2.3.4 Initial Velocity Analysis . . . . . . . . . . . . . . 27

2.3.5 Multiple Suppression . . . . . . . . . . . . . . . . 32

2.3.5.1 Deconvolution . . . . . . . . . . . . . 32

2.3.5.2 Parabolic Radon Transform and F-K filtering . . . 34

2.3.5.3 Surface Related Multiple Elimination . . . . . . . . 35

2.3.6 Secondary velocity analysis . . . . . . . . . . . . 35

2.3.7 Migration and Finalisation . . . . . . . . . . . . 37

2.4 Additional seismic reflection data . . . . . . . . . . . . . . . 41

2.5 Depth Conversion . . . . . . . . . . . . . . . . . . . . . . . 41

3 Seismic Stratigraphy $\quad 43$

3.1 Hikurangi Plateau and Chatham Rise . . . . . . . . . . . . . . . 44

3.1.1 SEQ Y - Early Oligocene to Late Cretaceous sediments . . . 44

3.1.2 CEN - Cenozoic sediments . . . . . . . . . . . . . . . 44

3.1.2.1 $\mathrm{PP}$ - Pliocene to Pleistocene sediments . . . . . . . 46

3.1.2.2 MIO/OLIG - Late Oligocene to Miocene sediments 46

3.1.3 MES - Mesozoic sediments . . . . . . . . . . . . . . . 46

3.1.4 HKB - Hikurangi Basement . . . . . . . . . . . . . . . 47

3.1.5 Torlesse - Continental crust of the Chatham Rise . . . . . . 47

3.2 Oceanic Crust and sediments . . . . . . . . . . . . . . . . . . 48

3.2.1 Sedimentary cover . . . . . . . . . . . . . . . . . . 48

3.2.2 Oceanic Crust . . . . . . . . . . . . . . . . . . . . . . 48

4 Results and Analysis $\quad 51$

4.1 CHAT $-4 \ldots \ldots \ldots \ldots \ldots$. . . . . . . . . . . . . . 52

4.2 CHAT-3 . . . . . . . . . . . . . . . . 58

4.3 AWI-20160006 . . . . . . . . . . . . . . . 64

4.4 AWI-20160004 . . . . . . . . . . . . . . . . 70

4.5 The West Wishbone Ridge . . . . . . . . . . . . . . . . . . . 74

4.6 Summary . . . . . . . . . . . . . . . . . . . . 77

5 Discussion $\quad 83$

5.1 Moho and Oceanic crust on CHAT-4 . . . . . . . . . . . . . . 85

5.2 Hikurangi Plateau and the Chatham Rise . . . . . . . . . . . . . 88

5.2.1 Modelling a volcanic intrusion . . . . . . . . . . . . . . . 89

5.2.2 Modelling the edge-effect of a slab . . . . . . . . . . . . . . 93 
5.2.3 Gravity modelling across the interface between the Hikurangi Plateau and the continental crust of the Chatham Rise 96

5.3 The West Wishbone Ridge as a Transform Fault . . . . . . . . . . . 104

5.3.1 Sense of motion . . . . . . . . . . . . . . . . . 105

5.3.2 A Leaky Transform Fault? . . . . . . . . . . . . . . . . . . 108

5.4 Summary . . . . . . . . . . . . . . . . . . . . . 109

5.4.1 The south-eastern edge of the Hikurangi Plateau . . . . . . 109

5.4 .2 The West Wishbone Ridge . . . . . . . . . . . . . . . . . . . 110

6 Tectonic Implications and Conclusions 113

6.1 Tectonic Implications . . . . . . . . . . . . . . . . . . . . . . . . 113

6.2 Conclusions . . . . . . . . . . . . . . . . . . . . . . 117

6.3 Suggestions for future work . . . . . . . . . . . . . . 118

$\begin{array}{lr}\text { Bibliography } & 119\end{array}$

$\begin{array}{lr}\text { Appendices } & 126\end{array}$

A Seismic reflection processing sequence for CHAT-3 and CHAT-4127

$\begin{array}{ll}\text { B Magnetic data } & 131\end{array}$

$\begin{array}{ll}\text { C Isostatic mass balancing for gravity modelling } & 133\end{array}$

$\begin{array}{ll}\text { D Final migrated seismic reflection profiles } & 137\end{array}$ 


\section{List of Figures}

1.1 Bathymetric and satellite gravity maps showing the Chatham Rise region and the locations of data referred to in this thesis . . . . . 2

1.2 Ontong-Java Nui super-LIP reconstruction at ca. $120 \mathrm{Ma}$. . . . . . 4

1.3 Regional reconstruction showing the West Wishbone Ridge as a pre115 Ma fracture zone, $115 \mathrm{Ma}$ arc, and post-115 Ma rift feature, as postulated by Mortimer et al. (2006) . . . . . . . . . . . 8

1.4 Bathymetric data across the Wishbone Ridge with age constraints overlain . . . . . . . . . . . . . . . . . . . . . 9

1.5 Scientific crew of the voyage SO-246 of R/V Sonne . . . . . . . . . 12

$1.6 \mathrm{R} / \mathrm{V}$ Sonne during SO-246 surveying . . . . . . . . . . . . . . . 12

2.1 Geometry of multi-channel seismic reflection . . . . . . . . . . . 16

2.2 Types of multiple reflection in layered ground . . . . . . . . . . . 18

2.3 Seismic reflection acquisition set-up on SO-246 . . . . . . . . . . 21

2.4 Flowchart detailing initial quality control processing steps . . . . . 22

2.5 Single fold section of AWI-20160004 . . . . . . . . . . . . . . . 22

2.6 Shot 600 from AWI-20160004 after high-pass filtering . . . . . . . . 23

2.7 Flowchart detailing the preliminary processing steps . . . . . . . . . 24

2.8 Schematic of a common depth point gather . . . . . . . . . . . 25

2.9 Flowchart detailing the pre-stack processing steps . . . . . . . . 25

2.10 CDP stacks showing the effect of applying pre-stack processing steps of amplitude recovery, trace edits and swell noise removal . . . . . . 28

2.11 Amplitude plots highlighting sources of noise on the profiles . . . . 29

2.12 Frequency spectrum of AWI-20160004 after the application of trace edits . . . . . . . . . . . . . . . . . . . 29

2.13 Initial velocity analysis using a semblance spectrum . . . . . . . . 30

2.14 Constant Velocity Analysis on AWI-20160004 . . . . . . . . . . . 31

2.15 Velocity analysis using the Claritas utility isovels . . . . . . . . . 32

2.16 Autocorrelation window to test deconvolution parameters . . . . . . 33 
2.17 CDP stacks to test the effect of multiple removal techniques (Radon Transform and Surface Related Multiple Elimination) . . . . . . . . 36

2.18 Principles of migration . . . . . . . . . . . . . . . . . . . . 38

2.19 Comparing Radon Transform and SRME multiple removal techniques after migration . . . . . . . . . . . . . . . . . . . 39

2.20 Flowchart summarising the total processing sequence applied to AWI-20160006 and AWI-20160004 . . . . . . . . . . . . . . 40

3.1 Portion of migrated seismic profile AWI-20160006, showing seismic stratigraphy which is typical of that overlying the Hikurangi Plateau further west along the Chatham Rise margin . . . . . . . . . . . . . 45

3.2 Portion of migrated seismic profile CHAT-4, highlighting stratigraphy which is typical of oceanic crust . . . . . . . . . . . . . 49

4.1 Bathymetry and Satellite Gravity maps highlighting the position of the four profiles discussed in this chapter . . . . . . . . . . . . 52

4.2 Time-Migrated seismic reflection profile and satellite gravity anomaly data across CHAT-4, with boxed overlays showing the location of later figures . . . . . . . . . . . . . . . . . 53

4.3 Portion of the time-migrated seismic profile CHAT-4 between CDPs 5600 to 8500 , showing the shear zone at the base of the crust, and the deformation above that feature. . . . . . . . . . . . 56

4.4 Portion of the time-migrated seismic profile CHAT-4 between CDPs 3500 and 6000 , showing compressional faulting zones. . . . . . . . 57

4.5 Portion of the time-migrated seismic profile CHAT-4 between CDPs 350 and 3500, showing thrust faulting . . . . . . . . . . . . 58

4.6 Time-Migrated seismic reflection profile and satellite gravity anomaly data across CHAT-3, with boxed overlays showing the location of later figures . . . . . . . . . . . . . . . . . . . . . 59

4.7 Portion of the time-migrated seismic profile CHAT-3 between CDPs 1500 and 4000, showing the Hikurangi Plateau under-thrusting beneath the Chatham Rise margin . . . . . . . . . . . . . . . . 61

4.8 Portion of the time-migrated seismic profile CHAT-3 between CDPs 4000 and 7000, showing the accretionary prism structure south-east of rotated block C3-RB1 . . . . . . . . . . . . . . . . .

4.9 Portion of the time-migrated seismic profile CHAT-3 between CDPs 7000 and 10000, showing the half-graben south-east of rotated block

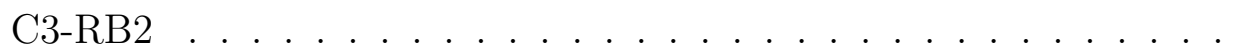


4.10 Portion of the time-migrated seismic profile CHAT-3 from CDP 11000 to the south-east end of the profile, showing the south-eastern series of rotated fault blocks . . . . . . . . . . . . . . . . . . . 64

4.11 Time-Migrated seismic reflection profile and satellite gravity anomaly data across AWI-20160006, with boxed overlays showing the location of later figures . . . . . . . . . . . . . . . . . . . 65

4.12 Portion of the time-migrated seismic profile AWI-20160006 between CDPs 3350 and 1000, showing rotated block faults A6-RB1 and

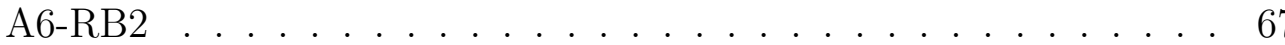

4.13 Portion of the time-migrated seismic profile AWI-20160006 between CDPs 1500 and 250, showing the half-grabens on the south-east of this profile

4.14 Acoustic backscatter and multi-beam images showing surfacial lava flow on AWI-20160006 . . . . . . . . . . . . . . . . . .

4.15 Time-Migrated seismic reflection profile and satellite gravity anomaly data across AWI-20160004, with boxed overlays showing the location of later figures . . . . . . . . . . . . . . . . . . . 71

4.16 Portion of the time-migrated seismic profile AWI-20160004 between CDPs 1 and 1300, showing the location of interpreted Cretaceous subduction on this profile . . . . . . . . . . . . . . . . 72

4.17 Portion of the time-migrated seismic profile AWI-20160004 between CDPs 2250 and the south-east end of the profile, showing a series of half-grabens and rotated fault blocks . . . . . . . . . . . . . 74

4.18 Time-migrated seismic reflection profile across CHAT-4, with interpretations overlain . . . . . . . . . . . . . . 78

4.19 Time-migrated seismic reflection profile across CHAT-3, with interpretations overlain . . . . . . . . . . . . . . . . . 79

4.20 Time-migrated seismic reflection profile across AWI-20160006, with interpretations overlain . . . . . . . . . . . . . . . 80

4.21 Time-migrated seismic reflection profile across AWI-20160004, with interpretations overlain . . . . . . . . . . . . . . . 81

5.1 Bathymetry and satellite gravity maps of the broader Chatham Rise region with annotations highlighting key results from previous work as well as the characteristics of the four profiles studied here . . . . 84

5.2 Gravity model across profile CHAT-4 . . . . . . . . . . . . . . 87 
5.3 Portion of seismic reflection profile AWI-20160006 showing the volcanic feature A6-V1, and the magnetic and gravity anomalies at this location . . . . . . . . . . . . . . . . . . . . . . . . . . 89

5.4 The gravity and magnetic anomalies which would result from an inclined dipole within a sphere . . . . . . . . . . . . . . . . . . 92

5.5 The net gravity anomaly and vertical-component of the magnetic anomaly which would result from the modelled edge-effect of an anomalous slab . . . . . . . . . . . . . . . . 95

5.6 Gravity model across profile CHAT-3 . . . . . . . . . . . . . . . . . 100

5.7 Gravity model across profile AWI-20160006 . . . . . . . . . . . . . . 102

5.8 Gravity model across profile AWI-20160004 . . . . . . . . . . . . . . 103

5.9 Schematic illustrating the compressional and extensional faulting regimes created when a fault steps laterally along strike. . . . . . . 106

5.10 Line drawing of the Wishbone Ridge showing the location of compressional and extensional regimes along the WWR . . . . . . . . 107

6.1 Tectonic schematic showing the revised sequence of Cretaceous motion at the intersection of the West Wishbone Ridge with the Chatham Rise . . . . . . . . . . . . . . . . . . . . . 114

A.1 Flowchart summarising the processing sequence for CHAT-3 and CHAT-4, which was developed and applied by Robertson Reseach (2002) . . . . . . . . . . . . . . . . . . . 129

C.1 Isostatic mass balancing columns constructed for the $\mathrm{E}$ and $\mathrm{W}$ ends of CHAT-4. . . . . . . . . . . . . . . . . . . . . . 134

C.2 Isostatic mass balancing columns constructed for the SE and NW ends of CHAT-3. . . . . . . . . . . . . . . . . . . . . . . 134

C.3 Isostatic mass balancing columns constructed for the SE and NW ends of AWI-20160006. . . . . . . . . . . . . . . . . . 135

C.4 Isostatic mass balancing columns constructed for the SE and NW ends of AWI-20160004. . . . . . . . . . . . . . . . . . . . . 135 


\section{List of Tables}

1.1 Suggested timing of Hikurangi-Gondwana Subduction Margin Events from previous literature ............... 6

2.1 Seismic acquisition parameters for profiles AWI-20160004 and AWI-

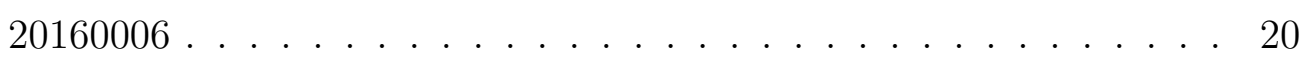

5.1 Geophysical characteristics of oceanic crust . . . . . . . . . . . 87

5.2 Parameters and equations for gravity and magnetic modelling of simple geometric structures . . . . . . . . . . . . . . . . . 91

5.3 Geophysical characteristics of the Hikurangi Plateau and continental crust . . . . . . . . . . . . . . . . . . . . 97

A.1 Seismic acquisition parameters for profiles CHAT-3 and CHAT-4 . . 128 


\section{Chapter 1}

\section{Introduction}

\subsection{Project Overview}

The Wishbone Ridge is an oceanic feature which extends southwards from the eastern end of the Osbourn Trough spreading centre at $26^{\circ} \mathrm{S}$, and is apparent in high-resolution bathymetry and gravity anomaly data (Figure 1.1). South of $31^{\circ} \mathrm{S}$, the Wishbone Ridge divides into the southward-striking East Wishbone Ridge (EWR) and south-west-striking West Wishbone Ridge (WWR). The WWR intersects the northern margin of the Chatham Rise at $171.5^{\circ} \mathrm{W}$ (Figure 1.1).

The nature of the WWR and what motion may have been transferred along it remain uncertain, although several theories have been suggested. These range from the WWR being an extinct spreading ridge (Luyendyk, 1995), that strikeslip motion was fed southwards along it (Sutherland and Hollis, 2001, Davy et al., 2008), or that it was an intra-oceanic rift zone (Mortimer et al., 2006); so, it is a plate boundary, but of unknown type.

Using newly acquired seismic reflection profiles orientated roughly perpendicular to the strike of the WWR, together with magnetic data and gravity anomalies calculated from satellite altimetry data (Sandwell et al., 2014), this study aims to 


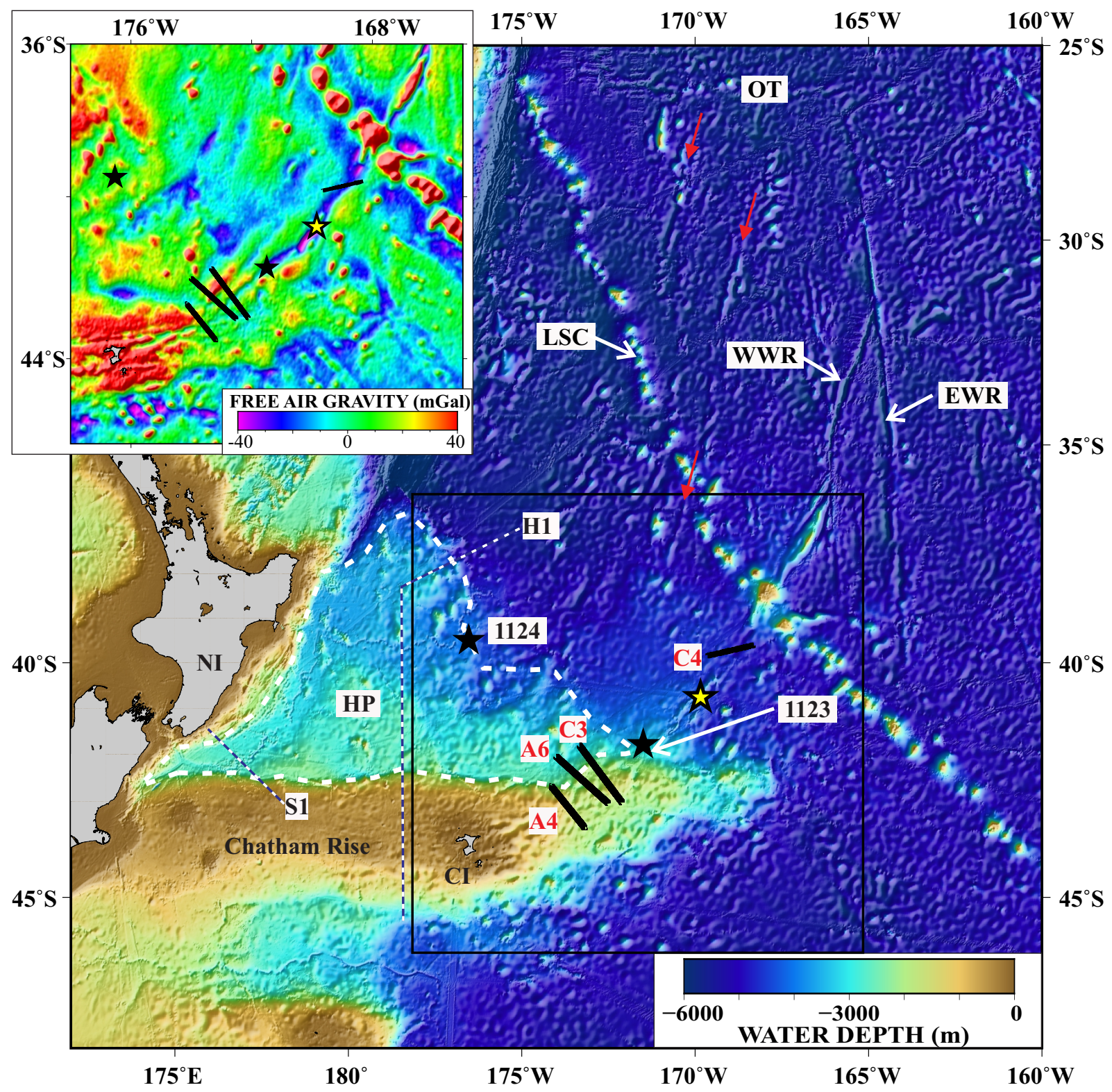

Figure 1.1: Bathymetric map showing the Chatham Rise region and the locations of data referred to in this thesis. Inset shows satellite altimetry derived gravity data (Sandwell et al., 2014) (outlined by black box overlay on bathymetry data). The dotted white line shows the outline of the Hikurangi Plateau (HP) as seen at the surface. OT = Osbourn Trough; NI $=$ North Island of New Zealand; CI $=$ Chatham Islands; LSC $=$ Louisville Seamount Chain; WWR = West Wishbone Ridge; EWR = East Wishbone Ridge. The black stars labelled as 1124 and 1123 mark the locations of ODP sites 1124 and 1123 respectively. The yellow star marks the location of a dredge collected from the WWR (Mortimer et al., 2006). The black lines indicate seismic data analysed in this thesis: A4 $=$ AWI-20160004; A6 = AWI-20160006; C3 = CHAT-3; C4 = CHAT-4. White/black lines: $\mathrm{H} 1=\mathrm{HKDC} 1 ; \mathrm{S} 1=\mathrm{SAHKE}-1$. Red arrows highlight the strike of fracture zones. Bathymetric data is from the General Bathymetric Chart of the Oceans (GEBCO) 2014. 
better constrain the structure of the WWR, what motion was fed along it, and the timing of any motion. Of particular interest is the intersection between the WWR and the Chatham Rise and the nature of the interaction of the WWR with this margin.

\subsection{Geological Setting}

\subsubsection{The Hikurangi Plateau}

The Hikurangi Plateau is a Large Igneous Province (LIP) (Mortimer and Parkinson, 1996) which lies east of New Zealand (Figure 1.1). LIPs are predominantly mafic in composition and, while a number of theories have been suggested, are commonly thought to result from ascending mantle plumes (Taylor, 2006).

The western margin of the Hikurangi Plateau is currently being subducted beneath the North Island of New Zealand at the Hikurangi Trench at an average rate of 44 mm/yr (DeMets et al., 1994). To the south, geophysical and geological data reveal that the Hikurangi Plateau underlies the Chatham Rise (Figure 1.1), beneath which it subducted during the Late Cretaceous (Bradshaw, 1989, Wood and Davy, 1994). At the time of this subduction, the Chatham Rise marked the northern margin of the New Zealand sector of Gondwana. The southernmost extent of the Hikurangi Plateau remains under discussion (e.g. Davy et al., 2008, Reyners et al., 2011, Davy, 2014).

Geochemical and age distribution data indicate that the Hikurangi Plateau is comparable in both age and composition to the Manihiki and Ontong-Java Plateaux (Mahoney et al., 1993, Billen and Stock, 2000) which lie to the north and northwest of Hikurangi Plateau respectively. These similarities led Taylor (2006) to suggest a super-LIP, combining the Ontong-Java, Manihiki and Hikurangi Plateaux (Ontong-Java Nui - reconstruction shown in Figure 1.2), and initially located near 


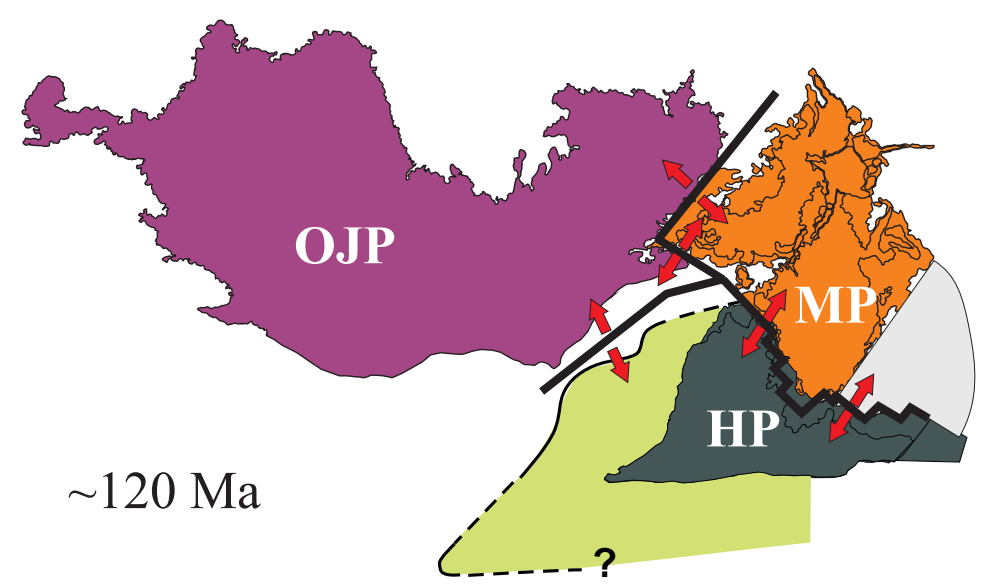

Figure 1.2: A reconstruction at ca. $120 \mathrm{Ma}$ of the three plateaux - Ontong-Java (OJP), Manihiki (MP) and Hikurangi (HP) - shows a good fit of their edges. The light green region shows the extension to Hikurangi Plateau inferred from Reyners et al. (2011). Modified from Davy (2014).

the Tongareva triple junction. The first stage of Ontong-Java Nui volcanism occurred ca. $123 \mathrm{Ma}$ (Neal et al., 1997). It is estimated that this super-LIP covered 1.1\% of Earth's surface at the time of formation (Hochmuth et al., 2015). This theory of a single emplacement event for the three plateaux has been widely adopted (e.g. Davy et al., 2008, Reyners et al., 2011, Chandler et al., 2012).

Rifting of Ontong-Java Nui initiated ca. 120 Ma, soon after the initial volcanism stage of the super-LIP (Taylor, 2006, Worthington et al., 2006). Plate motion data and rotated block basement structure along the north-eastern Hikurangi Plateau indicate that rifting of the Hikurangi and Manihiki plateaux occurred at the Osbourn Trough (Billen and Stock, 2000, Downey et al., 2007). The Hikurangi Plateau initially migrated towards the SSW. When it reached the Gondwana margin, the Hikurangi Plateau began to subduct (Wood and Davy, 1994) and can be traced 50 - $100 \mathrm{~km}$ beneath the Chatham Rise on seismic reflection profiles (Davy et al., 2008). The timing of this impact on the Chatham Rise margin has been suggested to be between 110 and 105 Ma (Davy et al., 2008, Davy, 2014, Reyners et al., 2017). This corresponds with a regional change in tectonic regime from convergent to extensional (Bradshaw, 1989, Laird and Bradshaw, 2004). Following the impact of the Hikurangi Plateau with the Chatham Rise, or perhaps 
as a result of this impact (Bradshaw, 1989, Wood and Davy, 1994), subduction along the margin began to stall ca. 105 Ma (Davy et al., 2008, Reyners et al., 2011). A modern-day analogue exists at the North Solomon Trench, east of Papua New Guinea, where the Ontong-Java Plateau is thought to be stalling subduction (Mann and Taira, 2004, Miura et al., 2004).

Uncertainties in the timing of events in this region arise because much of the oceanic crust in the western Pacific was emplaced during the Cretaceous Normal Superchron (Chron 34) (Sutherland, 1999). This means that the timing of the onset, slowing, and cessation of subduction at the Chatham Rise margin cannot be constrained by magnetic seafloor-spreading anomalies. Consequently, timing estimates are primarily based on the amount of the Hikurangi Plateau subducted beneath the continental crust of the Chatham Rise and the timing of initial Gondwana margin deformation (Davy et al., 2008, Reyners et al., 2017).

Between 105 and $101 \mathrm{Ma}$, the rate of subduction slowed (most significantly onshore and more gradually offshore), resulting in an anticlockwise rotation (to N-S orientation) of sectors of the convergent margin offshore before subduction ceased altogether (Davy, 2014, Zhang and Li, 2016). This rotation was accommodated by margin offset and offshore extension zones which formed between, and within, rotated crustal blocks, and are evident in both gravity and seismic profiles (Davy et al., 2008, Davy, 2014). Seafloor spreading fabric in the vicinity of the Osbourn Trough indicates that the region which extends north of the Gondwana margin to the Osbourn Trough followed this same sequence of slowing, rotation and cessation of motion over the same period (Downey et al., 2007, Davy et al., 2008). Cessation of spreading at this time is supported by a recently dated basaltic basement sample from $250 \mathrm{~km}$ north of the Osbourn Trough. This sample indicates that seafloor-spreading at the Osbourn Trough ceased ca. $101 \mathrm{Ma}$ (Zhang and Li, 2016).

A summary of this sequence of events is shown in Table 1.1. 
Table 1.1: Suggested timing of Hikurangi-Gondwana Subduction Margin Events from previous literature

\begin{tabular}{|c|c|c|}
\hline Age & Event & Reference \\
\hline ca. $123 \mathrm{Ma}$ & $\begin{array}{l}\text { First volcanism stage of Ontong- } \\
\text { Java Nui super-LIP }\end{array}$ & Neal et al. (1997) \\
\hline ca. $120 \mathrm{Ma}$ & Onset of Ontong-Java Nui rifting & $\begin{array}{l}\text { Taylor (2006), Wor- } \\
\text { thington et al. (2006) }\end{array}$ \\
\hline $110-105 \mathrm{Ma}$ & $\begin{array}{l}\text { Hikurangi Plateau first enters the } \\
\text { Gondwana margin }\end{array}$ & $\begin{array}{l}\text { Davy et al. (2008), } \\
\text { Davy (2014), Reyners } \\
\text { et al. (2017) }\end{array}$ \\
\hline 110-105 Ma & $\begin{array}{l}\text { Regional tectonic regime changes } \\
\text { from convergent to extensional }\end{array}$ & $\begin{array}{l}\text { Bradshaw (1989), Laird } \\
\text { and Bradshaw (2004) }\end{array}$ \\
\hline ca. $105 \mathrm{Ma}$ & Subduction begins to stall onshore & $\begin{array}{l}\text { Davy et al. (2008), } \\
\text { Davy (2014) }\end{array}$ \\
\hline 105-101 Ma & $\begin{array}{l}\text { Convergent margin rotation, accom- } \\
\text { modated by margin offset and off- } \\
\text { shore extension }\end{array}$ & Davy (2014) \\
\hline $101 \mathrm{Ma}$ & $\begin{array}{l}\text { Spreading ceases at the Osbourn } \\
\text { Trough. Subduction at the Gond- } \\
\text { wana margin ceases. }\end{array}$ & Zhang and Li (2016) \\
\hline
\end{tabular}

\subsubsection{The West Wishbone Ridge}

At its southern end, the West Wishbone Ridge (WWR) is coincident with the eastern margin of the Hikurangi Plateau, intersecting the northern margin of the Chatham Rise at $\sim 171.5^{\circ} \mathrm{W}$ (Figure 1.1). The extent of the WWR south of this intersection is not obvious from either satellite gravity or bathymetry maps (Figure 1.1). Sutherland and Hollis (2001) suggested that the WWR can be extended westwards through the Chatham Islands, based on satellite altimetry-derived gravity data (Figure 1.1); however, it is also possible that the WWR extends southwards onto the Campbell Plateau, extends east of the Campbell Plateau, ceases at the Chatham Rise margin, or is subdivided into some combination of these. North of 
$42^{\circ} \mathrm{S}$, the WWR lies east of oceanic crust which formed at the Osbourn Trough (Billen and Stock, 2000). The Louisville Seamount Chain crosses the WWR at approximately $167^{\circ} \mathrm{W}$. This seamount chain was formed by hotspot volcanism from ca. $79 \mathrm{Ma}$ (Beier et al., 2011).

The region between the north-eastern margin of the Hikurangi Plateau and the Osbourn Trough is marked by NNE-striking fracture zones (Figure 1.1 Davy, 2014). The crust immediately west of the WWR is characterised by similarly striking, parallel ridge structures that have been suggested to be volcanic in nature (Hoernle and Participants, 2003, Davy et al., 2008). As discussed in the Project Overview (Section 1.1), several theories have been suggested for what motion may have occurred along the WWR. These theories are discussed in the following section.

\subsubsection{The West Wishbone Ridge: An extinct spreading ridge, a re- gion of strike-slip faulting or a former intra-oceanic arc?}

Based on similarities of the gravity signature of the WWR with stalled spreading ridges west of the Antarctic Peninsula and in the west Scotia Sea (Sandwell and Smith, 1992), Luyendyk (1995) suggested that the WWR marks the rift valley of such a spreading ridge that stalled outboard of the trench. However, the identification of the Osbourn Trough (Figure 1.1) as an extinct spreading ridge (Billen and Stock, 2000) revealed that this stalled-rift model for the WWR is unlikely. Strike-slip motion was suggested for the WWR (Sutherland and Hollis, 2001, Davy et al., 2008) and is consistent with bathymetric fabric evident in multibeam data (Davy et al., 2008). On the basis of satellite altimetry-derived gravity data (Figure 1.1), Sutherland and Hollis (2001) suggested that the WWR extends through the Chatham Islands.

Two lavas and a volcaniclastic sandstone recovered from the WWR at $40.45^{\circ} \mathrm{S}$ (Figure 1.1) have an average age of $115 \pm 1 \mathrm{Ma}$ (Mortimer et al., 2006). Analysis of 


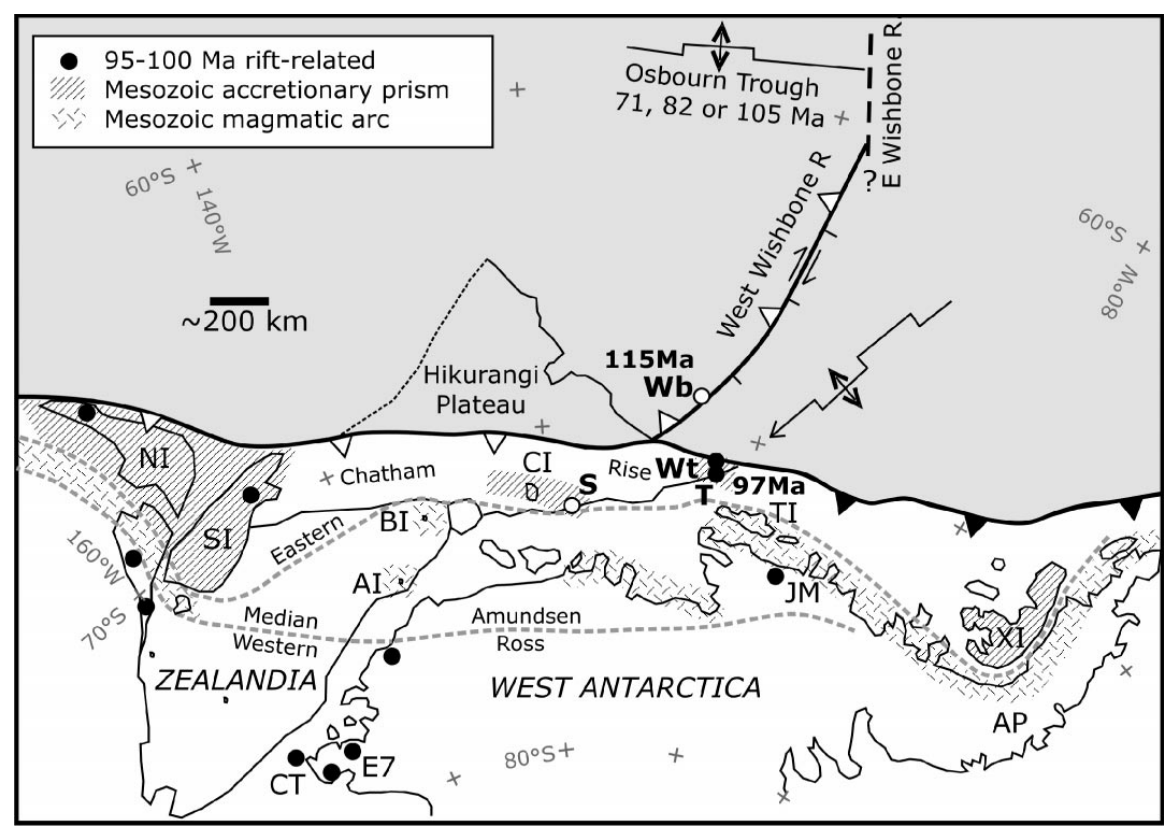

Figure 1.3: Reconstruction at ca. 90 Ma from Mortimer et al. (2006), showing their suggestion of the WWR as a pre-115 Ma fracture zone, $115 \mathrm{Ma}$ arc, and post-115 Ma rift feature. The sense of strike slip and arc polarity along the West Wishbone Ridge are speculative.

these samples revealed low concentrations of High Field Strength Elements (HFSE) and high concentrations of Large Ion Lithophile Elements (LILE), characteristics indicative of slab de-watering and subduction. This led Mortimer et al. (2006) to postulate that the WWR was an intra-oceanic fracture zone prior to $115 \mathrm{Ma}$, an arc at $115 \mathrm{Ma}$, and a rift system after this time (Figure 1.3).

The chemical composition of dredged lava samples from the Louisville Seamount Chain seamounts which overlie the WWR at $167^{\circ} \mathrm{W}$ (Figure 1.1) is indicative of intra-plate oceanic basalts, rather than subduction-related arc magmatism at this location (Beier et al., 2011).

\subsubsection{Crustal age on either side of the West Wishbone Ridge}

Similarly to the crust elsewhere in the region, the ages of the crust on either side of the WWR are poorly constrained by seafloor anomalies (Figure 1.4). This has proved to be a problem for determining both the type and timing of motion along 
the WWR.

Oceanic crust west of the WWR and north of the Hikurangi Plateau was formed at the Osbourn Trough between the onset of rifting ca. 120 Ma (Mortimer et al., 2006, Taylor, 2006) and cessation of rifting ca. 101 Ma (Zhang and Li, 2016). If the spreading rate was constant until cessation, this indicates a full spreading rate of approximately $190 \mathrm{~mm} / \mathrm{yr}$ (Zhang and Li, 2016).

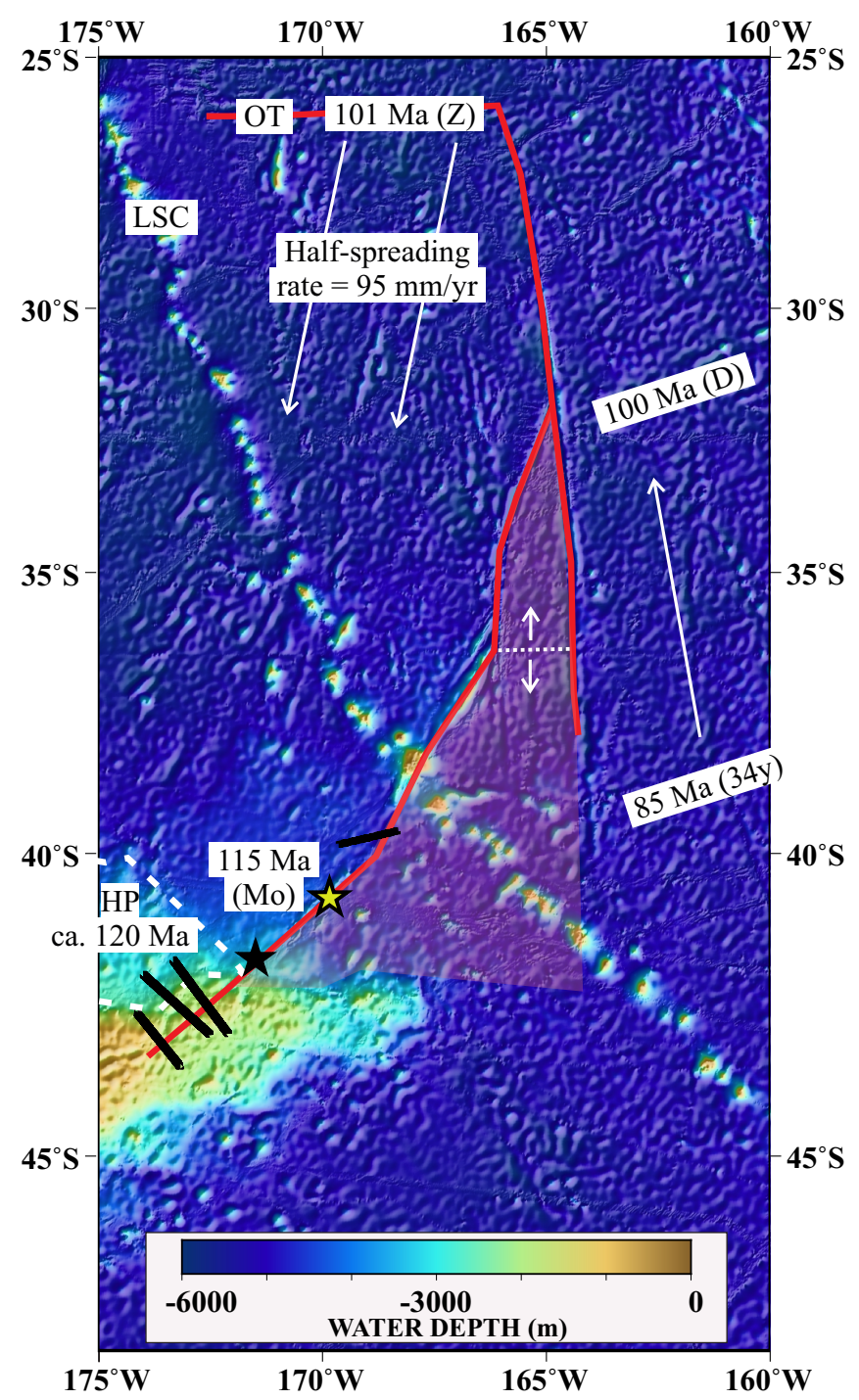

Figure 1.4: Bathymetric data across the Wishbone Ridge with age constraints overlain. The shaded red section highlights the region between the West and East Wishbone Ridges. Ages within this region are poorly constrained. The white arrows delineate the direction of seafloor spreading during the Cretaceous. White dotted line $=$ outline of HP (Hikurangi Plateau). OT = Osbourn Trough; LSC = Louisville Seamount Chain. Z = Zhang and Li (2016); D = Davy (2014); Mo = Mortimer et al. (2006). 
The oceanic crust east of the East Wishbone Ridge (EWR) (Figure 1.4) was formed at the Pacific-Antarctic Rise (Billen and Stock, 2000). Magnetic anomaly 34y (ca. $85 \mathrm{Ma}$ ) is mapped east of the southern extent of the EWR (Larter et al., 2002), and Davy (2014) estimated the crust at $32^{\circ} \mathrm{S}$ to be ca. $100 \mathrm{Ma}$ (Figure 1.4).

Müller et al. (2008) linearly interpolated seafloor spreading isochrons in the direction of spreading to create a global model of crustal age, spreading rate and asymmetry. Beier et al. (2011) used the results of this model to estimate the age of the crust along the Louisville Seamount Chain (LSC), suggesting an age of ca. $80 \mathrm{Ma}$ on the east of the EWR, and ca. 135 Ma west of the EWR, where it crosses the LSC (Figure 1.4). However, as much of the crust in this region was formed during the Cretaceous Normal Superchron, magnetic anomalies provide an unreliable estimate of crustal age in the region. Consequently, the age of the crust between the EWR and WWR remains poorly constrained.

\subsection{Research Voyage SO-246}

Research voyage SO-246 of R/V Sonne acquired geophysical and geological data across the Eastern Chatham Rise between 1 February and 21 March 2016 (Figures 1.5 and 1.6). The primary objectives of the voyage were to study the process of super-continent break-up and the change from convergent to extensional tectonic regimes associated with the cessation of subduction at the Gondwana margin in the Cretaceous (Gohl et al., 2016). The Hikurangi Plateau is thought to have played a significant role in the continental rifting and break-up of Gondwana (Sutherland and Hollis, 2001, Davy et al., 2008). Better understanding of the WWR, which lies along the eastern margin of the Hikurangi Plateau, could provide further insight into the tectonics of the region at that time.

Two multi-channel seismic reflection profiles (AWI-20160004 and AWI-20160006) collected during the SO-246 voyage were made available for this thesis courtesy 
of the Alfred Wegener Institute for Polar and Marine Research (AWI - Bremerhaven, Germany). These two profiles were processed and interpreted as part of this thesis, providing important information about the nature of the WWR near its intersection with the Chatham Rise. These profiles were supplemented by two other seismic reflection profiles (CHAT-3 and CHAT-4) which were collected by MV Geco Resolution during 2001 on behalf of GNS Science who made these profiles available for this thesis. Magnetic profiles collected during SO-246 and satellite altimetry-derived gravity data were also used to aid in interpretation.

\section{$1.4 \quad$ Project Objectives}

This study seeks to address the following questions:

1. What do the seismic profiles CHAT-4, CHAT-3, AWI-20160006 and AWI20160004 (Figure 1.1) reveal about the nature of the WWR along strike? How does this relate to what previous studies have suggested, i.e. can the WWR be described as a rift structure, does it show evidence of convergence, or is it dominated by transform motion?

2. What happens to the WWR after its intersection with the northern margin of the Chatham Rise at $171.5^{\circ} \mathrm{W}$ ? Can it be mapped through and/or beyond the Chatham Rise?

3. Can the relative timing of any motion which occurred along the WWR be constrained based on the results of this study? 


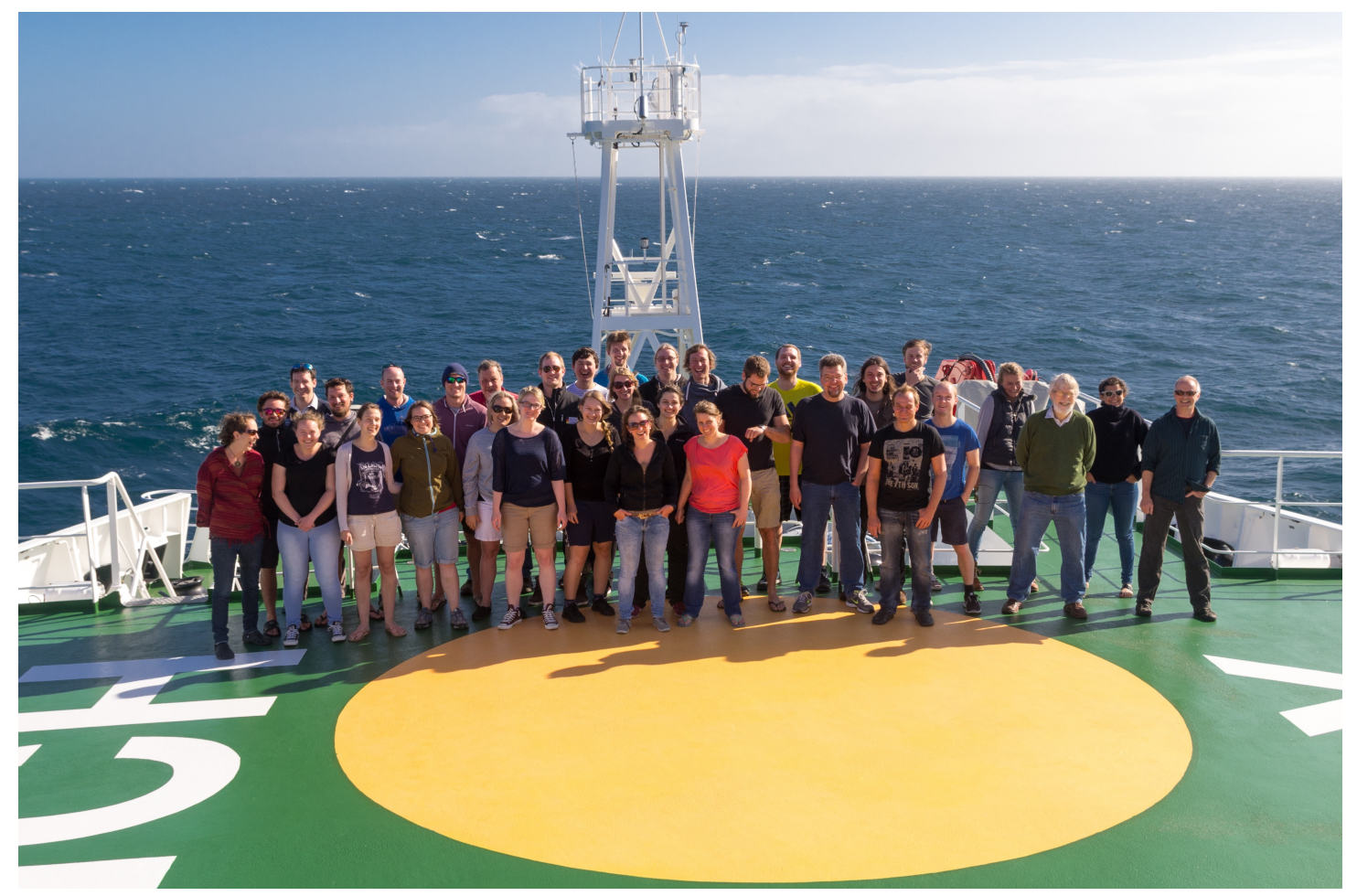

Figure 1.5: Scientific crew of the voyage SO-246 of R/V Sonne

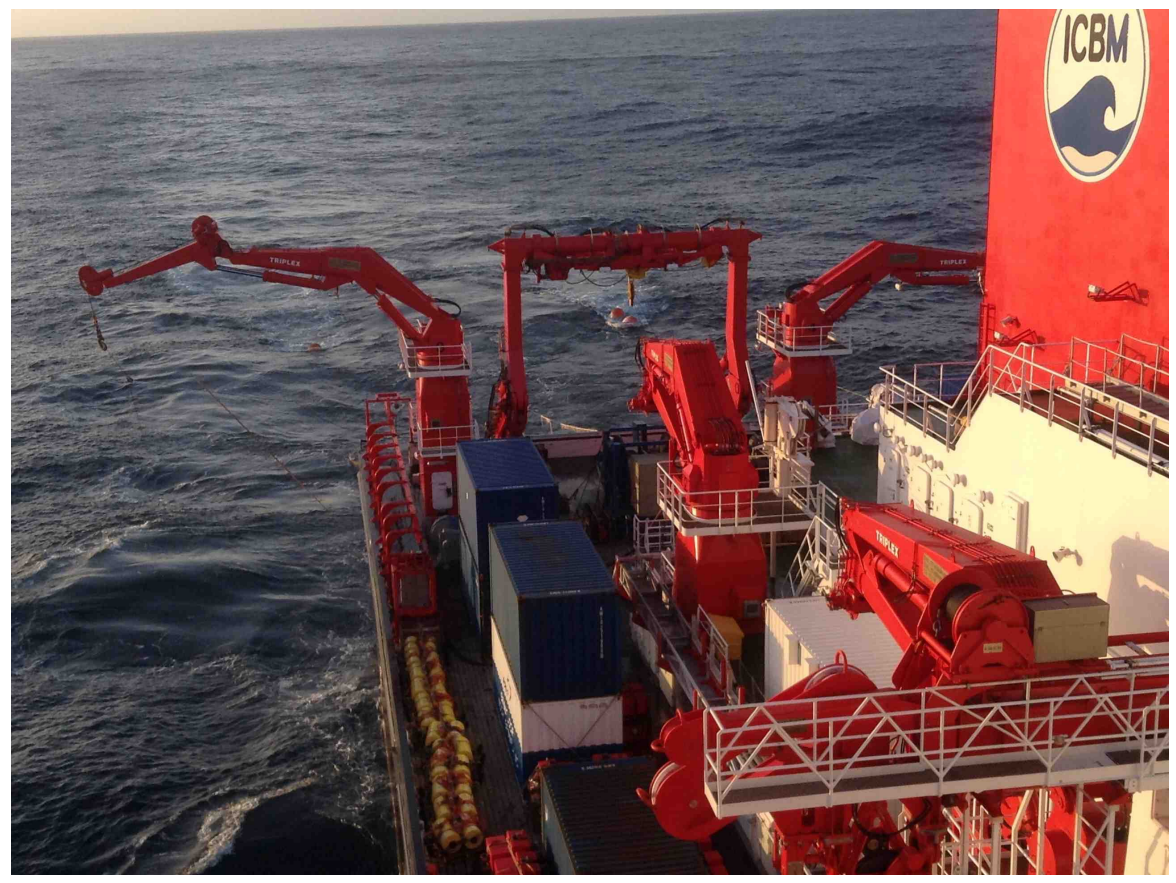

Figure 1.6: R/V Sonne tows the seismic streamer, seismic airgun arrays, the magnetometer and the passive acoustic monitoring system during SO-246 surveying (Photo: K. Gohl). 


\subsection{Thesis Structure}

- Chapter 1 (this chapter): An overview of this project, a discussion of the geological setting and the various theories that have been suggested for the nature of (and motion along) the West Wishbone Ridge, an overview of research voyage SO-246 of $\mathrm{R} / \mathrm{V}$ Sonne, and project objectives.

- Chapter 2: An overview of the theory of seismic reflection, and a discussion of the acquisition and seismic processing of two of the four seismic profiles studied as part of this thesis.

- Chapter 3: An overview of the seismic stratigraphy interpreted in this study, including example cross sections from two profiles.

- Chapter 4: An interpretation of four seismic profiles that cross the West Wishbone Ridge near its intersection with the Chatham Rise margin. Where present, magnetic and gravity data across the profiles are incorporated to aid in this interpretation.

- Chapter 5: A discussion of the nature of the crust on CHAT-4, the interaction between the south-east edge of Hikurangi Plateau and the continental crust of the Chatham Rise, and the nature of the West Wishbone Ridge. Gravity and magnetic modelling across those four profiles interpreted in Chapter 4 guides initial discussion.

- Chapter 6: A discussion of the tectonic implications of these findings, conclusions drawn from this study and suggestions for future work. 


\section{Chapter 2}

\section{Multi-Channel Seismic Reflection}

\section{Data}

This chapter outlines the theory of the multi-channel seismic reflection method, and discusses the acquisition and processing sequence applied to seismic reflection profiles AWI-20160004 and AWI-20160006. These profiles were acquired by the Alfred Wegener Institute (AWI - Bremerhaven, Germany) using R/V Sonne in March 2016 as part of the SO-246: CHATHAM RISE project. Processing of profiles AWI-20160004 and AWI-20160006 was undertaken by the author using GLOBE Claritas $^{\mathrm{TM}}$, Version 6.3.1.12576 - Production (Ravens, 1995).

Two additional seismic reflection profiles (CHAT-3 and CHAT-4) were interpreted for this study. These profiles were collected in 2001 by M/V Geco Resolution on behalf of GNS Science, and were processed by Robertson Research (Perth, Australia). The acquisition of these profiles is briefly outlined here, and details of the processing sequence can be found in Appendix A.

The seismic reflection method is well documented, and has been extensively used to image sub-surface structures, particularly by the exploration industry. Consequently, it should be noted that this chapter serves only as an overview of the 
theory, and the acquisition and processing parameters applied to profiles AWI20160006 and AWI-20160004. For a more in-depth analysis, the reader is referred to the work of Yilmaz (2001), or to general geophysics textbooks - such as those by Kearey et al. (2002) and Reynolds (1997).

\subsection{Theory}

The seismic reflection method produces an image of the subsurface by recording the time taken for a seismic wave to travel from a source, reflect off an interface across which there is an acoustic impedance contrast, and arrive at a receiver (Figure 2.1). There are two types of seismic waves which travel through the body of the earth - compressional $(\mathrm{P})$ and shear $(\mathrm{S})$ waves. S-waves cannot be transmitted through water and so, because this study is concerned only with marine seismic reflection data with near-vertical incidence angles (Fowler, 2005), all discussion from this point is related to $\mathrm{P}$-waves. The acoustic impedance of a material is the product of the density and wave velocity associated with it; properties which, in turn, can be related to physical structure (Yilmaz, 2001). Seismic reflection data produce direct images of the subsurface, from which interpretations of the geology can be made.

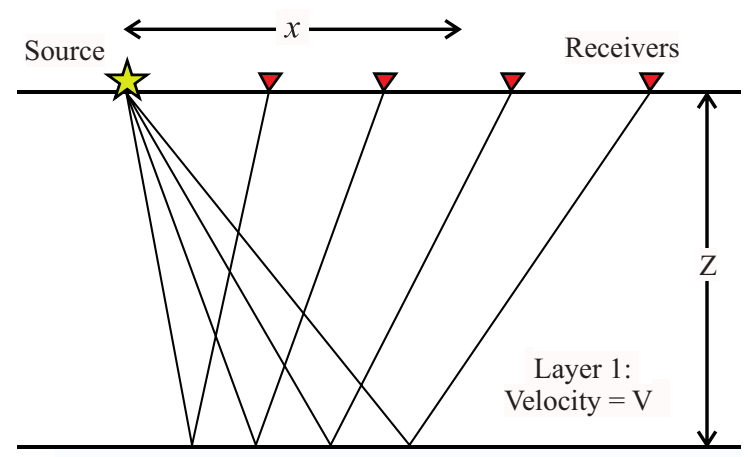

Layer n: Velocity $=\mathrm{V}_{n}$

Figure 2.1: Geometry of multi-channel seismic reflection, where a single shot reflects off an interface and is recorded by multiple receivers. 
The use of multiple receivers (such as in marine multi-channel seismic reflection) allows the data to be stacked, improving the signal-to-noise ratio and allowing the velocity field of the region covered to be calculated (Yilmaz, 2001).

When the source and receiver are offset by a distance $x$, and the depth of the interface is given by $z$ (Figure 2.1), then the time $(t)$ for a reflected ray to travel through a layer of velocity $V$, reflect off the base and travel back to the top of the layer is given by:

$$
t=\frac{\left(x^{2}+4 z^{2}\right)^{1 / 2}}{V}
$$

This equation can be rewritten in hyperbolic form as

$$
t^{2}=\frac{4 z^{2}}{V^{2}}+\frac{x^{2}}{V^{2}}
$$

The difference in travel time $(\Delta T)$ for a reflected ray arriving at offset $x\left(t_{x}\right)$ versus at zero-offset $\left(t_{o}\right)$ is referred to as normal moveout (NMO) (Kearey et al., 2002). For small offsets, NMO can be approximated by

$$
\Delta T \approx \frac{x^{2}}{2 V^{2} t_{o}}
$$

If the difference in arrival time at different offsets $(\Delta T)$ is known, Equation (2.3) can be rearranged to solve for the velocity of the geological unit above the reflector:

$$
V \approx \frac{x}{\sqrt{2 \Delta T t_{o}}}
$$

The hyperbolic shape of reflection events (as described by Equation 2.2) makes them easily identifiable in seismic reflection data. Applying an NMO velocity correction (Equation 2.4) shifts these reflection events to zero-offset time (Yilmaz, 
2001). Traces which sample a common subsurface point can then be stacked, enhancing the signal-to-noise ratio. These stacked traces are plotted in a time section, from which the sub-surface structure can be determined.

\section{Multiples}

For the simple case illustrated in Figure 2.1, the ray leaves the source, reflects off an interface, and is recorded upon its arrival at a receiver. In reality, a ray may have been reflected between the same pair of interfaces multiple times before being recorded at a receiver (Figure 2.2). Such rays are known as multiples.

A ray loses energy when it is reflected at an interface. Consequently multiples, having been reflected at several interfaces, tend to have a lower amplitude than primary reflections. However, when the impedance contrast across an interface is large, the multiples corresponding to that interface tend to have high amplitudes, similar to those of primary reflections (Kearey et al., 2002). For marine seismic reflection data, the sea floor and the interface between water and air are two boundaries that can have strong multiples associated with them. This is par-

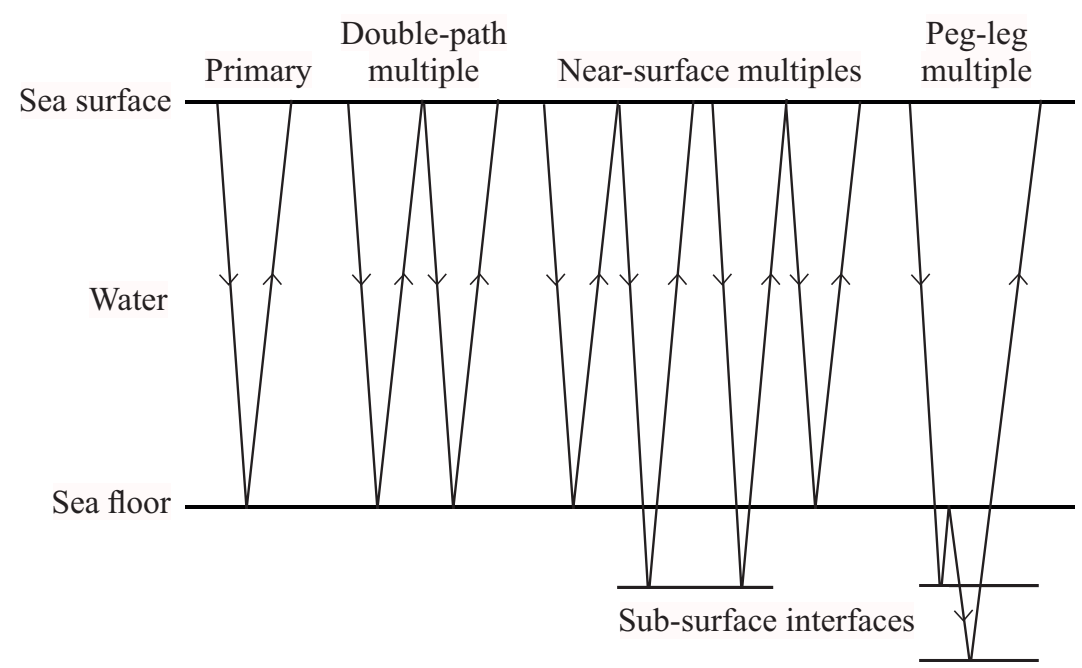

Figure 2.2: Types of multiple reflection in layered ground. Modified from Kearey et al. (2002). 
ticularly a problem for data collected in deep water, where traditional methods of multiple removal (e.g. predictive deconvolution, parabolic radon transform and tau-p deconvolution) often prove to be ineffective (Stewart et al., 2007). Intralayer reflections (e.g. near-surface or peg-leg multiples, Figure 2.2) can also pose a problem for the identification of primary reflections.

Their regular geometry (Figure 2.2) means that multiples tend to have regular arrival times relative to the arrival time of the primary reflection (Kearey et al., 2002). For example, a double-path multiple has an arrival time which is an integer multiple of the arrival time of the primary reflection.

\subsection{Data Acquisition}

The main motivation of the SO-246 voyage of $\mathrm{R} / \mathrm{V}$ Sonne was to study the break-up of the Gondwana super-continent and the continental rifting which accompanied that break-up (Gohl et al., 2016). Consequently, crustal-scale features are of particular interest and the parameters chosen for the acquisition (and processing) of seismic data reflect this (Table 2.1, Figure 2.3).

The vessel travelled at an average speed of 5 knots and shots were electronically triggered at 20 second intervals. If a constant speed is assumed, then this corresponds to a shot interval of 50 metres. However, particularly for AWI-20160004, rough sea conditions meant that the speed was not constant. For AWI-20160004, the shot spacing varied between 23.2 and 96.8 metres, averaging $54.7 \mathrm{~m}$. For AWI20160006, the shot spacing varied between 41.0 and 57.6 metres, averaging 50.1 m. However, once the data are sorted into CDP gathers, variations in shot spacing do not have a significant effect (Maslen, 2016, pers. comms.) so, for the sake of computational time in later processing steps, a regularised shot geometry of $50 \mathrm{~m}$ intervals is assumed. 
Table 2.1: Seismic acquisition parameters for profiles AWI-20160004 and AWI-20160006 collected during the voyage SO-246 of R/V Sonne.

\begin{tabular}{|c|c|}
\hline Source & 6 G-Guns with a total volume of $3120 \mathrm{in}^{3} / 51$ litres \\
\hline Average source depth & $6 \mathrm{~m}$ \\
\hline Shot interval & $20 \mathrm{~s}$ \\
\hline Nominal operating pressure & $2900 \mathrm{psi} / 200$ bars \\
\hline Seismic streamer & $3000 \mathrm{~m}$ active length, digital solid \\
\hline Hydrophones & 240 at $12.5 \mathrm{~m}$ spacings \\
\hline Average streamer depth & $10 \mathrm{~m}$ controlled by 12 DigiBird depth regulators \\
\hline Near group number & 1 \\
\hline $\begin{array}{l}\text { First hydrophone offset } \\
\text { from source }\end{array}$ & $170 \mathrm{~m}$ \\
\hline $\begin{array}{l}\text { Last hydrophone offset from } \\
\text { source }\end{array}$ & $3157.5 \mathrm{~m}$ \\
\hline Initial sampling rate & $1 \mathrm{~ms}$, resulting in $500 \mathrm{~Hz}$ Nyquist frequency \\
\hline Record length & $15 \mathrm{~s}$ \\
\hline Recording system & SERCEL Sentinel $^{T M}$ and SEAL ${ }^{T M}$ \\
\hline Storage format & SEG-D \\
\hline Average vessel speed & 5 knots over land \\
\hline Average shot spacing & $50 \mathrm{~m}$ \\
\hline Average shooting direction & $\begin{array}{l}\text { AWI-20160004: } 150^{\circ} \\
\text { AWI-20160006: } 321^{\circ}\end{array}$ \\
\hline Total Profile length & $\begin{array}{l}\text { AWI-20160004: } 128 \mathrm{~km} \\
\text { AWI-20160006: } 167 \mathrm{~km}\end{array}$ \\
\hline
\end{tabular}

During processing the length of the profiles was reduced to remove the curvature at the start and end of the profiles as the ship was turning onto or off the profile. This curvature occurred because shooting was continuous between AWI-20160004, linking profile AWI-20160005 (not discussed in this thesis) and AWI-20160006.

The highest frequency that can be resolved for a given sampling rate $(\Delta t)$ is referred to as the Nyquist frequency $\left(f_{N}\right): f_{N}=1 /(2 \Delta t)$ (Yilmaz, 2001). Then, for an initial sampling rate of $1 \mathrm{~ms}, f_{N}=500 \mathrm{~Hz}$ (Table 2.1). In practice, however, it is unlikely that frequencies higher than $\sim 100 \mathrm{~Hz}$ will be effectively resolved (Kearey et al., 2002). 


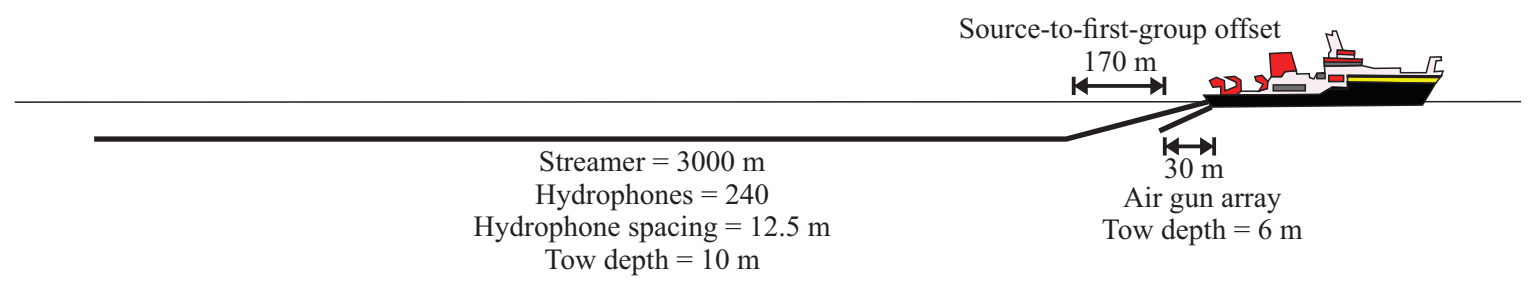

Figure 2.3: Seismic reflection acquisition set-up on SO-246.

\subsection{Seismic Processing}

The goal of seismic processing is to maximise the signal-to-noise ratio of the data and enhance features of interest while maintaining the relative amplitudes of reflectors (Yilmaz, 2001). Each step in the processing work-flow should enhance the quality of the data. Consequently, quality control is of great importance and each process and parameter is thoroughly checked before application.

The processing sequence consisted of the standard sequence of initial quality control followed by pre-stack (shot domain) and post-stack (CDP domain) stages, and was designed so as to image crustal-scale features at high resolution. Of particular interest on these profiles is the nature and extent of the West Wishbone Ridge which runs perpendicular to both profiles (Figure 1.1).

\subsubsection{Quality Control}

The first stage in Quality Control was undertaken during data acquisition. Following each shot, the shot record was converted from the intial SEG-D to SEG-Y format and a high-pass filter (2-4 Hz) was applied. Filtering the data removes low frequency swell noise which otherwise dominates the seismic record. A single channel (Channel 45) was extracted from the record and was added to the display of an onboard screen to create a single-fold section (Figures 2.4 and 2.5). This section provides an immediate overview of the subsurface geology and also allows the identification of groups of shots which have a higher noise content. 


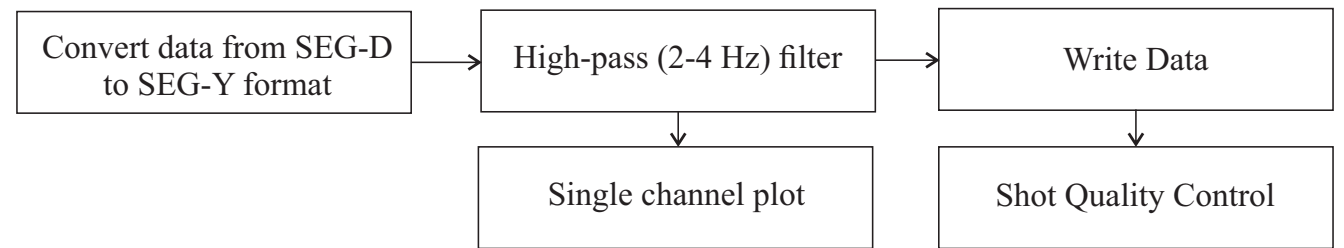

Figure 2.4: Initial quality control processing steps.

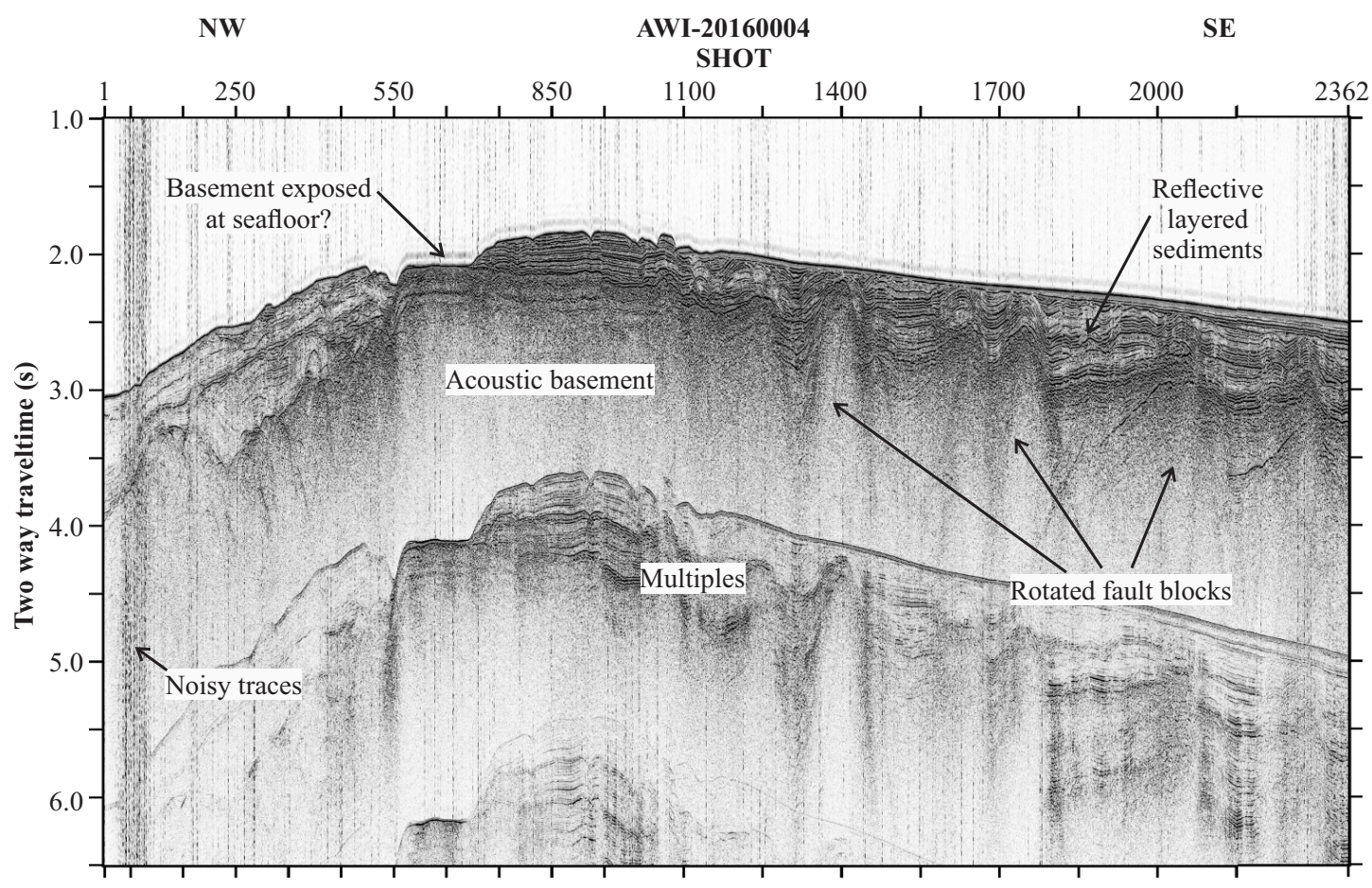

Figure 2.5: Single fold section showing the record of Channel 45 from each shot during AWI-20160004.

The following features are interpreted in the single-fold section (Figure 2.5):

- A reflective, laminated sedimentary section overlying acoustic basement.

- A strong reflector exposed at the sea floor between shots 550 to 650 .

- A series of rotated fault blocks and half-grabens south of shot 1250 .

- Strong long-period multiples which dominate the record at depths greater than twice that of the sea floor primary reflection and conceal any primary reflections that may be present deeper in the section.

Secondary Quality Control involved visually examining a subset of shot records (Figure 2.6) with the aim of identifying any shots that might present problems 


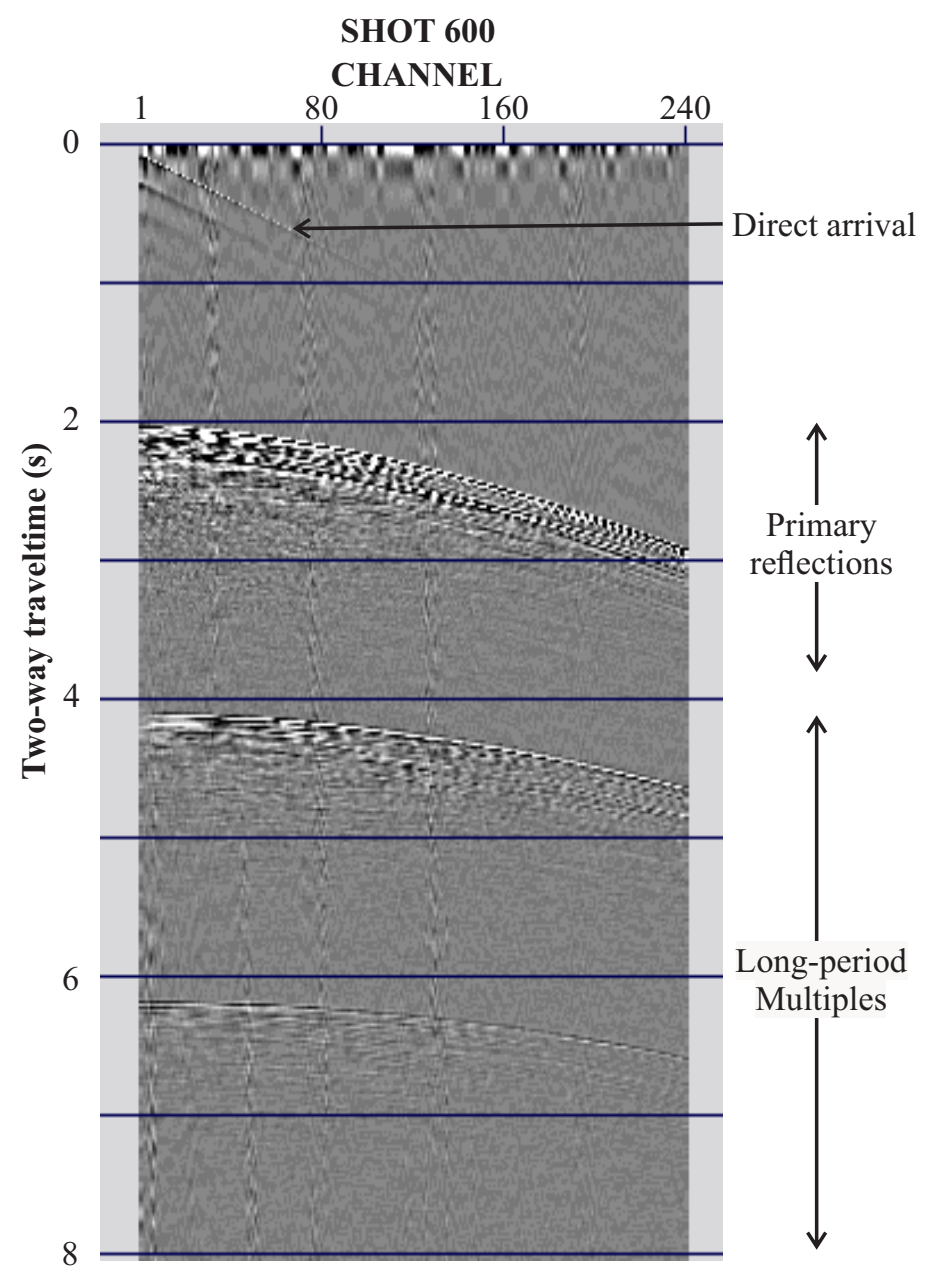

Figure 2.6: Shot 600 from AWI-20160004 after high-pass filtering.

when processing, or traces that are consistently noisy. For this step, every 100th shot (approximately every $5 \mathrm{~km}$ ) was considered and anomalous shots or traces were flagged for later editing. Primary reflections as well as the direct arrival and long-period multiples are evident in these shot records (Figure 2.6).

\subsubsection{Preliminary Processing}

Reading data, resampling and applying geometry are standardised steps which are applied as a matter of course during seismic processing and so are applied without testing. The data were read in SEG-Y and converted to Claritas internal (.hdf5) format for processing before being resampled at $4 \mathrm{~ms}$, resulting in a Nyquist frequency of $125 \mathrm{~Hz}$ (Figure 2.7). As we are interested in deeper crustal structure, 


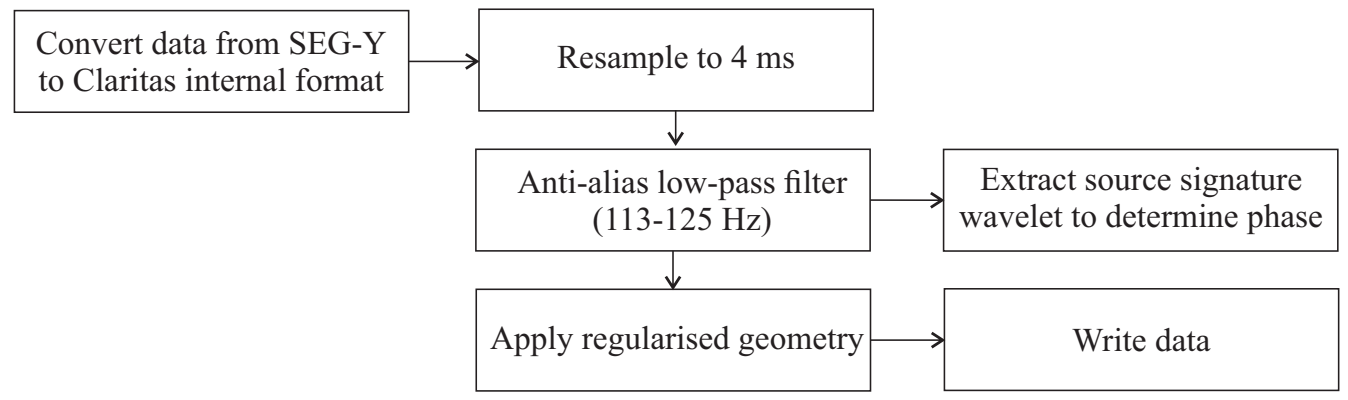

Figure 2.7: Preliminary processing steps.

this resampling has a negligible effect on the data; however, the reduction in the size of the dataset greatly increases the speed of later processing. Resampling can result in data aliasing (Yilmaz, 2001) and so an anti-alias low-pass filter (113-125 $\mathrm{Hz}$ ) was applied to the data.

The source signature wavelet was extracted from the dataset and analysed to determine its phase. Ideally, a seismic wavelet would be a spike, with maximum amplitude at every frequency, but this is not practical. A zero phase wavelet is one whose energy is centred on an event and, consequently, is the form that is closest to a spike in application; however, the source response is more typically represented by a minimum phase wavelet, where all the energy of the wavelet arrives after the event (Yilmaz, 2001). Analysis showed that the source signature wavelet for these datasets is near minimum phase and so no phase conversion was performed.

The final step in this preliminary processing sequence was to apply geometry to the data (Figure 2.7). Geometry is regularised with shot spacings of $50 \mathrm{~m}$ across the profile (as discussed in Section 2.2).

\subsubsection{Pre-Stack Processing}

Pre-stack processing prepares the data for stacking and velocity analysis, and is done in the shot domain, with multiple iterations at each step. This sequence of steps culminates in the production of a common depth point (CDP) stack, 


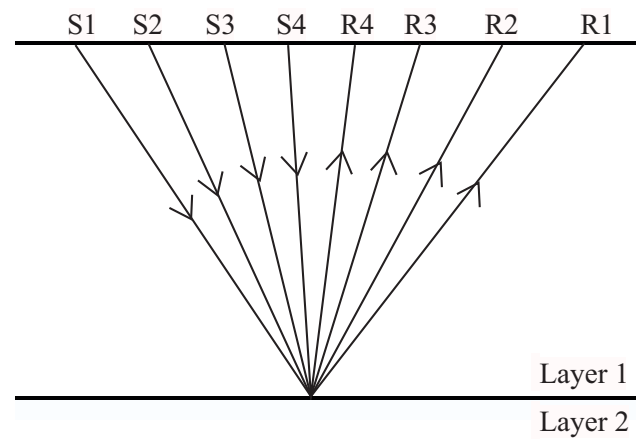

Figure 2.8: Common depth point gather showing how a single sub-surface point is sampled by multiple shot $\left(S_{n}\right)$ and receiver $\left(R_{n}\right)$ combinations. Adapted from Kearey et al. (2002).

where each CDP corresponds to a depth point that is sampled by multiple shotreceiver combinations (Figure 2.8). Traces with the same depth point are stacked, improving the signal-to-noise ratio (Figure 2.9). The natural CDP spacing is half that of the receiver spacing (i.e. $6.25 \mathrm{~m}$ for these profiles); however, the signal can be further enhanced by increasing the spacing between CDPs. The features we are interested in are crustal-scale and so, while increasing the CDP spacing to enhance the signal results in a loss of horizontal resolution, this is deemed a worthwhile trade-off. The natural CDP spacing is overruled and the CDPs are spaced at 25 $\mathrm{m}$ intervals. The resultant maximum fold is 120 .

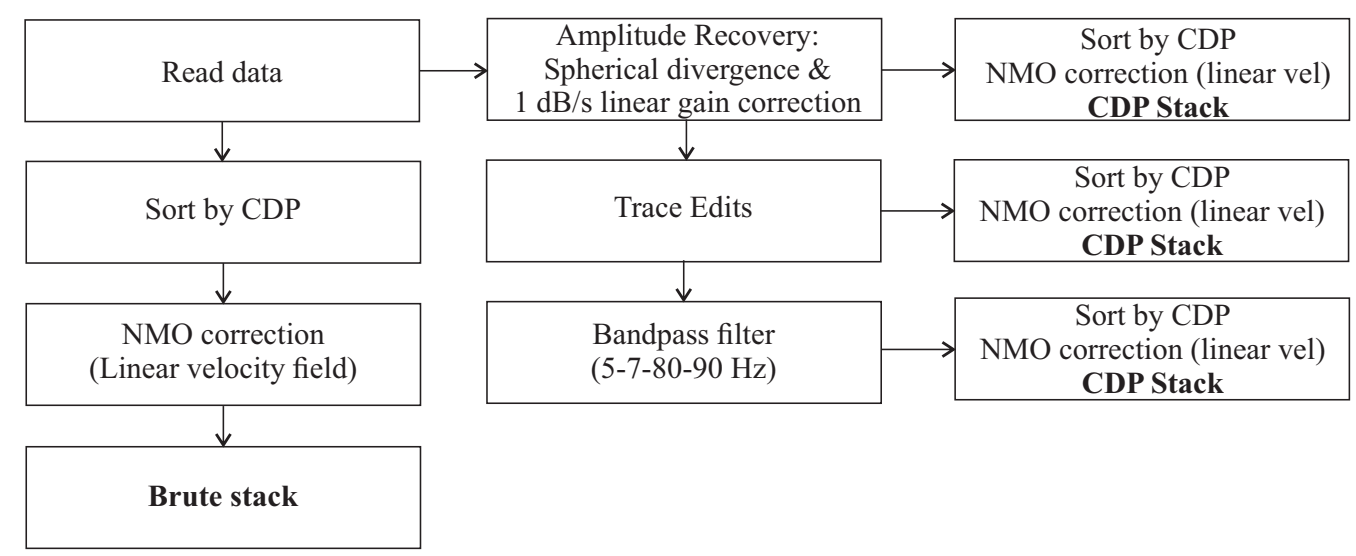

Figure 2.9: Pre-stack processing steps. 


\subsubsection{Brute Stack}

The first step in pre-stack processing was to compile a brute stack. This stack was produced using a simplified processing sequence where the data were stacked based on CDP spacing, and a normal moveout (NMO) correction was applied using a linear velocity field approximation (Figure 2.9). This brute stack (Figure 2.10a) acts as a quality control measure, where later stacks can be compared against the brute to ensure that the subsequent processing has enhanced the data as required.

\subsubsection{Amplitude Recovery}

The amplitude of seismic waves attenuates with distance from the source due to energy dissipation and geometrical spreading. This attenuation can be corrected for by applying a spherical divergence correction - a function that considers the twoway travel time, source-receiver offset and stacking velocity of each point (Yilmaz, 2001). The spherical divergence correction applied makes use of a linear velocity field, the same one used to correct for normal moveout when the brute stack was compiled. Applying parameters that are laterally constant helps to prevent variable amplitude scaling of adjacent traces. Additionally, a constant linear gain correction of $1 \mathrm{~dB} / \mathrm{s}$ was applied to the whole dataset (Figure 2.9). These amplitude corrections have the side-effect of also increasing the amplitude of the noise in the data, particularly at depth (Figure 2.10b); however, this is outweighed by the benefits of having accurately represented the amplitude of the reflections.

\subsubsection{Trace Edits}

The RMS amplitude of each trace was extracted and plotted in the areal module of Claritas. This allowed the identification of traces that are high in amplitude relative to surrounding traces. For AWI-20160004, this amplitude plot reveals that channels nearer the ship (Channels 1 to 34) have a higher noise content 
than channels further away (Figure 2.11a). Most high amplitude traces that were identified are within this range of channels. The traces of AWI-20160006 shots do not exhibit this same ship-related noise pattern; instead they are dominated by high-amplitude wave noise which travelled along the streamer and was picked up by different receivers over a series of shots (Figure 2.11b). Once identified, noisy traces were removed from the data and a revised stack was created (Figure 2.10c).

\subsubsection{Swell Noise Removal}

Low frequency swell noise is persistent throughout the stacked CDP section (Figure 2.10c). The averaged frequency spectrum (Figure 2.12) contains several peaks which are a result of ghost notching - interference due to reflections from the sea surface (Kearey et al., 2002). However, the comparatively high amplitude of the peak below $8 \mathrm{~Hz}$ is a result of swell noise at these frequencies. A bandpass filter with corner frequencies at 5, 7, 80 and $90 \mathrm{~Hz}$ was applied to remove the swell noise. While crude filtering such as this has the potential to remove signal in addition to noise, in this case deeper reflected energy does not seem to have been attenuated by application of the filter. Figure 2.10d shows the updated CDP stack after removal of swell noise.

\subsubsection{Initial Velocity Analysis}

Normal moveout is a function of travel time and offset distance (Equation 2.3), which results in the characteristic hyperbolic shape of a reflection (Equation 2.2). An accurate understanding of the velocity structure of the subsurface enables normal moveout to be corrected for and reflectors to be flattened. Stacking velocity describes the velocity that flattens a reflection (Yilmaz, 2001). Plots of coherency (semblance) of the traces within a CDP stack were used in conducting an initial velocity analysis (Figure 2.13), with stacking velocity picks made iteratively ev- 

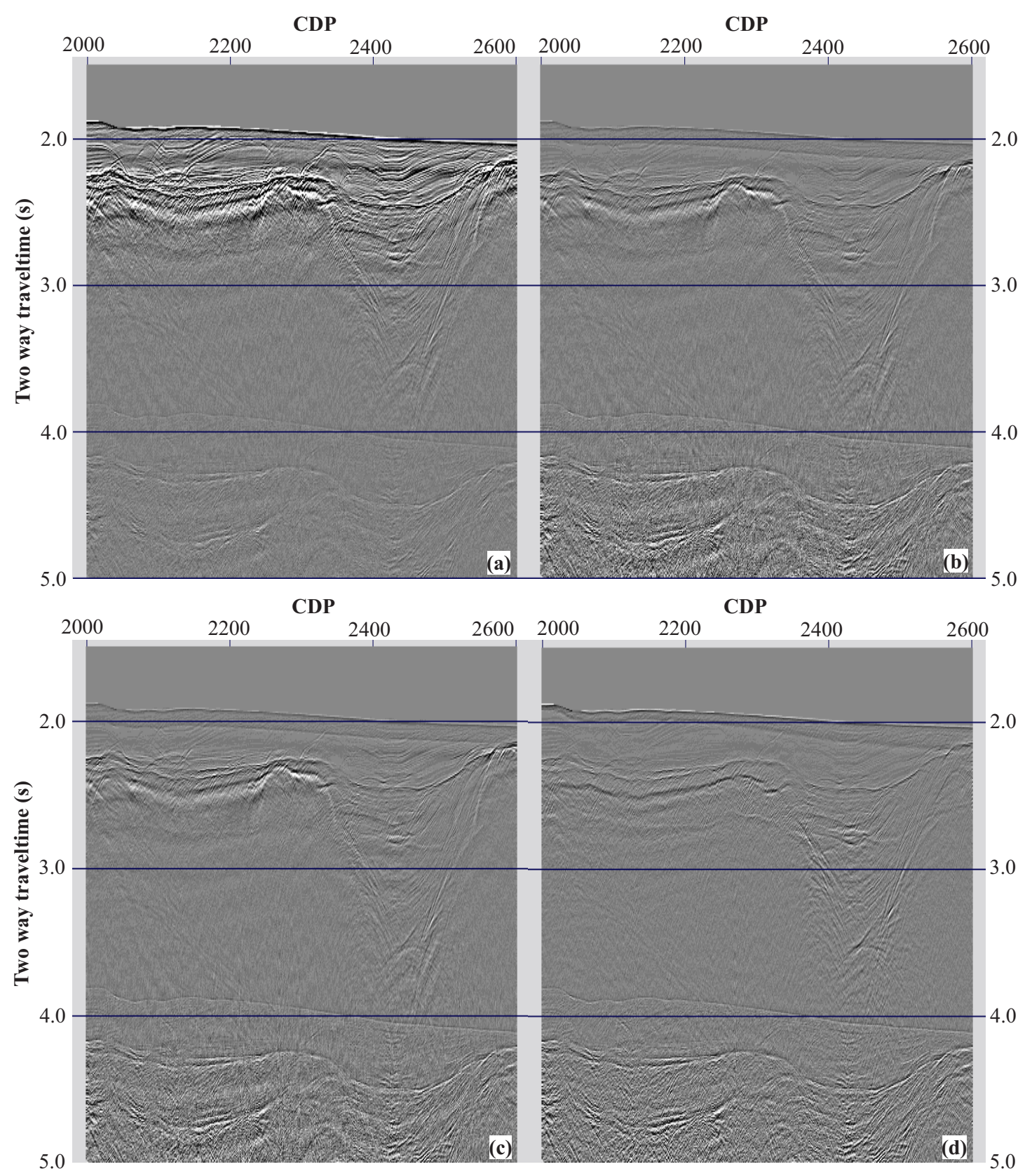

Figure 2.10: Pre-stack processing of AWI-20160004. (a) Portion of the brute stack; and CDP stacks after (b) amplitude recovery, (c) trace edits, and (d) swell noise removal. 


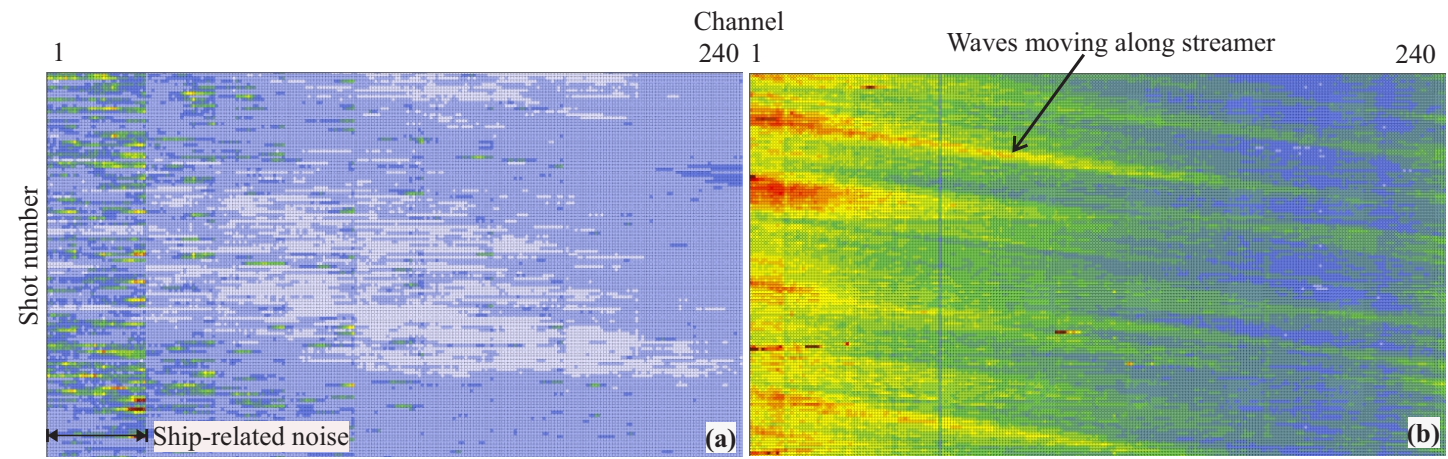

Figure 2.11: Amplitude plots from the areal module reveal two main sources of noise: (a) ship-related noise and (b) waves moving along the streamer.

ery 100 CDPs $(2.5 \mathrm{~km})$. These picks coincide with locations of high coherence. Subsurface velocities between pick locations were interpolated.

It is important to note that any noise that is present on multiple traces will also behave coherently. Consequently, considerable effort was put into removing noise prior to this initial velocity analysis. Long-period sea floor multiples still pose a problem in this data and care was taken to avoid picking their velocities.

The second stage in this initial velocity analysis was undertaken using the constant velocity analysis ( $c v a)$ module of Claritas. In this module, constant velocity gathers and constant velocity stacks (Figure 2.14) are used in tandem to refine the stacking velocity picks from the semblance analysis (Figure 2.13). A constant velocity gather (CVG) includes all the traces of a CDP, ordered in terms of offset and with a constant normal moveout velocity applied (Equation 2.4). In a constant velocity stack (CVS), the traces from each CDP are stacked and a constant normal moveout velocity is applied (Yilmaz, 2001). Adjacent CDPs are also included in

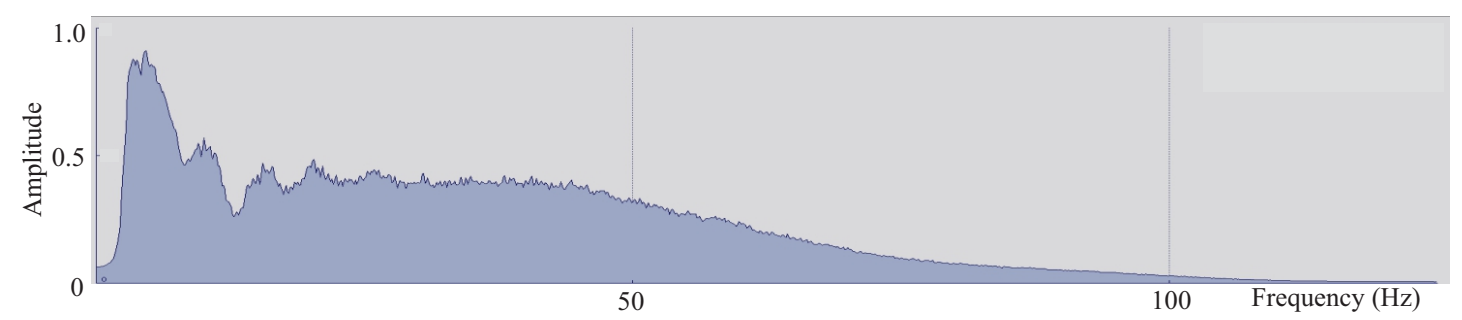

Figure 2.12: The frequency spectrum averaged across 525 traces (CDPs 2033 to 2557) on AWI-20160004, after the application of trace edits. 


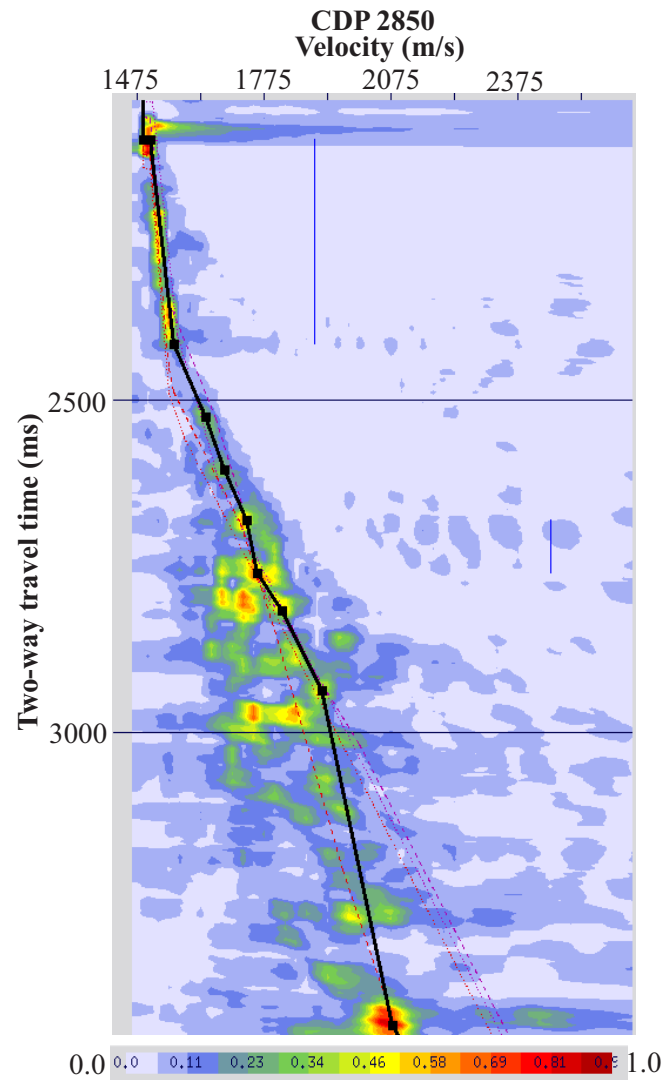

Figure 2.13: Initial velocity analysis for AWI-20160004 using a semblance spectrum.

the constant velocity stack. Applying a velocity to a reflection using CVS and CVG is an iterative process, where multiple velocities are tested to find the one which best flattens the reflection (Figure 2.14).

Below the sedimentary cover, an absence of reflectors made velocity analysis challenging. Additionally, due to the deep water depth along the profiles, any subbasement reflectors are at a depth greater than the maximum offset distance along the streamer $(3157.5 \mathrm{~m})$. Consequently, there is little moveout at these depths to constrain velocity picks and these deeper velocities are poorly constrained. An upper velocity bound of $6000 \mathrm{~m} / \mathrm{s}$ was set at a depth of $8 \mathrm{~s}$ two-way travel time (TWTT) for the model. The velocity of the water column was set to $1490 \mathrm{~m} / \mathrm{s}$ based on the results of sound velocity profiles collected during SO-246 (Gohl et al., 2016). 

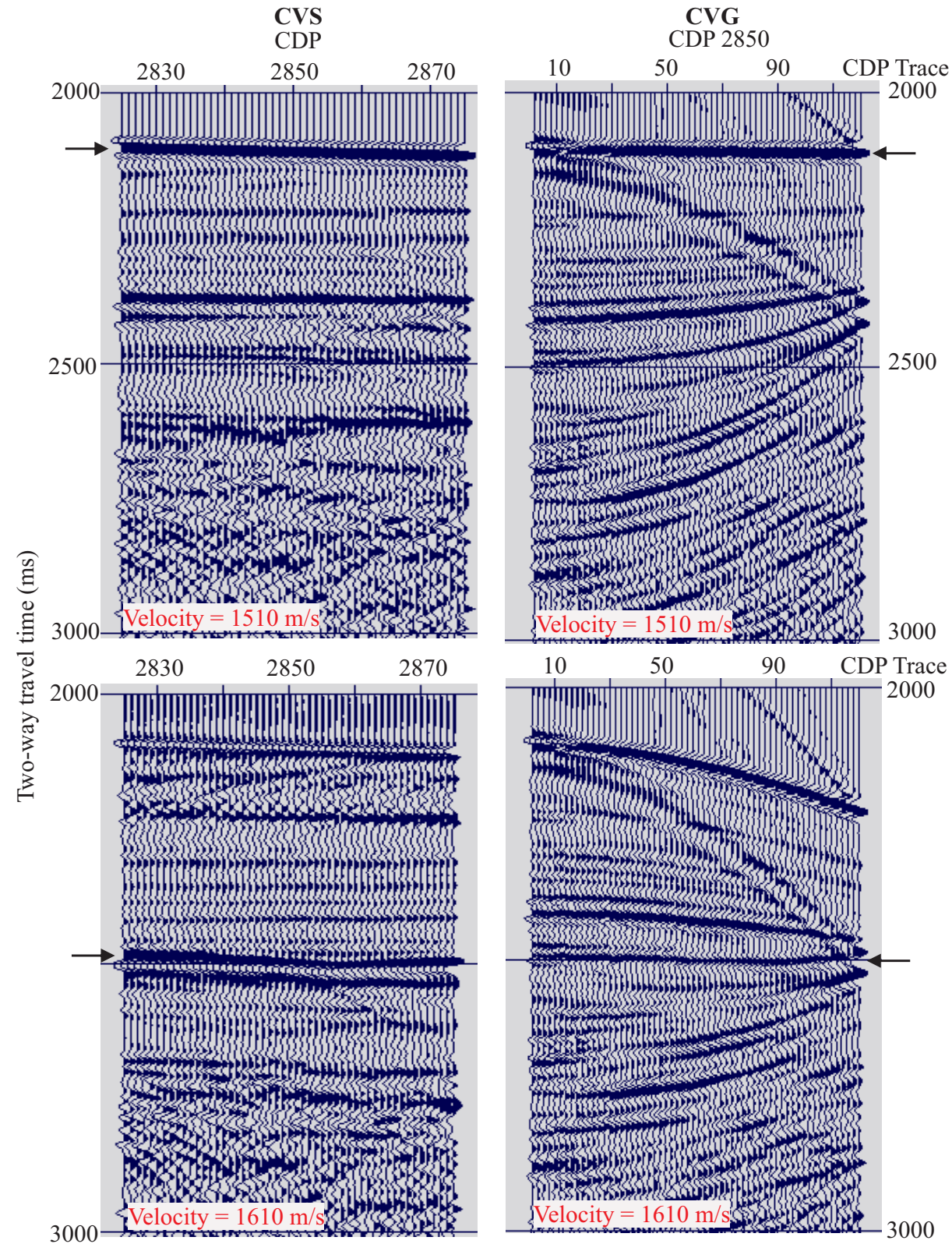

Figure 2.14: Constant Velocity Stacks (CVS) and Constant Velocity Gathers (CVG) for CDP 2850 of AWI-20160004. (Top) An NMO velocity of $1510 \mathrm{~m} / \mathrm{s}$ flattens the sea floor reflection at this CDP. In the lower plots, an NMO velocity of $1610 \mathrm{~m} / \mathrm{s}$ is applied across the full trace length. This flattens the reflection at $2500 \mathrm{~ms}$ TWTT, but the sea floor reflection is now over-corrected, curving downwards.

These velocities were visually checked using the cva and isovels (Figure 2.15) modules and anomalous values were removed. 


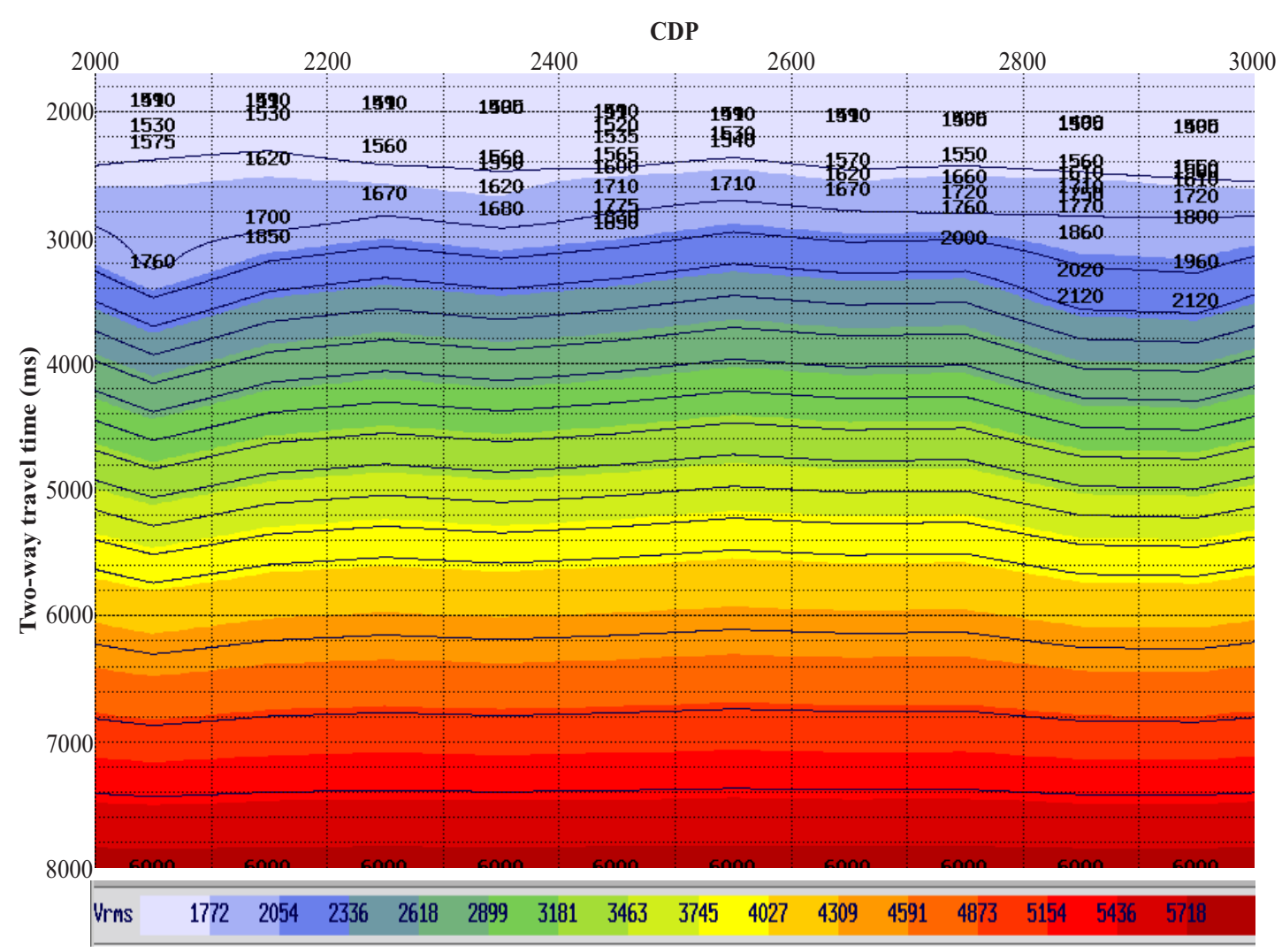

Figure 2.15: Velocity analysis using isovels across a subset of AWI-20160004.

\subsubsection{Multiple Suppression}

While stacking has reduced the effect of long-period multiples, they continue to dominate the signal at depths greater than twice that of the sea floor (Figure 2.10). There are several techniques which can be employed to suppress the signal of these multiples. Three methods (Predictive Deconvolution - Peacock and Treitel (1969), Parabolic Radon Transform - Hampson (1986) and Surface Related Multiple Elimination - Verschuur et al. (1992)) were tested and are discussed in the following sections.

\subsubsection{Deconvolution}

Predictive deconvolution aims to remove multiples based on their periodicity. Typically the window length which is scaled along the trace is six to ten times the length of the maximum multiple period (Wang, 2003). Correlations between reflections 
are found by autocorrelating the trace with itself. When there is no delay between the traces being autocorrelated, the amplitude of correlation will be a maximum (Yilmaz, 2001).

This technique is especially useful for removing short period multiples. For the deep water case, as in these profiles where the water depth varies between 1.75 and $3.9 \mathrm{~s}$ TWTT, the length of the trace tends to be somewhat short compared to the reverberation period. This results in poor autocorrelation estimates which makes effective deconvolution difficult (Wang, 2003). Attenuation of energy with depth can also affect correlation estimates. Autocorrelation windows (Figure 2.16) as well as tests of various deconvolution parameters (window length and gap length) revealed that deconvolution had little effect on removing the multiples and reverberations evident in the data, and so was not applied at any stage during the processing routine.

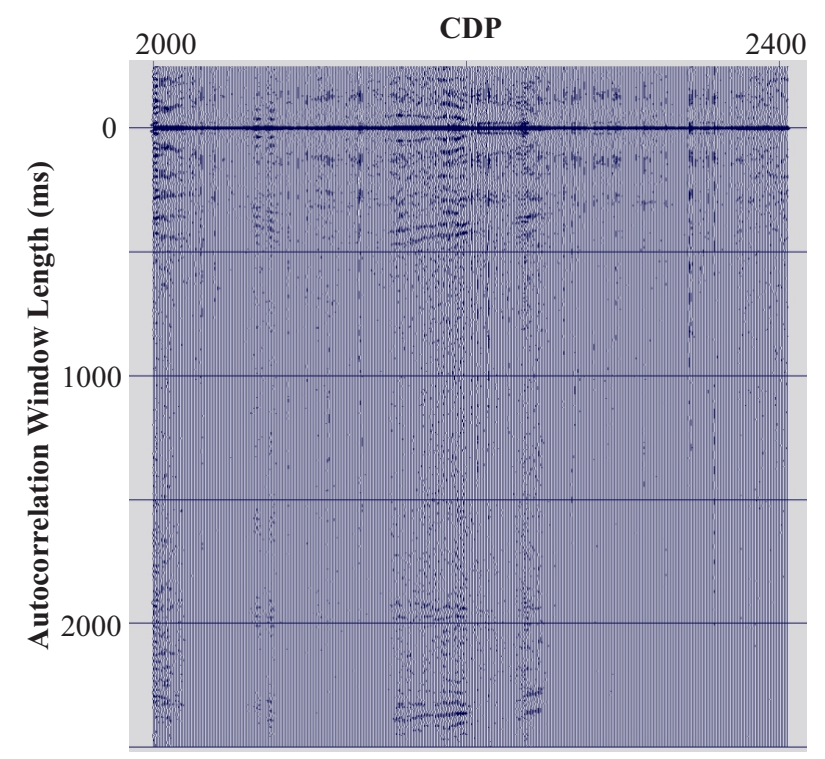

Figure 2.16: A $2500 \mathrm{~ms}$ autocorrelation window from the full trace length of a stack of CDPs 2000 - 2400 of AWI-20160004. This window length defines the maximum periodicity that can be identified. 


\subsubsection{Parabolic Radon Transform and F-K filtering}

Multiples tend to have lower stacking velocities and dip more steeply than primary reflections at the same depth. Consequently, the stacking velocity of a reflection can be used to suppress multiples. The Parabolic Radon Transform (PRT) method is one technique that makes use of stacking velocities, and is applied in conjunction with a normal moveout correction (Hampson, 1986). The velocities are scaled to $90 \%$ of their picked value so that primary energy is up-dip and multiple energy is either flat or down-dip when the correct NMO velocity is applied. Multiple energy can then be recognised by its dip and removed by muting.

A reflection has a characteristic hyperbolic shape as defined by Equation 2.2. When a Parabolic Radon Transform is applied, reflections are approximated to be parabolic and the traces are ordered by far offset moveout (Yilmaz, 2001). A matrix that describes the transform parameters and dips is constructed for each offset distribution within the CDPs. This process is computationally expensive and it was largely for this reason that the shot geometry was regularised after acquisition (Section 2.2).

Before performing the Radon Transform, the data are sorted into super-gathers, where two adjacent CDP gathers are combined into one super-gather. This accounts for differing offsets in the odd- and even-numbered CDPs. After supergathers are formed, each gather has the same offset distribution. An F-K filter is applied in conjunction with the Radon Transform, further enhancing the horizons.

Figure 2.17b shows the effect of applying a Parabolic Radon Transform and F-K filtering the data before stacking. The horizons are sharpened and sedimentary layers are more easily distinguished compared to the stack before Radon Transform (Figure 2.17a). The multiples, while still evident, have been suppressed. The normal moveout correction was removed after application of the Radon Transform. 


\subsubsection{Surface Related Multiple Elimination}

Surface Related Multiple Elimination (SRME) has been suggested as an effective way of removing long-period multiples such as those we struggle with here (e.g. Verschuur et al., 1992, Stewart et al., 2007, Sauter et al., 2016). In SRME, shot and receiver cross-correlations are used to create a model of expected multiple positions in the shot record (Verschuur et al., 1992). This model is calculated after Preliminary Processing (Section 2.3.2) and before Pre-Stack Processing (Section 2.3.3) as the modelling process needs to take place before multiple energy in the section is significantly attenuated. After creation, the model of predicted multiples is subtracted from the data, resulting in multiple attenuation. SRME was extensively tested in this processing sequence and a stacked section (Figure 2.17c) shows application of SRME has enhanced shallow reflections and the top of the basement in a similar way to the Radon Transform (Figure 2.17b). At this stage, application of SRME seems to attenuate more of the long-period multiple energy than the Radon Transform. These two stacks (one that has had SRME applied and one that has been Radon transformed) are processed further as described in the following sections.

\subsubsection{Secondary velocity analysis}

After applying a demultiple procedure and F-K filtering the data, horizons are more clearly defined (Figure 2.17). Velocities were repicked using Claritas' cva module using the initial velocity field as a starting model. Picks were again made at a regular spacing of 100 CDPs $(2.5 \mathrm{~km})$ but were more densely spaced across regions where change occurred rapidly. The resulting velocity model was smoothed and the velocities were converted to interval velocities. Interval velocity describes the velocity within a homogeneous geological unit and can be calculated using an equation derived by Dix (1955): 


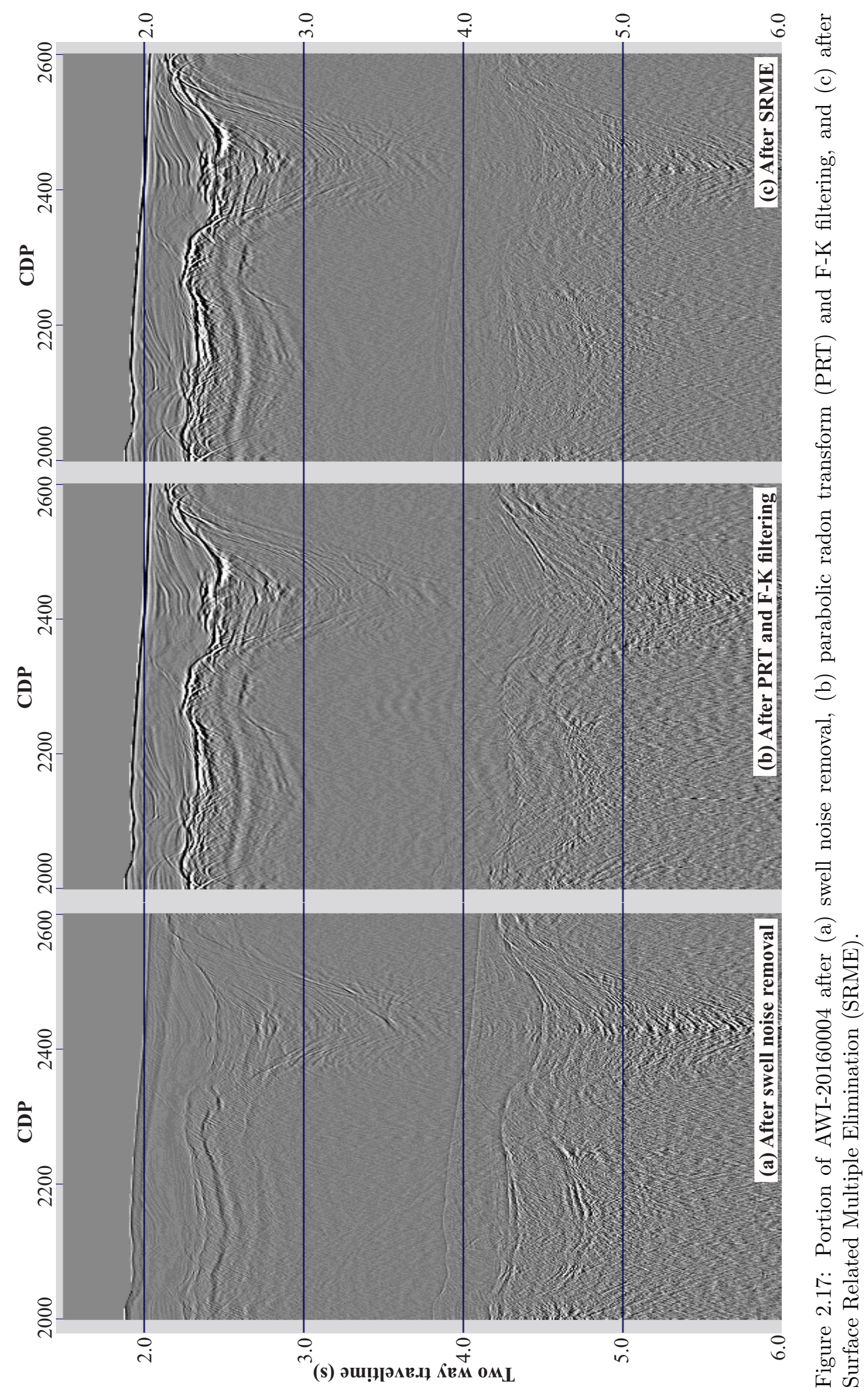




$$
V_{i n t}=\sqrt{\frac{t_{2} V_{R M S 2}^{2}-t_{1} V_{R M S 1}^{2}}{t_{2}-t_{1}}}
$$

The revised stacking velocity field was applied to the data to correct for moveout of the seismic data at far offsets. Interval velocities will be applied during the next stage: migration.

\subsubsection{Migration and Finalisation}

For a horizontal reflector, the reflection point lies beneath the mid-point of the corresponding CDP gather. However, for a dipping reflector, the reflection point is displaced relative to the mid-point of the gather (Figure 2.18). Migration aims to correct for this by repositioning reflection events so that they coincide with their correct spatial and temporal location (Yilmaz, 2001). The part of an interface from which energy is reflected to create the reflected signal is known as the Fresnel zone. For a curved reflector, the Fresnel zone can be significantly larger than a point reflector, resulting in energy dispersion (Kearey et al., 2002). The process of migration aims to correct for this dispersion, as well as that associated with diffraction off point reflectors (Figure 2.18).

In finite difference time migration, an approximation of the wave equation is used to find the location of the reflector at depth. Input data are extrapolated to increasing depths by finite increments and the change in waveform which would result from this change in depth is predicted (Onajite, 2014). Migration makes use of the interval velocity model determined during the secondary velocity analysis stage. This velocity field was multiplied by a scalar of 0.65 , a value which was found to reduce diffraction smiles to a minimum. The two-dimensional data mean that only features which are in the plane of the seismic section can be relocated by migration (Kearey et al., 2002). Features which are out-of-plane may remain as artefacts in the migrated section and careful comparison of the migrated and 
pre-migrated profile is required to identify such features.

As a further test on the demultiple processing, post-stack finite difference time migration was applied to the SO-246 reflection profiles after the separate application of Radon Transform and SRME (Figure 2.19). For both Radon Transform and SRME, migration has relocated reflections and has condensed diffractions, such that the resulting section is more focussed than previous stacked sections (e.g. Figure 2.17). Migration after the application of SRME has attenuated the multiples to a greater extent than migration after Radon Transform; however, the section that has had SRME applied to it contains point diffraction migration artefacts in the sedimentary section that are not as prevalent in the post-Radon Transform migrated section (Figure 2.19). The resolution at depth in these seismic sections (a function of source volume, streamer length, water depth and energy attenuation in the section) is low. Consequently, few primary reflections are observed at depth, so SRME's benefit of attenuating the multiples does not outweigh the downside of the post-migration artefacts on the SRME section. As a result,
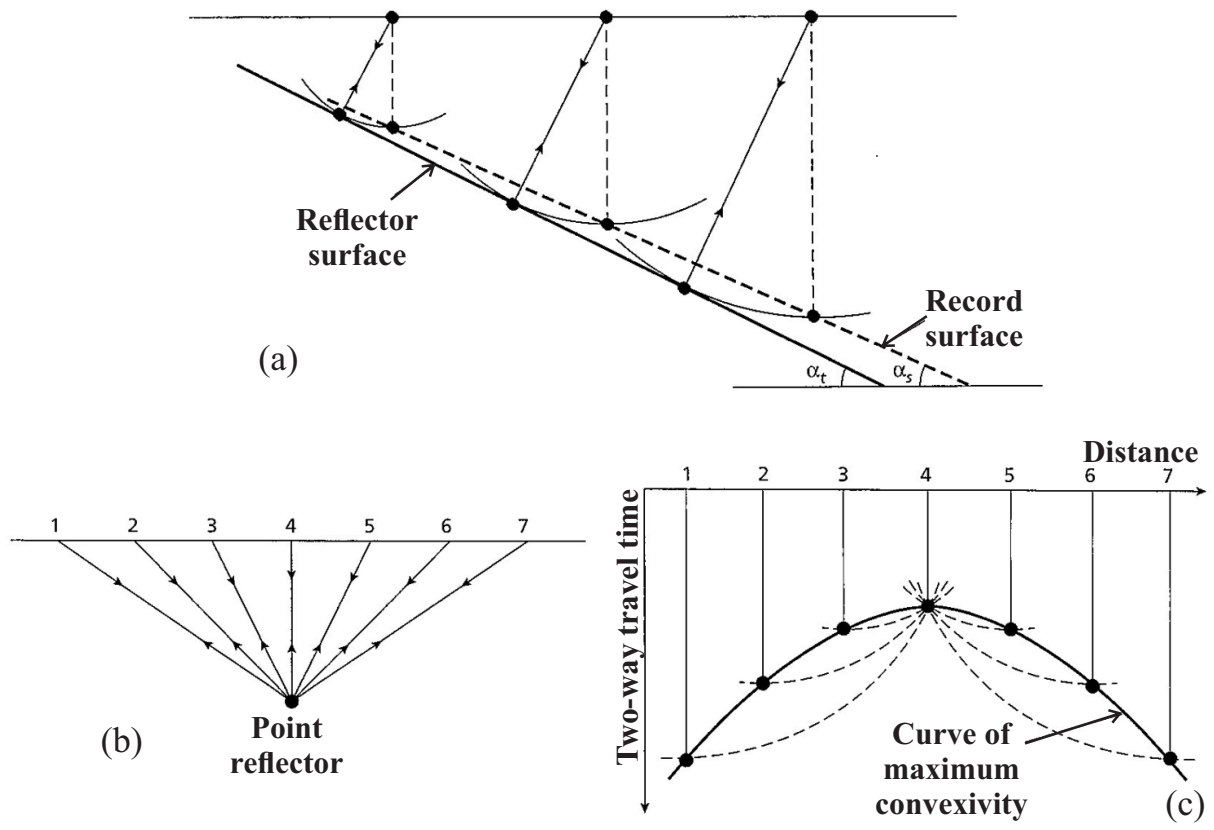

Figure 2.18: Principles of migration: (a) Migration returns reflections to their correct spatial and temporal position. (b) Diffraction results from a point reflector but can be corrected through the process of migration (c). Modified from Kearey et al. (2002). 


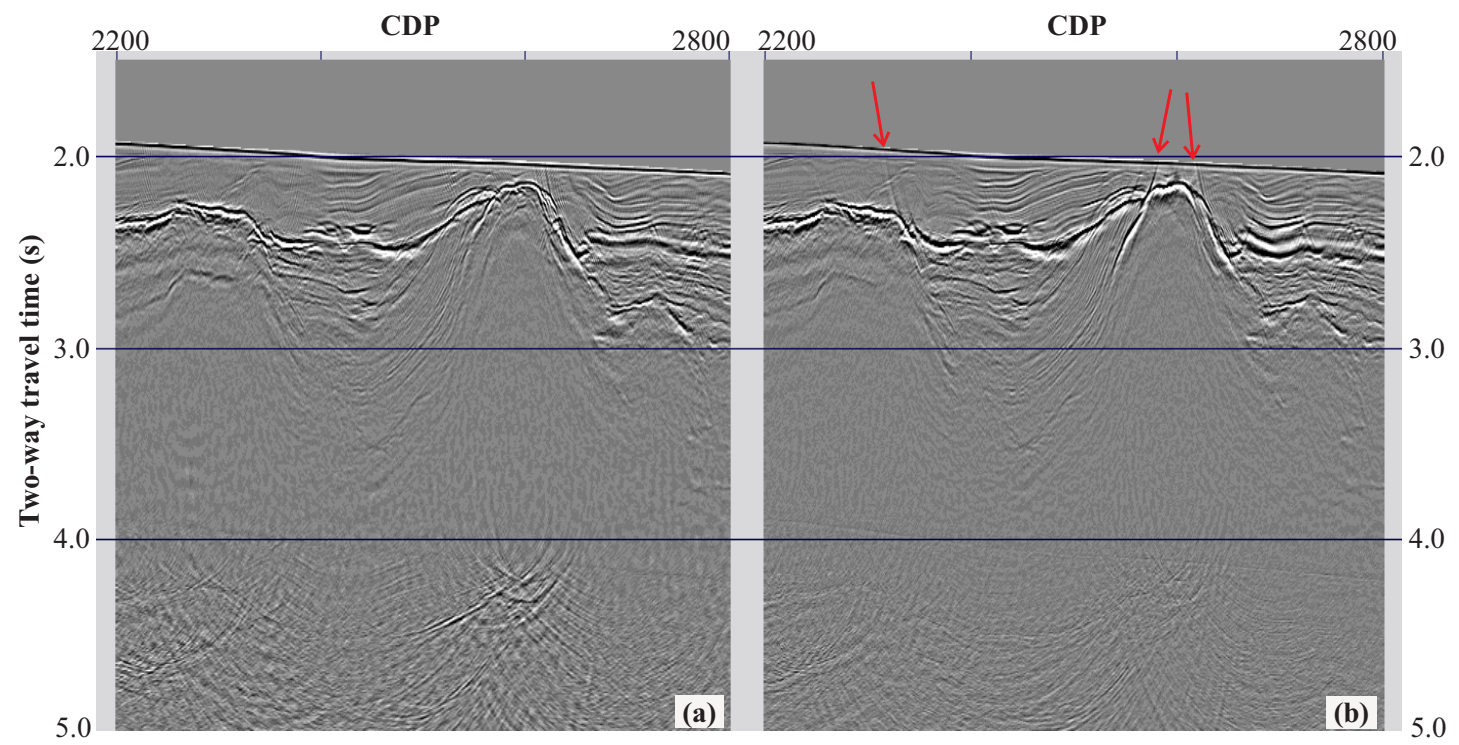

Figure 2.19: Portion of AWI-20160004 (a) after Radon Transform and finite difference time migration; and (b) after Surface Related Multiple Elimination and finite difference time migration. The red arrows highlight point diffraction artefacts of migration.

SRME was not included in the final processing work-flow (Figure 2.20).

Two final steps are applied to improve the amplitude scaling of the output. The first is a full trace balance. This scales the average amplitude over the whole trace to 1.00 and reduces attenuation (Yilmaz, 2001). The second process to be applied in this finalisation stage is an Automatic Gain Control (AGC). AGC normalises amplitudes within a sliding window of a set length, reducing the amplitudes of highamplitude reflections which might mask nearby low-amplitude reflections (Yilmaz, 2001). This process can have the downside of making low-amplitude reflections more difficult to see. Tests of various AGC window lengths were conducted and it was found that applying two AGCs with lengths of 500 and 996 ms effectively normalised amplitudes while not having a significant effect on the resolution of sedimentary layers. These finalised, time-migrated profiles are included in Appendix D. 


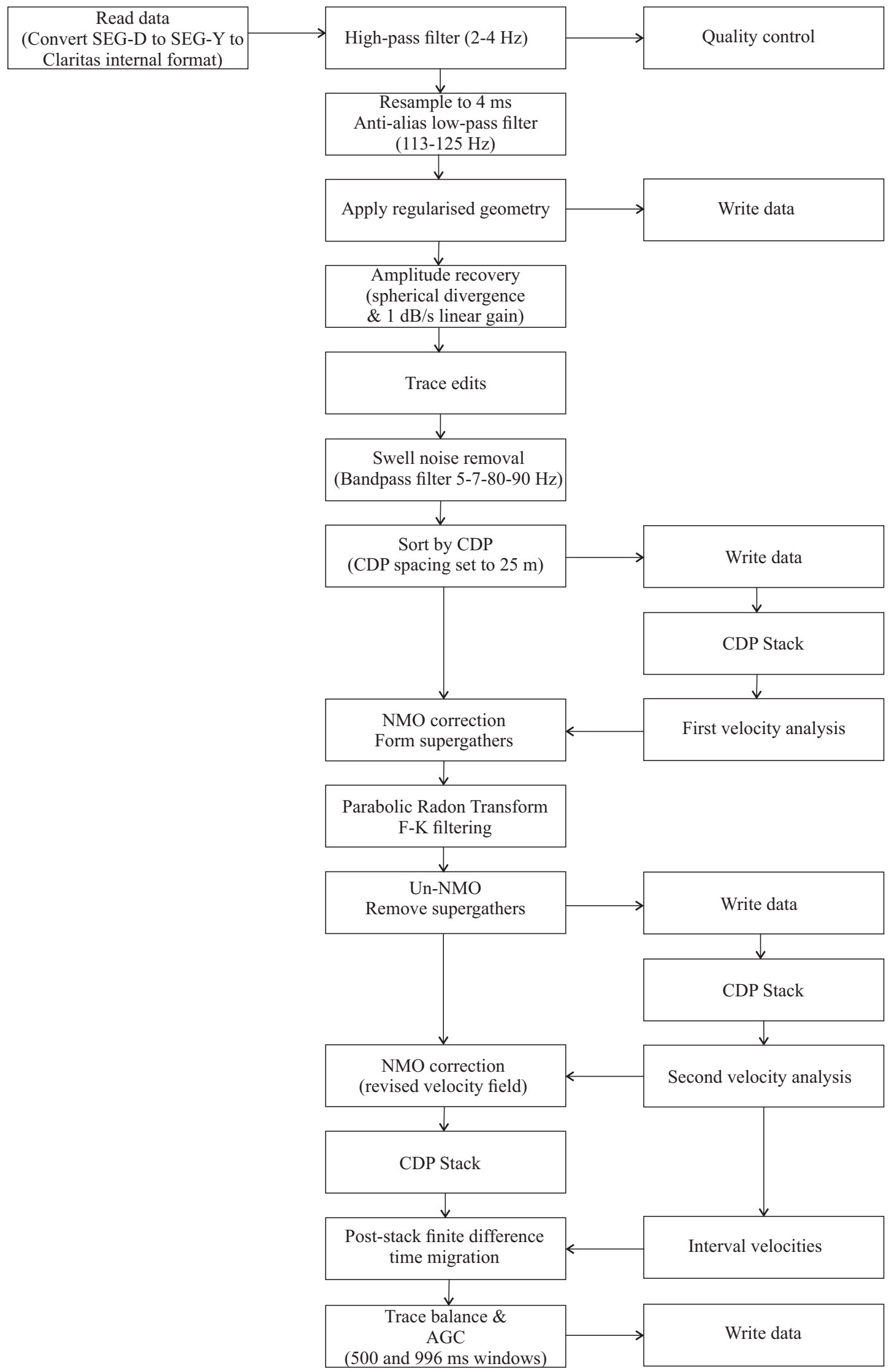

Figure 2.20: Summarised sequence of steps applied during processing of SO-246 seismic reflection data. 


\subsection{Additional seismic reflection data}

Two additional seismic profiles (CHAT-3 and CHAT-4 - Figure 1.1) are interpreted in this thesis. These profiles were collected for GNS Science by M/V Geco Resolution in 2001, and were processed by Robertson Research (Perth, Australia) on behalf of GNS Science. The acquisition and processing parameters applied for these profiles are discussed in full in the processing report of Robertson Reseach (2002). A summary of those parameters is included in Appendix A. The final migrated sections for these profiles are included in Appendix D.

\subsection{Depth Conversion}

Converting the time section to units of depth can be helpful for a geological interpretation of the sub-surface. For the simple case of a reflection from the sea floor, this conversion is done using the relation

$$
z=\frac{v_{\text {int }}}{t / 2}
$$

where $z$ is the depth, $v_{\text {int }}$ is the interval velocity of the water layer and $t$ is the total time that the wave spends within that layer (Kearey et al., 2002). This equation is easily expanded for the multi-layer case. However, the deep water along these profiles means that the velocity structure (which is relied upon for depth conversion - Equation 2.6) has limited resolution, especially at depth. This results in distortion of the depth section. Consequently, seismic data in this study are predominantly displayed and discussed in terms of two-way travel time (TWTT), rather than in units of depth. Where depths are stated, the assumptions included in the velocity model are discussed. 


\section{Chapter 3}

\section{Seismic Stratigraphy}

This chapter provides an overview of the seismic stratigraphy that is characteristic of units overlying the Hikurangi Plateau and Chatham Rise (observed on AWI20160004, AWI-20160006 and CHAT-3 - Figure 3.1), as well as an overview of the characteristics of oceanic crust (observed on CHAT-4 - Figure 3.2).

Few cores have been collected in the immediate vicinity of the West Wishbone Ridge (WWR) so an interpretation of the seismic stratigraphy along the profiles considered in this study is primarily based on the results of ODP Leg 181 - Holes 1123 and 1124 (Figure 1.1), which extend down to Paleogene and Cretaceous sediments, respectively (Carter et al., 1999a,b). For the seismic profiles that cross the Hikurangi Plateau and Chatham Rise (AWI-20160004, AWI-20160006 and CHAT-3), the sedimentary horizons are correlated to those on seismic profiles from further west along the Chatham Rise; in particular, lines HKDC-1 (Davy et al., 2008) and SAHKE-1 (Bland et al., 2015) (Figure 1.1) which bear strong similarities in character. The unit-naming conventions of Davy et al. (2008) are adopted in this study. 


\subsection{Hikurangi Plateau and Chatham Rise}

\subsubsection{SEQ Y - Early Oligocene to Late Cretaceous sedi- ments}

Sequence Y (SEQ Y) is discussed first because its highly reflective, continuous series of horizons are easily identified and correlated across the broader Chatham Rise region (e.g. Davy et al., 2008, Bland et al., 2015, Wood et al., 1989). Elsewhere along the margin, this unit typically varies in thickness between 100 and $200 \mathrm{~ms}$ two-way traveltime (TWTT) (Wood and Davy, 1994), and similar thicknesses are observed on these profiles (e.g. Figure 3.1). In some regions, particularly where basement topography varies rapidly (such as through half-grabens), changes in the thickness of SEQ Y are observed. The results of ODP Sites 1123 and 1124 (Carter et al., 1999a,b) show that SEQ Y is composed of alternating layers of nanofossil chalk and mudstones, and extends from Early Oligocene through to Late Cretaceous in age. ODP Site 1124 bottomed at ca. 65 Ma, within but near the base of SEQ Y. Consequently, Davy et al. (2008) suggested that the base of SEQ Y can be extrapolated to 70 Ma. The upper limit of SEQ Y is demarcated by the Marshall Paraconformity (33-27 Ma) (Carter et al., 1999b), a regional feature observed across the New Zealand continental region and interpreted to have been the result of erosion beginning ca. 32 Ma (Carter et al., 2004). The regionally condensed nature of this sequence coupled with its high reflectivity (Figure 3.1) indicates wide-spread low-sedimentation rates during the period of deposition (Bland et al., 2015).

\subsubsection{CEN - Cenozoic sediments}

Data from ODP Sites 1123 and 1124 indicate that the sediments that overlie SEQ Y range from Late Oligocene to Recent in age (Carter et al., 1999a,b). These 


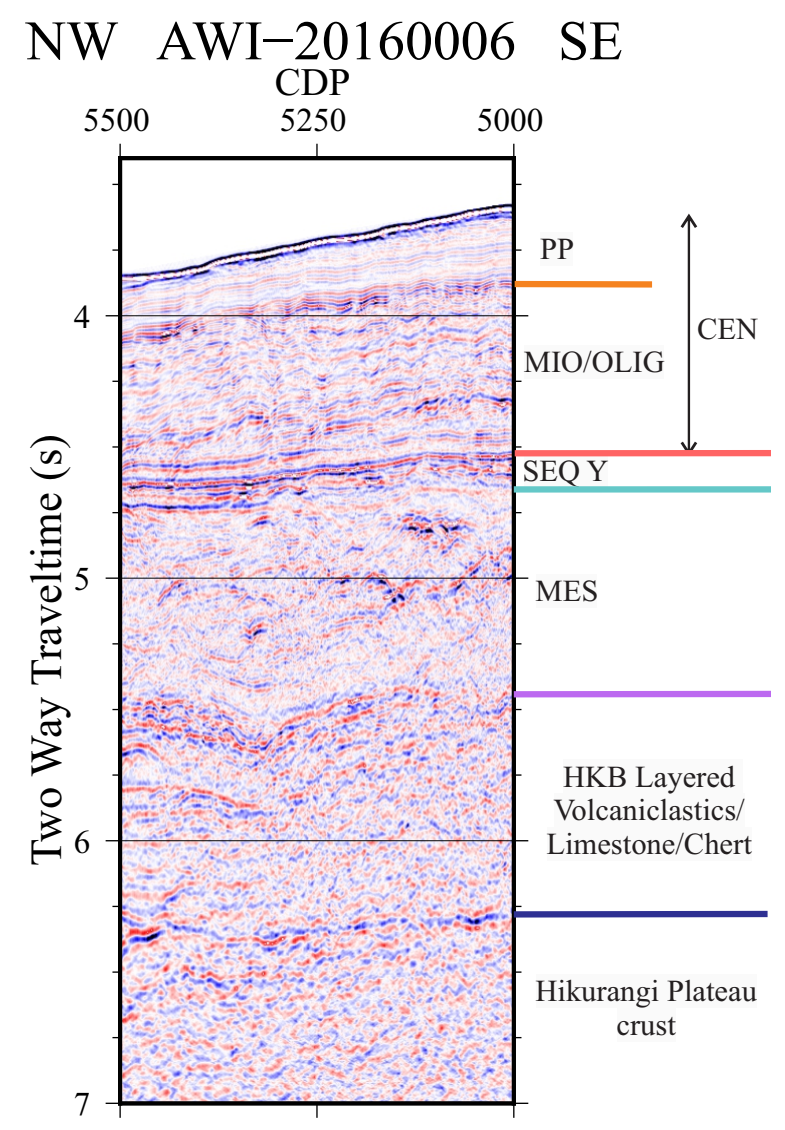

Figure 3.1: Portion of migrated seismic profile AWI-20160006, showing seismic stratigraphy which is typical of that overlying the Hikurangi Plateau further west along the Chatham Rise margin (e.g. Davy et al., 2008, Bland et al., 2015). The lines are coloured as follows: Orange $=$ base of PP (Plio-Pleistocene sediments), Pink = base of MIO/OLIG (Miocene to Late Oligocene sediments), Turquoise $=$ base of SEQ Y (Paleogene to Late Cretaceous sediments), Purple $=$ base of MES (Mesozoic sediments), Navy blue = Base of HKB (layered volcaniclastics/limestone/chert sediments which overlie the crust of the Hikurangi Plateau).

Cenozoic sediments (hereafter referred to as CEN) have a maximum thickness of 1000 ms TWTT; however, this is highly variable as CEN drapes over existing structures and is frequently interrupted by erosional channels, unconformities and faults (e.g. Figures 4.6, 4.11, 4.15). At Site 1123, CEN sediments were found to predominantly be nanofossil chalks interbedded with tephras and clay deposits in a glacial/interglacial cyclic sedimentation pattern (Carter et al., 1999a). The composition of CEN sediments remains similar through the unit; however, older (Miocene/Oligocene) sediments are more indurated than the Plio-Pleistecene sediments. Consequently, the Miocene/Oligocene sediments tend to have a higher 
reflectivity than the overlying Plio-Pleistocene sediments (Figure 3.1). Where possible, these units are mapped separately, and are referred to as PP and MIO/OLIG.

\subsubsection{PP - Pliocene to Pleistocene sediments}

Unit PP corresponds with Unit 1A at Site 1123, which extends to a depth of approximately $182 \mathrm{~m}$ below the sea floor (Carter et al., 1999a). Assuming an average unit velocity of $1700 \mathrm{~m} / \mathrm{s}$, this equates to $0.2 \mathrm{~s}$ TWTT (Equation 2.6). Where identified on these profiles, PP is a similar thickness as at Site 1123 (e.g. Figure 3.1).

\subsubsection{MIO/OLIG - Late Oligocene to Miocene sediments}

MIO/OLIG can be correlated with Units 1B - 3 of Carter et al. (1999a). At Site 1123, MIO/OLIG was found to be $405 \mathrm{~m}$ thick (Carter et al., 1999a). Assuming an average unit velocity of $1700 \mathrm{~m} / \mathrm{s}$, this is equivalent to $\sim 0.5 \mathrm{~s}$ TTWT, similar to the thickness of MIO/OLIG on the seismic profiles interpreted in this study (e.g. Figure 3.1).

\subsubsection{MES - Mesozoic sediments}

MES is a well-laminated sequence of sediments which underlie SEQ Y and have relatively low amplitude reflectivity (compared to SEQ Y - Figure 3.1). Sites 1123 and 1124 (Carter et al., 1999a,b) did not reach this depth but based on its stratigraphic position below SEQ Y (Early Oligocene to Late Cretaceous - Carter et al., 1999a), and above the Hikurangi Plateau (formed ca. $123 \mathrm{Ma}$ - Neal et al., 1997), MES is interpreted to have been deposited during the Cretaceous.

Unit MES described here can be correlated to units MES-2 of Wood and Davy (1994), MES of Davy et al. (2008) and Unit 3B of Bland et al. (2015). MES varies 
significantly in thickness between 0 and 2000 ms TWTT across this north-eastern region of the Chatham Rise (Figure 1.1) as it drapes over basement and infills basement topography. It is thickest where it infills half-grabens and thinnest (or

non-existent) in regions where basement is elevated such as over the top of the rotated fault blocks, or over domed volcanic structures (e.g. Figures 4.6, 4.11, 4.15).

\subsubsection{HKB - Hikurangi Basement}

North of the Chatham Rise margin, MES is underlain by a sequence of highlyreflective but deformed horizons (Figure 3.1). This sequence (here named HKB after the naming convention of Davy et al., 2008) varies between 500 and 1200 ms TWTT thick on the north-western side of profiles AWI-20160006 and CHAT-3 (Figures 4.6 and 4.11). Based on its reflective character and its stratigraphic position below MES (Figure 3.1), HKB is correlated to Unit 2 of Bland et al. (2015), and HKB of Davy et al. (2008). HKB is interpreted to contain volcaniclastic, limestone and chert sediments (Davy et al., 2008), and overlies the Hikurangi Plateau, similar to volcaniclastic/limestone/chert sediments which overlie the Ontong Java and Manihiki plateaux (e.g. Gladczenko et al., 1997, Pietsch and UenzelmannNeben, 2015).

\subsubsection{Torlesse - Continental crust of the Chatham Rise}

Basement underlying the Chatham Rise has been identified as continental crust belonging to the Torlesse Supergroup based on the results of dredges and extensive seismic profiling across the region (Wood and Davy, 1994). Torlesse consists of greywacke sandstone and argillite, and underlies much of the New Zealand continental region (Bradshaw, 1989). Two main subgroups are recognized based on age and level of deformation - the Rakaia (Permian to early Jurassic) and Pahau (late 
Jurassic to early Cretaceous) subterranes (Wood and Davy, 1994). The top of this acoustic basement is easily identified as a strong reflection on seismic profiles AWI-20160004, AWI-20160006 and CHAT-3 (Figures 4.6, 4.11, 4.15) which cross onto the north-eastern margin of the Chatham Rise. The Torlesse basement of the Chatham Rise has experienced significant deformation and is heavily faulted. A series of extensional half-grabens and rotated fault blocks cut through the basement throughout the Chatham Rise. Wood et al. (1989) found that these half-grabens tend to be fault-bounded on their northern side. This correlates with the configuration observed for half-grabens imaged on profiles AWI-20160004, AWI-20160006 and CHAT-3 (Figures 4.6, 4.11, 4.15).

\subsection{Oceanic Crust and sediments}

\subsubsection{Sedimentary cover}

The sedimentary sequence which overlies the oceanic crust on CHAT-4 is composed of finely laminated sediments of moderate reflectivity, and varies in thickness between 200 and $1700 \mathrm{~ms}$ (Figure 3.2). This sequence represents glacial/interglacial sedimentation patterns typical of marine deposits (e.g. Carter et al., 1999a).

\subsubsection{Oceanic Crust}

To a first approximation, oceanic crust can be separated into two layers: extrusive upper crust (Layer 2), and underlying gabbroic basement (Layer 3) (Figure 3.2).

Globally, Layer 2 is basaltic in composition and is typically $2-3 \mathrm{~km}$ thick $(0.8-1.2 \mathrm{~s}$ TWTT, assuming an average velocity of $5 \mathrm{~km} / \mathrm{s}$ ) (Carlson and Herrick, 1990). The results of seismic reflection and refraction studies in the Pacific and Atlantic oceans led Houtz and Ewing (1976) to suggest stratification within Layer 2, separating it 


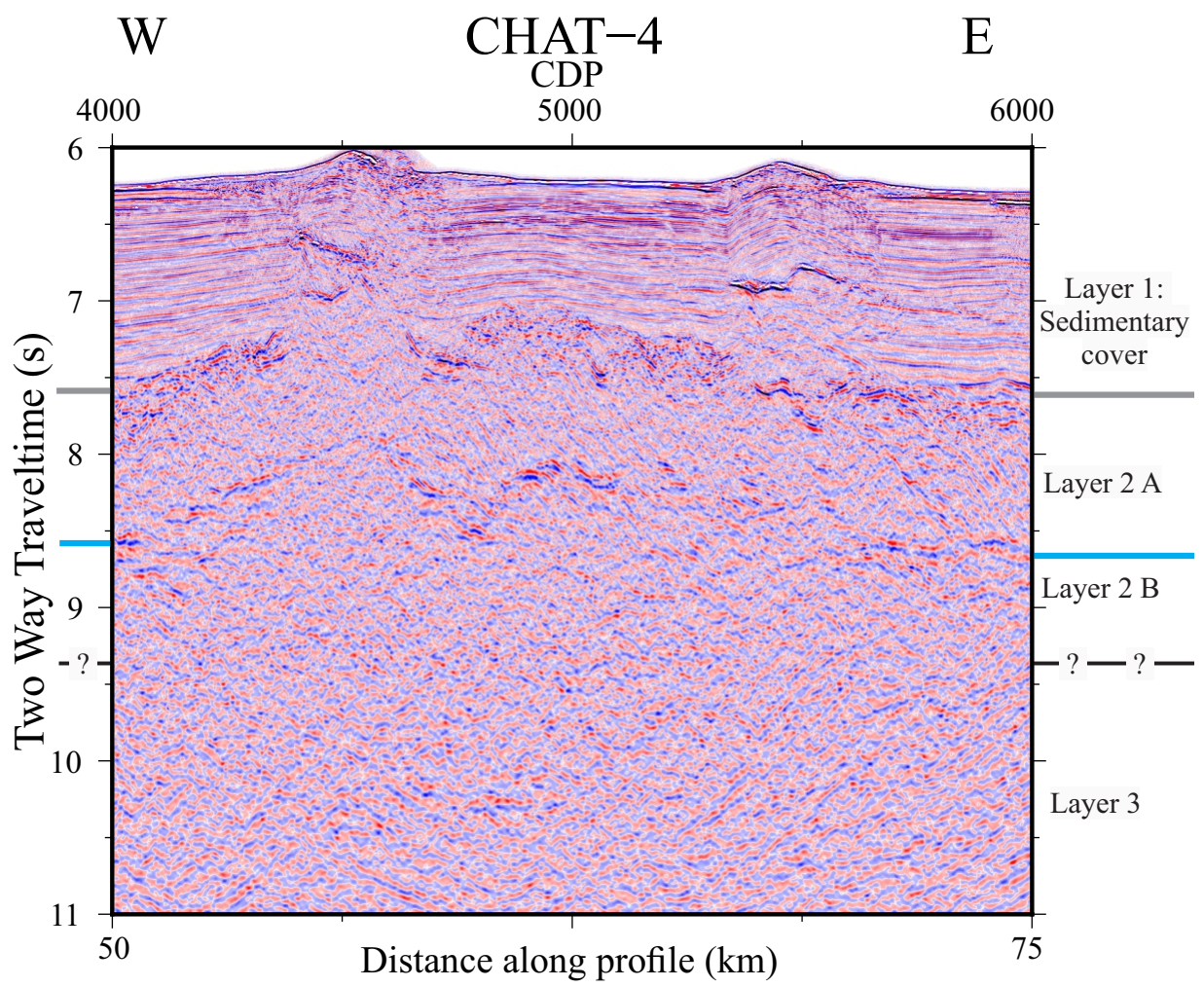

Figure 3.2: Portion of migrated seismic profile CHAT-4, highlighting stratigraphy which is typical of oceanic crust. The grey line indicates the base of the sedimentary cover, and the blue line indicates the interface between Layers $2 \mathrm{~A}$ and $\mathrm{B}$. The base of Layer $2 \mathrm{~B}$ is unresolved in seismic reflection data and is represented here by the black line with question marks overlain. The base of Layer 3 corresponds with the Moho, not shown on this figure.

into Layers $2 \mathrm{~A}$ and $\mathrm{B}$. These sub-layers are not indicative of differing compositions, rather they are a result of variations in the porosity of the extrusive crust (Carlson and Herrick, 1990). Layers 2A and 2B are distinguished on the basis of their velocity structures: Layer $2 \mathrm{~A}$ has a velocity of ca. $2-4 \mathrm{~km} / \mathrm{s}$, and Layer $2 \mathrm{~B}$ has velocities between $5-6 \mathrm{~km} / \mathrm{s}$ (Seher et al., 2010). The difference in these velocities means that a large velocity gradient is present at the base of Layer $2 \mathrm{~A}$, and the interface between Layers $2 \mathrm{~A}$ and $\mathrm{B}$ can be resolved using seismic reflection data (Detrick et al., 1994). Layer 2A is typically only ca. $0.5 \mathrm{~km}$ thick (e.g. Seher et al., 2010), but is 1.0 to $1.5 \mathrm{~km}$ thick on CHAT-4 (Figure 3.2). This is discussed in Section 4.1 . 
The boundary between Layers 2 and 3 is not a straight-forward stratigraphic contact; rather, it is a transition governed by changes in bulk porosity and fracture geometry that occurs over several hundred metres (Detrick et al., 1994). Consequently, this boundary is not generally imaged in seismic reflection data.

Layer 3 refers to the gabbroic basement, and has velocities which range between 6.5 and $7 \mathrm{~km} / \mathrm{s}$ (Carlson and Herrick, 1990). The base of this layer coincides with the base of the crust (the Moho). The total thickness of oceanic crust is typically 5-8.5 km (White et al., 1992).

The nature of the crust on CHAT- 4 will be discussed further in Sections 4.1 and 5.1. 


\section{Chapter 4}

\section{Results and Analysis}

In this chapter, four multi-channel seismic reflection profiles (CHAT-4, CHAT3, AWI-20160006 and AWI-20160004), which cross the West Wishbone Ridge (WWR) in the vicinity and immediately north of its intersection with the Chatham Rise (Figure 4.1), are interpreted. The acquisition and processing of these data are described in Chapter 2, and the seismic stratigraphy across these profiles is discussed in Chapter 3. Gravity and magnetic anomalies are also used to aid this interpretation. Gravity anomaly data along the seismic profiles of interest to this study were extracted from the satellite altimetry-derived gravity data of Sandwell et al. (2014) using the grdtrack utility of Generic Mapping Tools (Wessel et al., 2013). Magnetic data were collected during the acquisition of AWI-20160006 and AWI-20160004 (Gohl et al., 2016). The processing of these data is outlined in Appendix B. No magnetic data have been collected for profiles CHAT-3 and CHAT-4. 

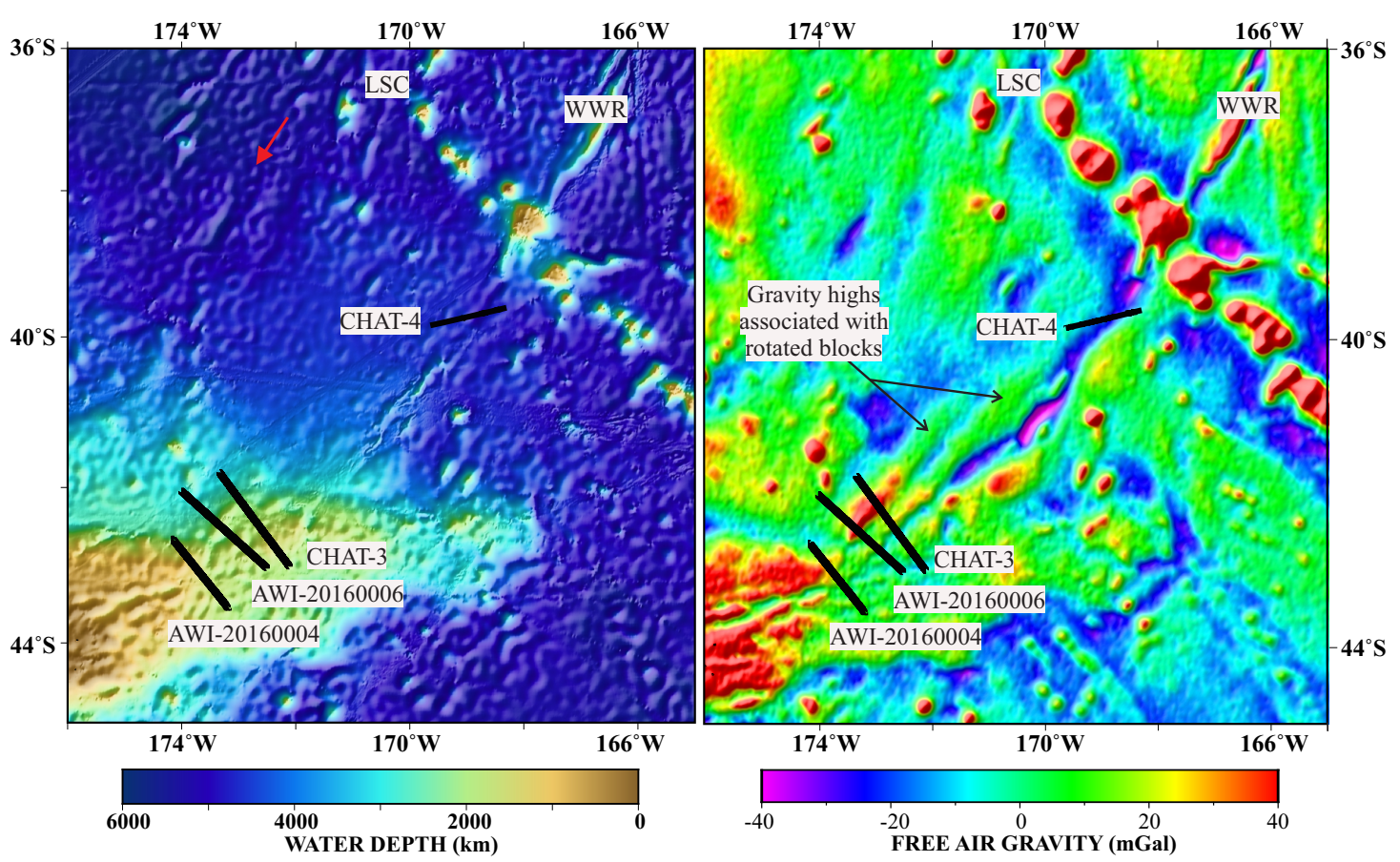

Figure 4.1: Bathymetry (left) and Satellite Gravity (right; sun-illuminated from the north-west) maps highlighting the position of the four profiles discussed in this chapter. $\mathrm{LSC}=$ Louisville Seamount Chain. WWR $=$ West Wishbone Ridge. Red arrow $=$ strike of crustal fracture zones. Bathymetric data are from GEBCO, 2014 and satellite gravity data are from Sandwell et al. (2014).

\subsection{CHAT-4}

CHAT-4 is a deep-water ( $>4500 \mathrm{~m}$ water depth) profile that crosses the WWR north-east of the Hikurangi Plateau (Figures 4.1 and 4.2).

Between CDPs 1 and 7000, the sediments which overlie the crustal basement have an average thickness of $\sim 1.6 \mathrm{~s}$ two-way travel time (hereafter referred to as TWTT, Figure 4.2). From CDP 8500 to the eastern end of the profile, these sediments thin to $\sim 0.25 \mathrm{~s}$ TWTT. This thinning of the sedimentary cover is accompanied by an upwards step in the elevation of the top of the crustal basement between CDPs 7000 and 8500 (approximately $1 \mathrm{~s}$ TWTT, which equates to $4.2 \mathrm{~km}$ if the average velocity is assumed to be $6 \mathrm{~km} / \mathrm{s}$ ), such that the sea floor elevation across the profile only varies by a total of $\sim 0.3 \mathrm{~s}$ (Figure 4.2 ).

Between CDPs 2500 and 6500, the crust has a layered structure indicative of 


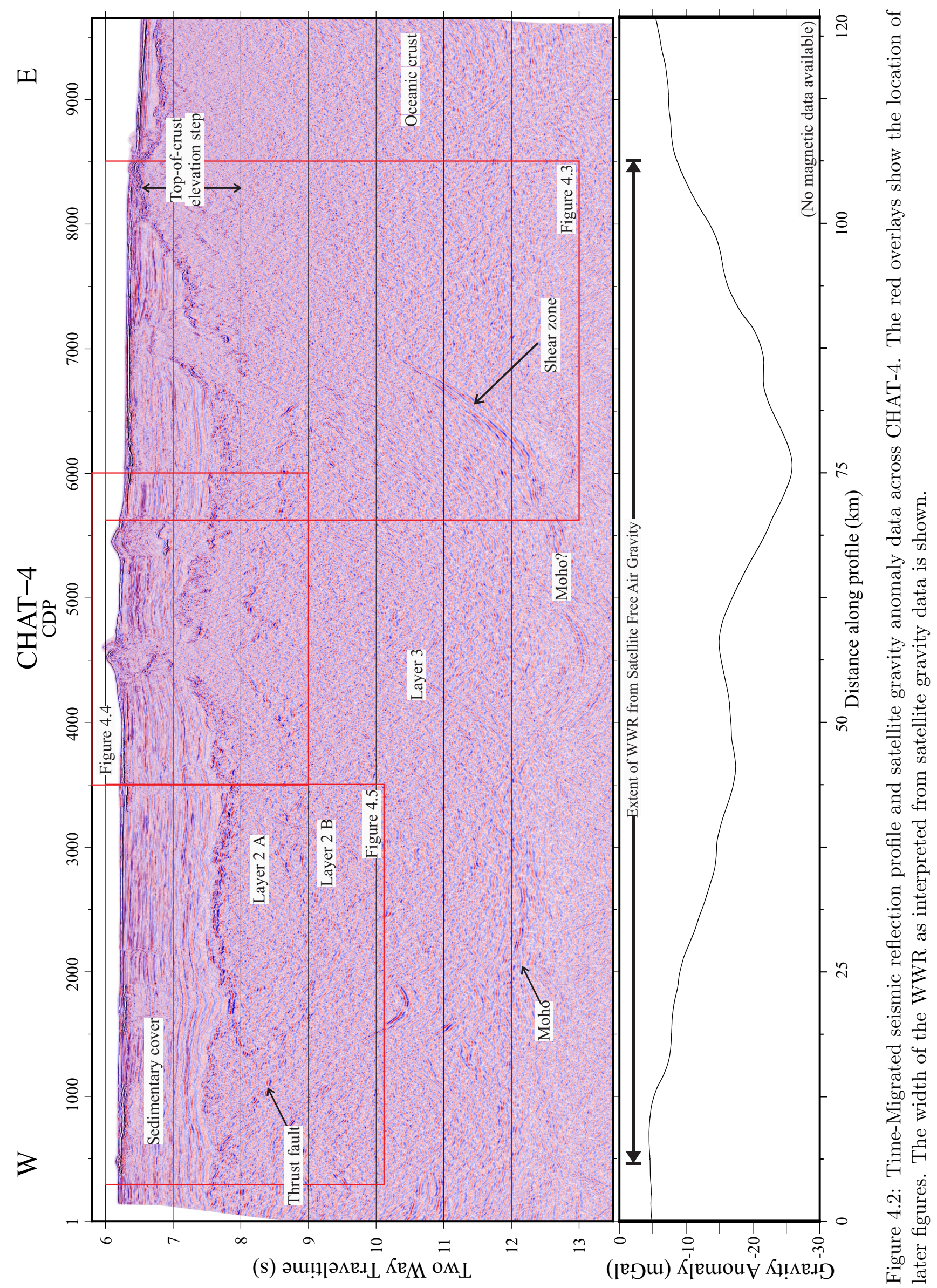


oceanic crust as described in Chapter 3.2 (Figure 4.2). At the top of the crustal basement, centred on a depth of $8 \mathrm{~s}$, a layer with an approximately constant thickness of $1 \mathrm{~s}$ TWTT is observed. On the basis of its reflectivity character and interval velocity $(3.6 \mathrm{~km} / \mathrm{s}$ near the top of the layer), this layer is interpreted as oceanic Layer 2A (Carlson and Herrick, 1990). Layer 2A overlies 2B - the base of which typically cannot be resolved in seismic reflection data due to this boundary being diffuse and likely spread over several hundred metres (Detrick et al., 1994). Together, Layers 2A and B constitute an extrusive, basaltic layer which overlies the gabbroic basement of Layer 3 (White et al., 1992).

A region of strong reflectivity that extends roughly from $11.9 \mathrm{~s}$ TWTT at CDP 500 to approximately $12.1 \mathrm{~s}$ TWTT at CDP 3000 is interpreted to mark the Moho (Figure 4.2). This indicates a crustal thickness of approximately $4.3 \mathrm{~s}$ TWTT (or $\sim 12.9 \mathrm{~km}$ if an average crustal velocity of $6 \mathrm{~km} / \mathrm{s}$ is assumed). This crustal thickness is thicker than the 5 to $8.5 \mathrm{~km}$ typically associated with oceanic crust (White et al., 1992), raising questions about the nature of the crust here. An argument for the oceanic nature of the crust on the western end of CHAT-4 (west of CDP 7200 - Figure 4.2) is found in its layered structure (Carlson and Herrick, 1990). Another is found in the NNE-striking fracture zone fabric west of the WWR (Figure 4.1), which is consistent with oceanic fracture zone fabric to the north, between the Osbourn Trough and the north-east margin of the Hikurangi Plateau (Figure 1.1 - Downey et al., 2007, Davy et al., 2008). Such thickening of oceanic crust has been identified adjacent to other Large Igneous Provinces, where a spreading centre (such as the Osbourn Trough) intersects hotter-than-normal mantle adjacent to mantle plumes (as has been suggested for the formation of Ontong Java Nui) (White et al., 1992).

Typical continental crust tends to be more deformed, older and thicker (25 to $70 \mathrm{~km}$ thick on average) than oceanic crust (Fowler, 2005), which serves as an argument against this crust being continental in nature. It should be noted that 
in regions of continental rifting, continental crust can be thinned to the thickness of thickened oceanic crust; however, such thinning of continental crust would be accompanied by features characteristic of rifting, such as rotated fault blocks and half-grabens (e.g. Le Pichon et al., 1982, Thinon et al., 2003, Van Avendonk et al., 2009). Such extensional features are not evident on this profile (Figure 4.2). On the basis of these arguments, it is interpreted that the crust west of CDP 7200 on CHAT-4, while thickened, is oceanic. Identification of the nature of the crust on the eastern side of the profile (east of CDP 7200 - Figure 4.2) is more challenging as the stratifications typically associated with oceanic crust are not evident in the seismic reflection data, and the fracture zone fabric associated with oceanic crust is not evident in the bathymetry data (Figure 1.1).

Between CDPs 7000 and 5500, a series of westward-dipping, parallel reflections extend from 10.5 to 12.5 s TWTT; their dip shallowing at depth to coincide with the Moho (Figure 4.3). Similar features at the base of the crust near the Shatsky Rise in the north-western Pacific Ocean have been interpreted to be shear zones formed as a result of basal drag at the Moho (Kodaira et al., 2014). Those authors interpreted the drag forces there to be a result of the differential rates of motion of the spreading crust and the underlying mantle. This feature could also result from differential motion within the crust, such as that associated with transform motion. The crust above this shear zone is deformed and the top of the crustal basement is offset in two steps (Figure 4.3). This coincides with the change in the thickness of the sedimentary section discussed previously. The crustal fabric west of the deep-crustal shear zone is sub-parallel to the shear zone (Figure 4.3). A change in the nature of the crust is also observed from west to east across this boundary: to the west, between CDPs 2500 and 6500, the interface between Layers $2 \mathrm{~A}$ and $\mathrm{B}$ is evident in the upper crust while east of CDP 7000, this interface is not able to be resolved in the seismic reflection data. These variations across this boundary suggest the juxtaposition of two crustal sections, such as that which 


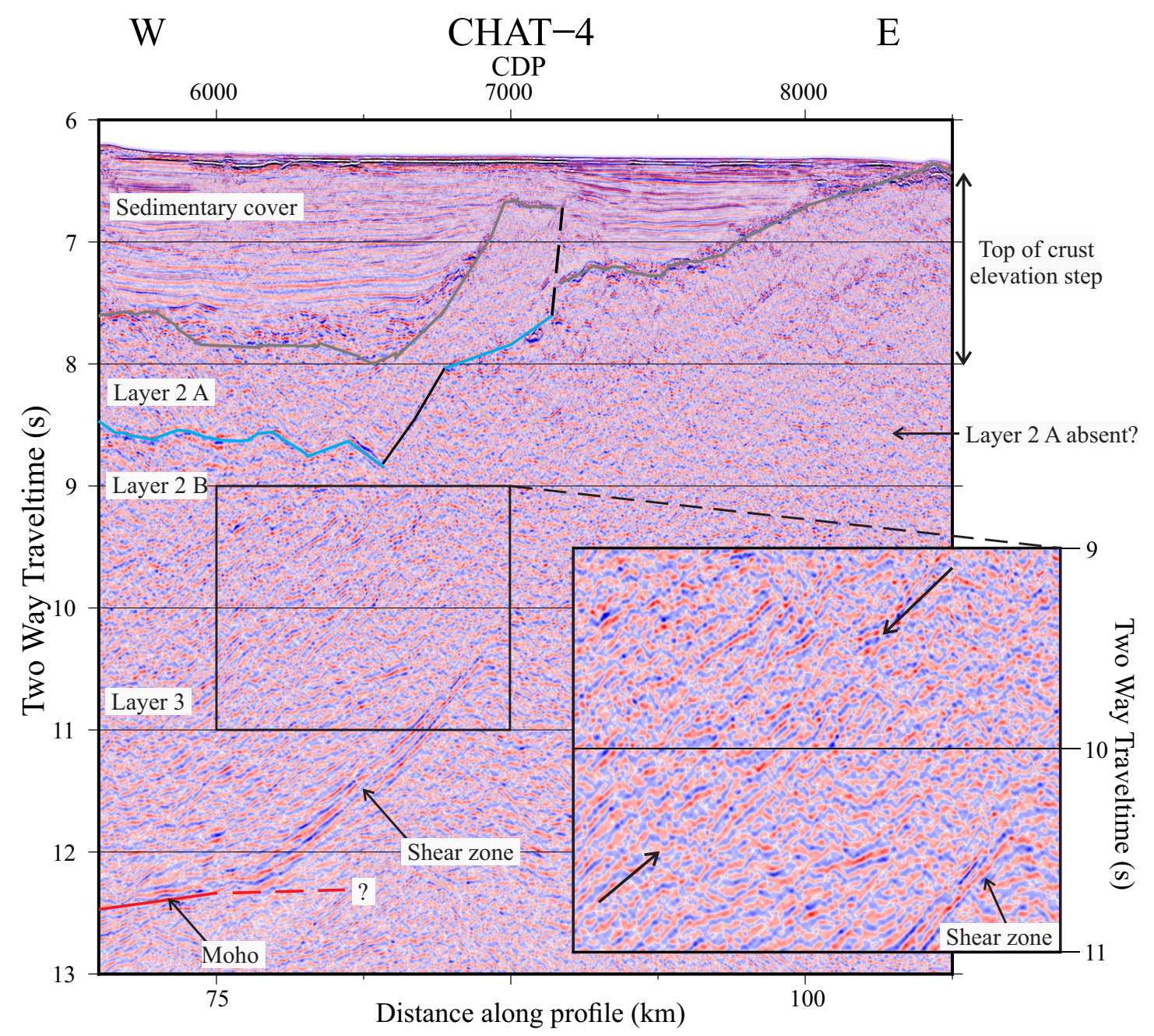

Figure 4.3: Portion of the time-migrated seismic profile CHAT-4 showing the shear zone at the base of the crust, and the deformation above that feature. The lines are coloured as follows: grey $=$ top of crustal basement; blue = interface between Layers $2 \mathrm{~A}$ and $\mathrm{B}$; red $=$ Moho; black $=$ faults; dashed lines $=$ interpolated. The arrows within the inset highlight crustal fabric which is sub-parallel to the orientation of the shear zone.

would occur as a result of transform faulting.

At two regions, centred on CDPs 4500 and 5400, the sea floor, top of the crust, and Layer 2A are uplifted and folded (Figure 4.4). These regions of uplift and folding are bound by steep faults on their eastern and western sides so that the full width of associated deformation is about 200 CDPs $(2.5 \mathrm{~km})$ wide for each region. The faults extend upwards through Layer 2A and the overlying sediments to offset the sea floor (Figure 4.4). This combination of folding, steep faulting and uplift is indicative of minor compressional faulting zones (Fowler, 2005). 


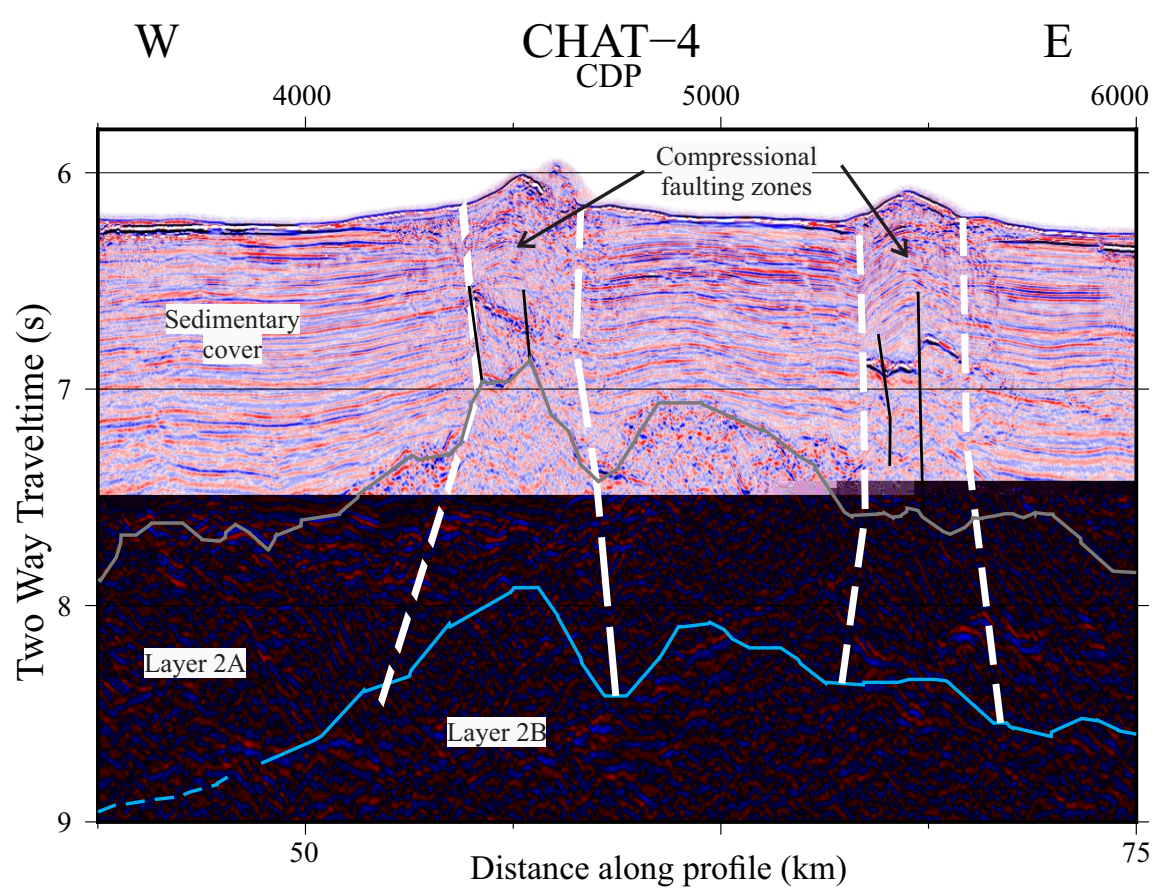

Figure 4.4: Portion of the time-migrated seismic profile CHAT-4 highlighting the regions of compressional faulting that are observed on this profile. The lines are coloured as follows: grey $=$ top of crustal basement; blue $=$ interface between Layers $2 \mathrm{~A}$ and B; black $=$ interpreted faults; dashed white $=$ borders of compressional faulting zones interpreted based on the step in the sea floor horizon, the top of the crustal basement and the interface between Layers $2 \mathrm{~A}$ and B; dashed lines (horizons) = interpolated.

On the western side of the WWR, between CDPs 500 and 2500 and traceable to a depth of $\sim 10 \mathrm{~s}$, an eastward dipping region of reflectivity is imaged (Figure 4.5). The interface between Layers $2 \mathrm{~A}$ and $\mathrm{B}$ is interpreted both east and west of this margin, although the depth of this interface on the western side is poorly constrained between 8.5 and $9 \mathrm{~s}$ in the seismic reflection data. In spite of this uncertainty, such offset of Layer 2A, where the hanging-wall is relatively uplifted, is indicative of thrust faulting. The sedimentary cover drapes over the top of the uplifted hanging-wall, and little faulting (if any) is seen in the overlying sediment (Figure 4.5). This constrains major motion along the thrust to before sediment deposition. The age of the sediment is poorly constrained but activity along the thrust must post-date the formation of the oceanic crust. This crust was formed at the Osbourn Trough, after the initiation of seafloor spreading ca. $120 \mathrm{Ma}$ (Mortimer et al., 2006, Taylor, 2006). 


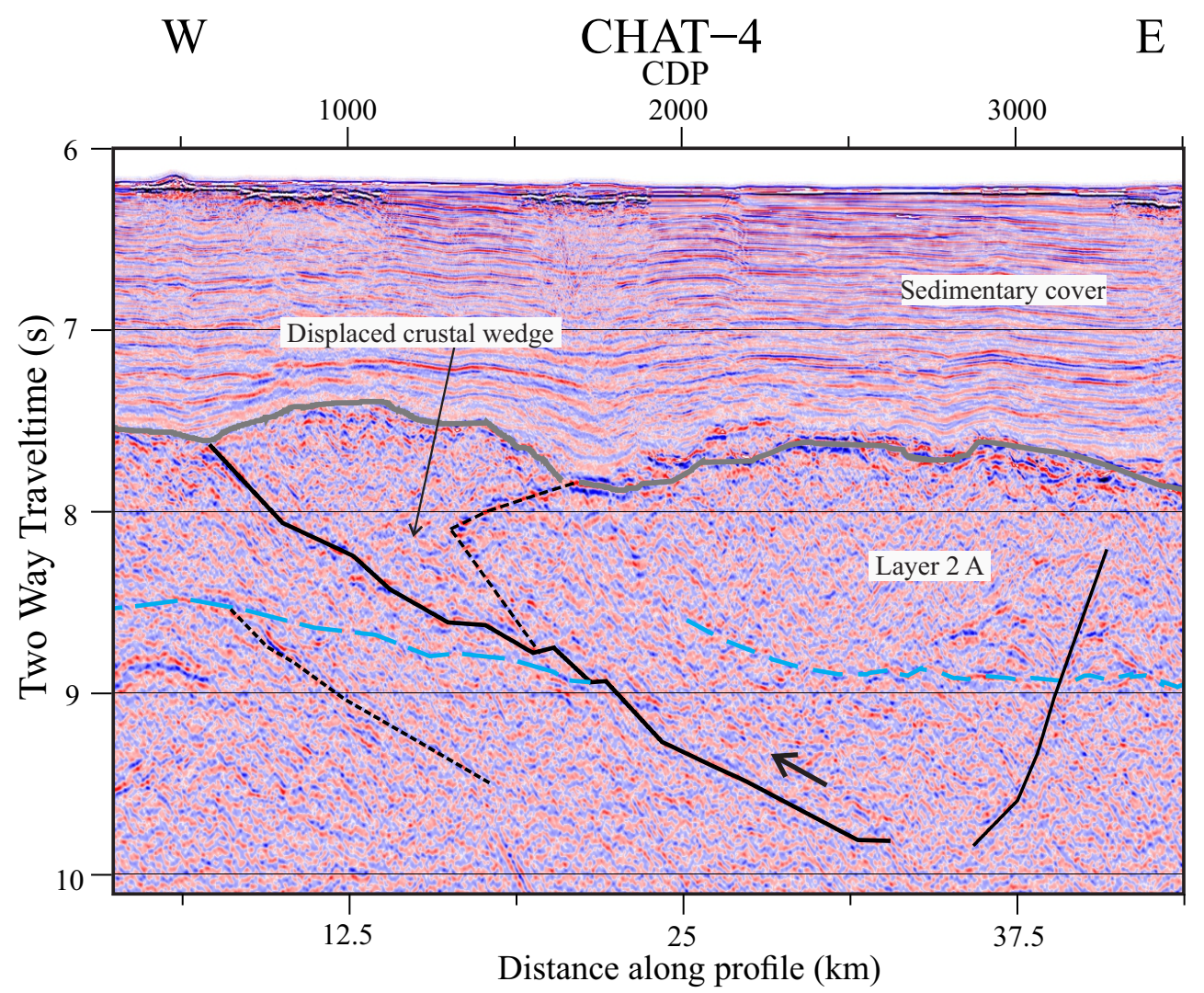

Figure 4.5: Portion of the time-migrated seismic profile CHAT-4 showing the thrust fault at the eastern end of this profile. The lines are coloured as follows: grey $=$ top of crustal basement; dashed blue $=$ suggested interface between Layers $2 \mathrm{~A}$ and $\mathrm{B}$; solid black $=$ faults; dotted black lines $=$ crustal fabric/faults. The arrow shows the direction of motion of the hanging-wall.

\subsection{CHAT-3}

This profile coincides with a transition from the Hikurangi Plateau (at the northwest) onto the Chatham Rise (Figure 4.1). This change in the nature of the underlying crust is accompanied by a shallowing in water depth from 3.2 to 1.5 km (Figure 4.6).

The sedimentary cover across CHAT-3 drapes over and infills basement topography, resulting in variable sedimentary thickness across the profile (Figure 4.6). A strong series of reflections, 0.1-0.2 s TWTT thick, is imaged within the sedimentary section (at approximately 5 s TWTT between CDPs 200 and 2200; and then draped over the rotated block at CDP 4100 and traceable through the rest of the 


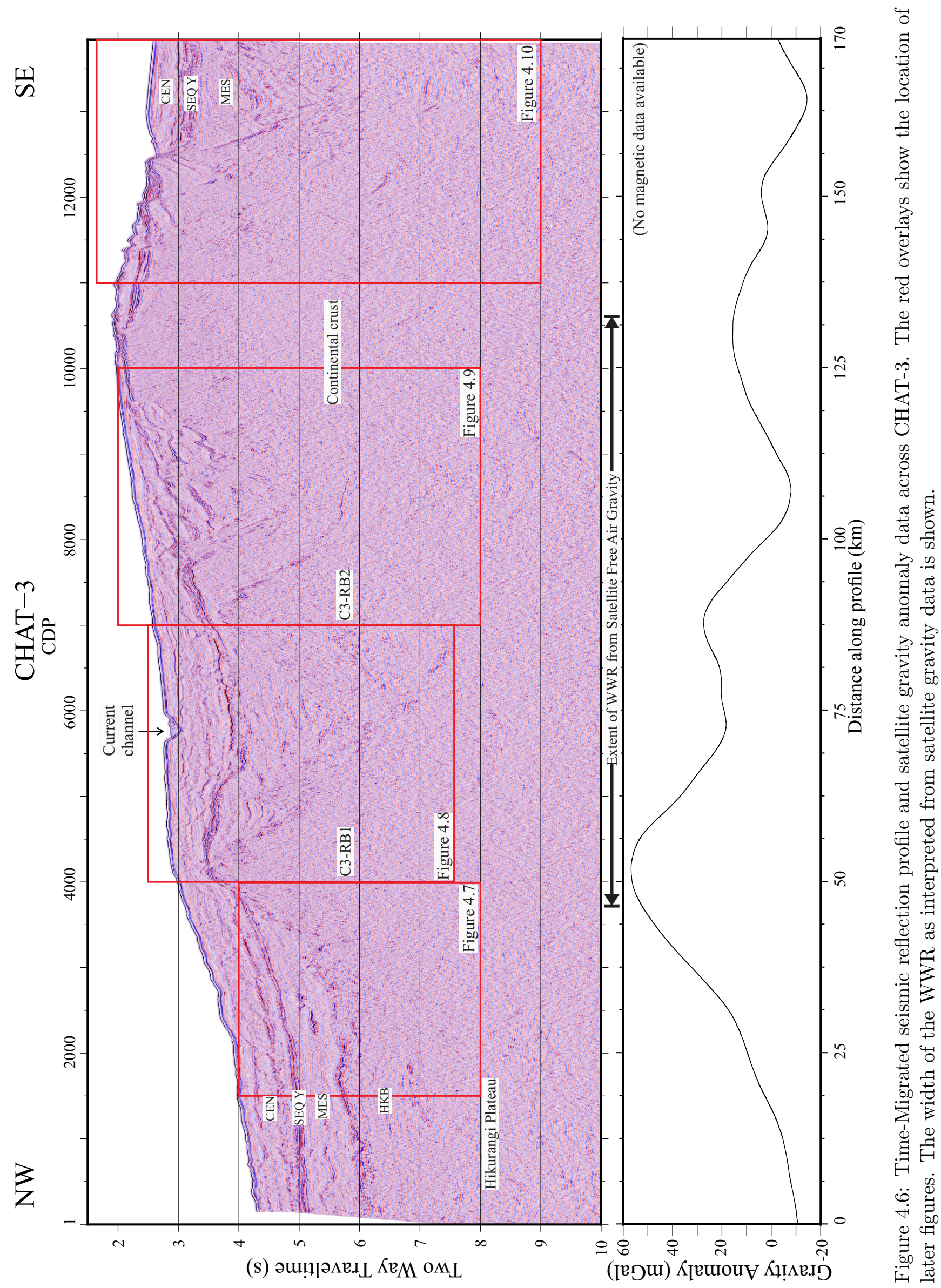


profile to the south-eastern end). Based on its high reflectivity and condensed nature, this unit is interpreted to be the Late Cretaceous/Paleogene Sequence Y (discussed in Chapter 3.1.1). Beneath CDP 5800, a channel has incised the upper $0.2 \mathrm{~s}$ TWTT of the sedimentary cover, and has later been infilled by sediment (Figure 4.6).

The crust on CHAT-3 (Figure 4.6) is more deformed than that on CHAT-4 (Figure 4.2). This is consistent with a change from oceanic to continental crust (Molnar, 1988). Between CDPs 1000 and 2000, a 1 s TWTT thick region of high reflectivity is observed below the base of the sedimentary cover (Figures 4.6, 4.7). At CDP 1600, the dip-direction of this series of reflections changes from north-west- to south-east-dipping. This series of reflections can be traced to a depth of about 7.3 s TWTT at CDP 3000 and bears a strong resemblance to sedimentary unit HKB that overlies the Hikurangi Plateau elsewhere in the Chatham Rise region, and is interpreted as such (Chapter 3.1.4). A highly-deformed crustal wedge overlies unit HKB between CDPs 2000 and 3500 (Figure 4.7). The folded and faulted nature of this crustal wedge suggests that it is an accretionary prism structure (Fowler, 2005). Similar accretionary structures have been identified further west along the Chatham Rise margin, e.g. on profiles HKDC1 and SAHKE1 (Davy et al., 2008, Bland et al., 2015) (Figure 1.1). On the basis of these two observations, this interface is interpreted as the Hikurangi Plateau under-thrusting the Chatham Rise. The nature of this interface between the continental crust of the Chatham Rise and the Hikurangi Plateau south-east of CDP 3000, and at depths greater than $\sim 7.3 \mathrm{~s}$ TWTT, is unconstrained by the seismic data (Figure 4.7). In Section 5.2, gravity modelling is used to further investigate this interface.

Centred beneath CDPs 4000 and 7000, two rotated fault blocks are identified, and are hereafter referred to as C3-RB1 and C3-RB2 (Figure 4.6). The fault which bounds the south-east side of C3-RB1 can be traced from $\sim 3.5 \mathrm{~s}$ TWTT beneath CDP 4100 to $\sim 7.5 \mathrm{~s}$ TWTT at CDP 6500 . Assuming an average velocity of 6 


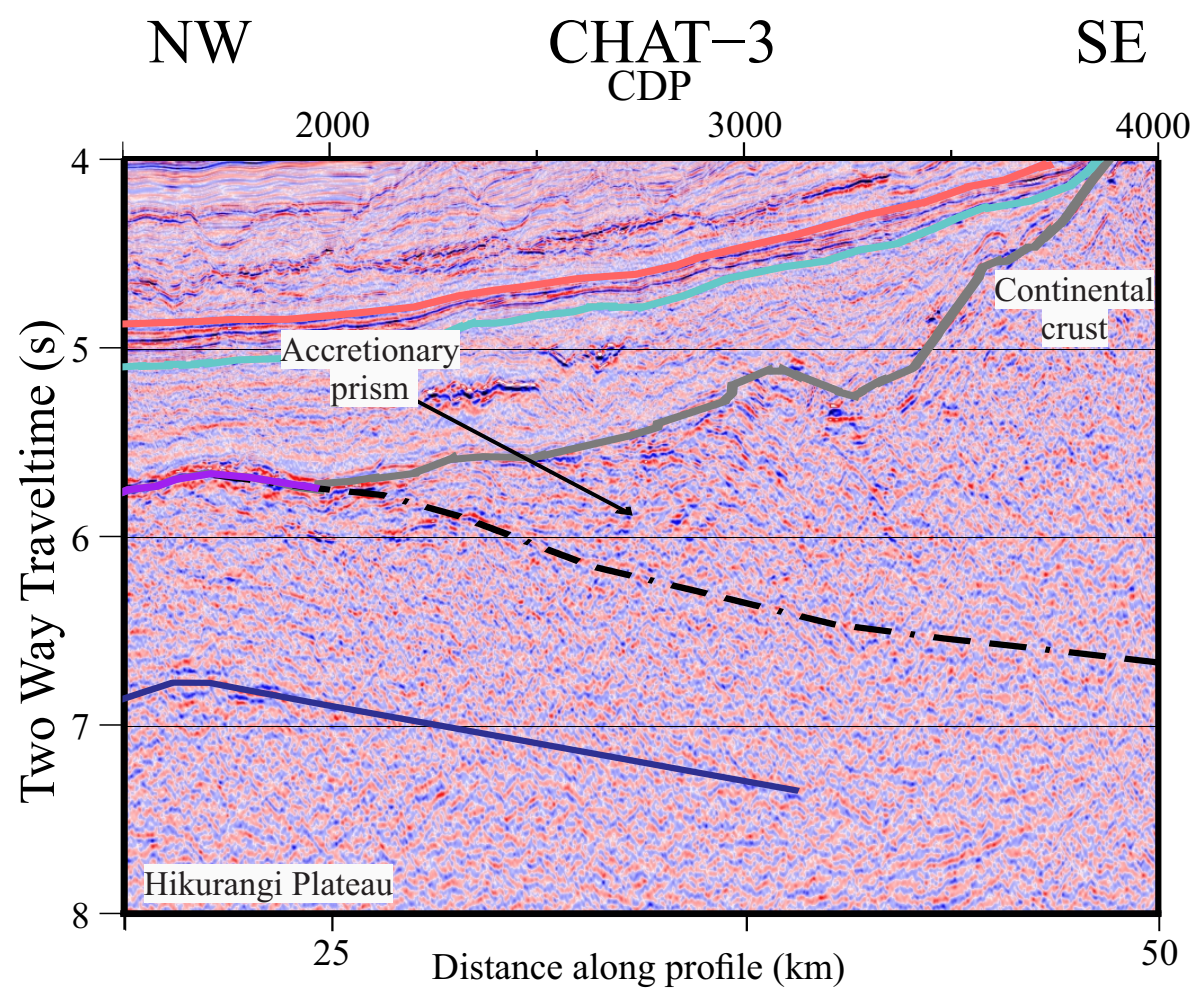

Figure 4.7: Portion of the time-migrated seismic profile CHAT-3 showing the Hikurangi Plateau under-thrusting the continental crust of the Chatham Rise on the north-western end of this profile. The lines are coloured as follows: pink = base of CEN (Cenozoic sediments); turquoise = base of SEQ Y (Late Cretaceous to Paleogene sediments); grey $=$ base of MES (Mesozoic sediments) where it overlies continental crust; purple = base of MES where it overlies HKB; navy = base of HKB (layered volcaniclastic/limestone/chert sediments); dashed/dotted black = top of HKB beneath continental crust.

$\mathrm{km} / \mathrm{s}$, this corresponds to a vertical distance of $\sim 12 \mathrm{~km}$. Rotated fault blocks and half-grabens such as these are widely observed across the Chatham Rise, with this same configuration (bound by a fault on the northern side) common to most (Wood et al., 1989). These are extensional features which have been attributed to Late Cretaceous Hikurangi Plateau subduction-related uplift and subsequent extension in this region (Bland et al., 2015).

South-east of rotated block C3-RB1, an interpreted second accretionary prism structure is observed. This interpretation is based on the folding of the fabric within the prism onto the south-eastern edge of rotated block C3-RB1 (Figure 4.8). This structure is difficult to reconcile with its location, and will be discussed further on. 


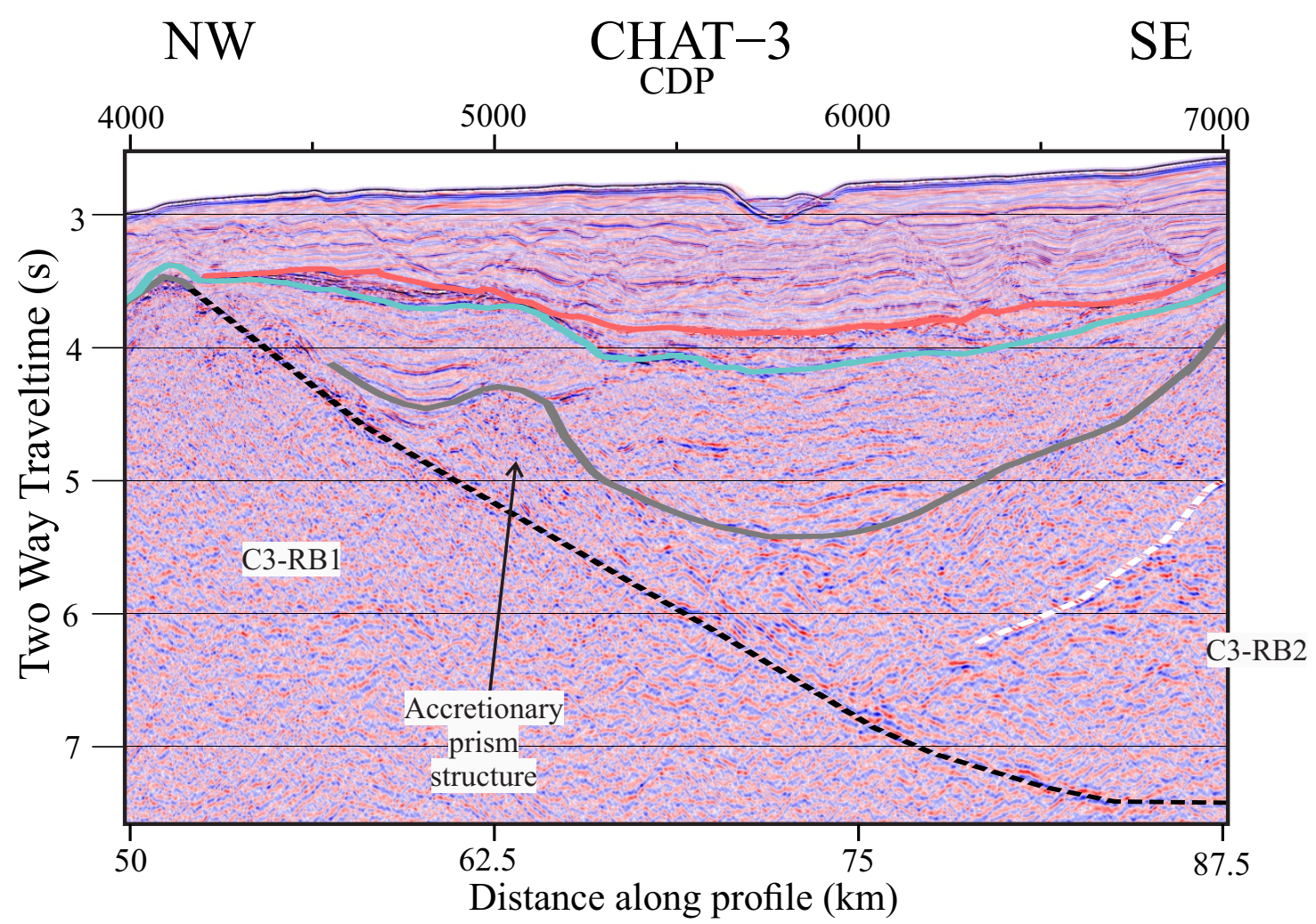

Figure 4.8: Portion of the time-migrated seismic profile CHAT-3 highlighting the accretionary prism structure south-east of rotated block C3-RB1. The lines are coloured as for Figure 4.7, with the addition of the dashed black line (fault which bounds the SE edge of rotated block C3-RB1), and the white dashed line (basement fabric/fault).

The sediment-filled half-grabens which lie on the south-eastern side of rotated blocks C3-RB1 and C3-RB2 are heavily faulted, particularly that south-east of C3-RB2 (Figure 4.9). In this half-graben, two flower structures (where high-angle normal and thrust faults splay off a common central fault) offset the sedimentary units. These features have previously been suggested to indicate transform motion orientated perpendicular to the seismic section (D'Onfro and Glagola, 1983).

At CDP 9600, the top of the crustal basement has been offset by $\sim 0.5 \mathrm{~s}$ TWTT by motion along a thrust fault (Figure 4.9). Assuming an average velocity of $6 \mathrm{~km} / \mathrm{s}$, this translates to an offset of $\sim 1.5 \mathrm{~km}$. South-east of this thrust fault (between CDPs 9600 and 10500), the crust is uplifted, and the sedimentary cover thins to $\sim 0.2 \mathrm{~s}$ TWTT thickness (Figures 4.6 and 4.9). The near-planar nature of the reflection which marks the top of the crustal basement is indicative of uplift to 


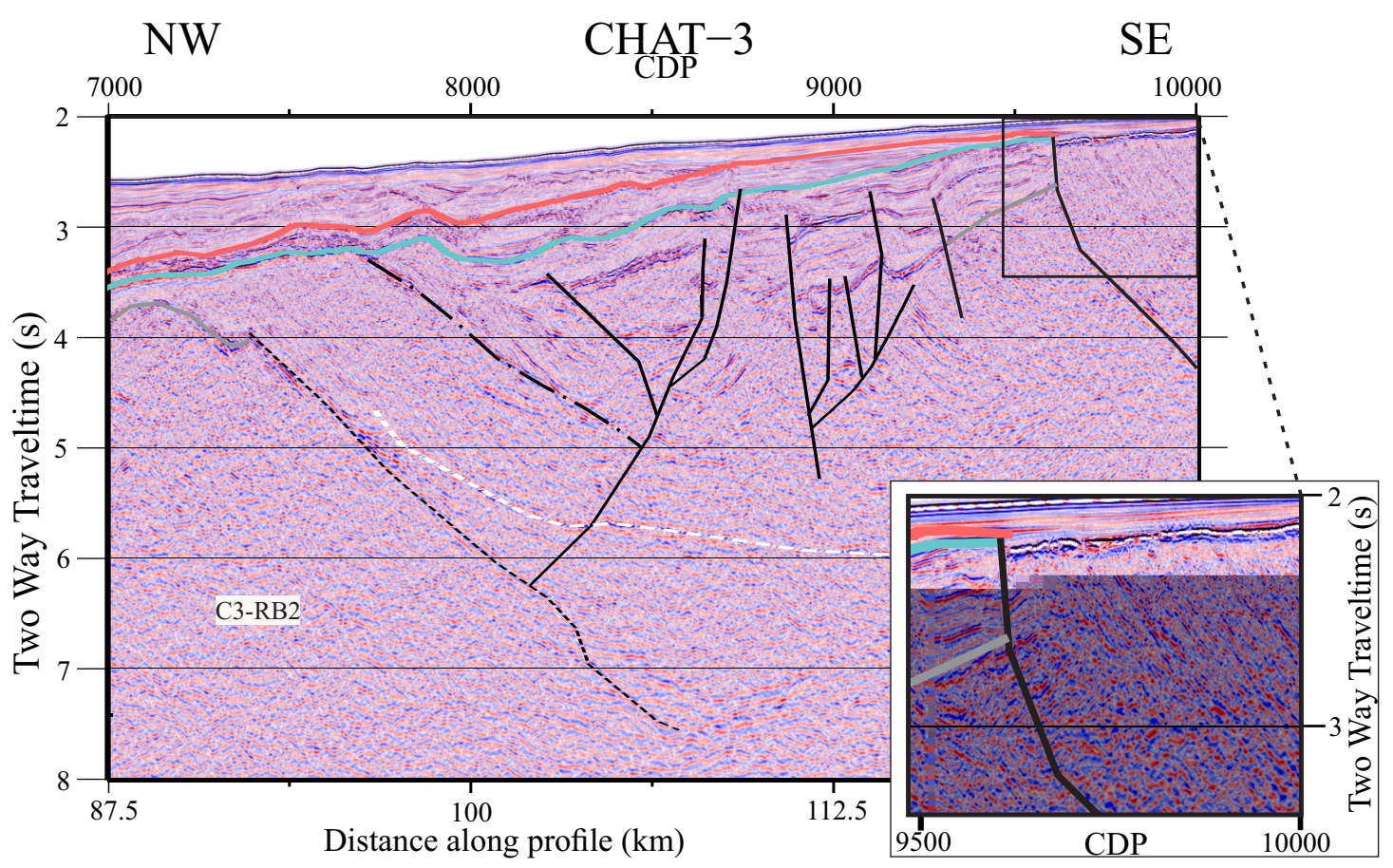

Figure 4.9: Portion of the time-migrated seismic profile CHAT-3 showing the half-graben south-east of rotated block C3-RB2. The lines are coloured as for Figure 4.8. Inset highlights the $\sim 45^{\circ}$ dipping basement fabric (see text for details).

sea level and subsequent erosion. The sediments which overlie this uplifted top of crust reflector are interpreted to be Oligocene to Recent in age, constraining the uplift and erosion observed here to have occurred before this period. The basement fabric within this region of uplifted crust dips at $\sim 45^{\circ}$ (assuming an average velocity of $6 \mathrm{~km} / \mathrm{s}$, Figure 4.9$)$.

South of the crustal uplift between CDPs 9600 and 11500, at least three more rotated fault blocks (hereafter identified as C3-RB3, C3-RB4 and C3-RB5) and associated half-grabens are identified (Figure 4.10). These rotated blocks are approximately 2 - $5 \mathrm{~km}$ wide, an order of magnitude smaller than rotated blocks C3-RB1 and C3-RB2 which are 20 - $35 \mathrm{~km}$ wide (Figure 4.6). South-east of C3RB5, a $\sim 3$ s TWTT thick sedimentary section overlies the basement (Figure 4.10). Several steeply dipping normal and thrust faults splay off the fault which marks the edge of rotated block C3-RB5, resembling a flower structure. 


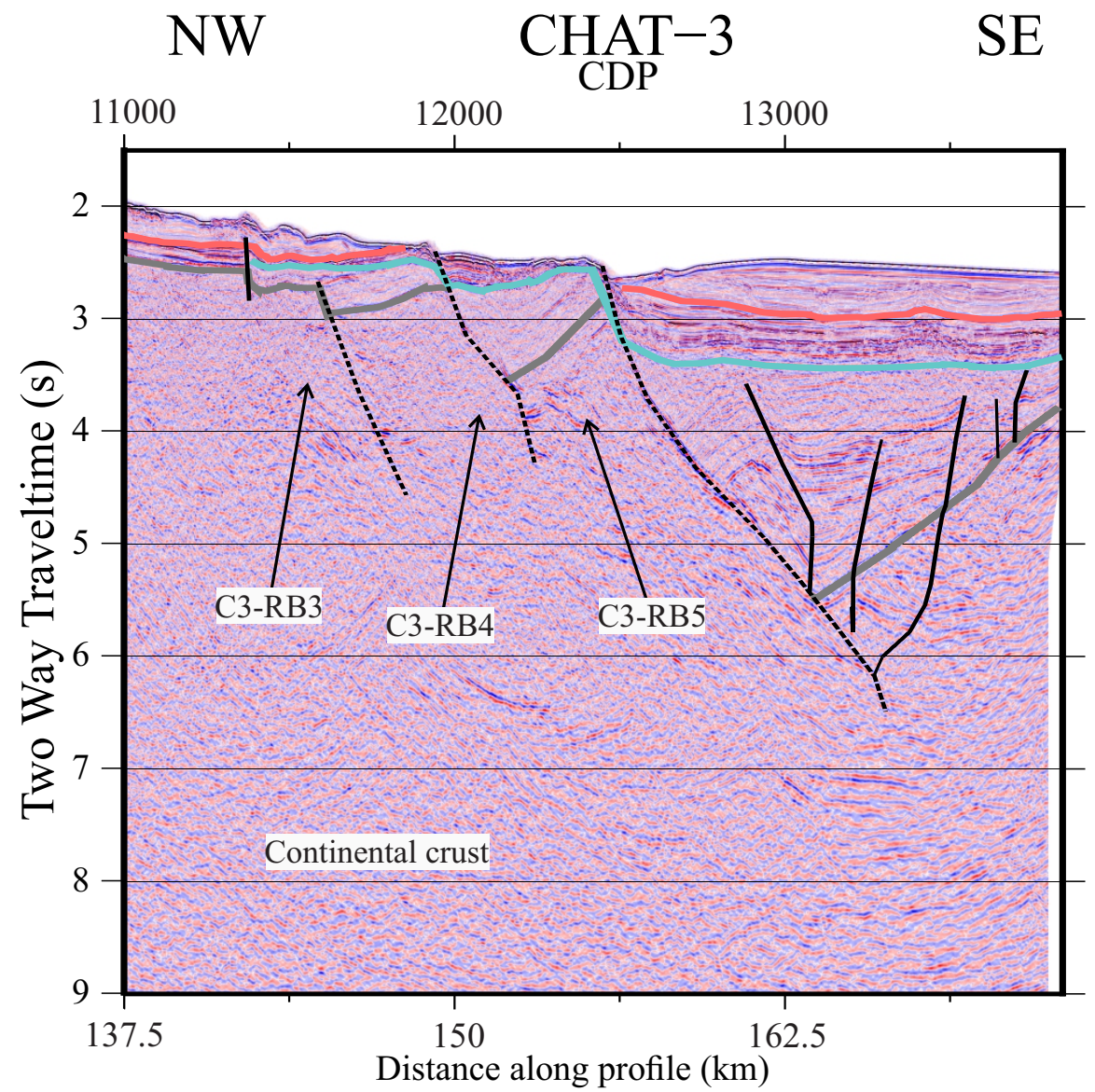

Figure 4.10: Portion of the time-migrated seismic profile CHAT-3 showing the series of rotated fault blocks on the south-eastern end of the profile. The lines are coloured as follows: orange $=$ base of CEN (Cenozoic sediments); turquoise $=$ base of SEQ Y (Late Cretaceous to Paleogene sediments); grey = base of MES (Mesozoic sediments) where it overlies continental crust; solid black = faults; dotted black = rotated block edge faults.

\subsection{AWI-20160006}

AWI-20160006 crosses from the Hikurangi Plateau (at the north-west) onto the Chatham Rise margin (Figure 4.1). The seafloor elevation reflects this transition, varying from $2.9 \mathrm{~km}$ to $1.7 \mathrm{~km}$ water depth across the profile (Figure 4.11).

On the north-western end of AWI-20160006, between CDPs 6500 and 4500, a 1.6 s TWTT thick sedimentary section is imaged (Figure 4.11). Within this section, a highly reflective, condensed sequence of sediments is observed (between 4.5 and 4.7 s TWTT at CDP 6500, and traceable to 3 s TWTT at CDP 3750). This sequence is interpreted to be the Late Cretaceous/Paleogene limestones of Sequence Y (SEQ 


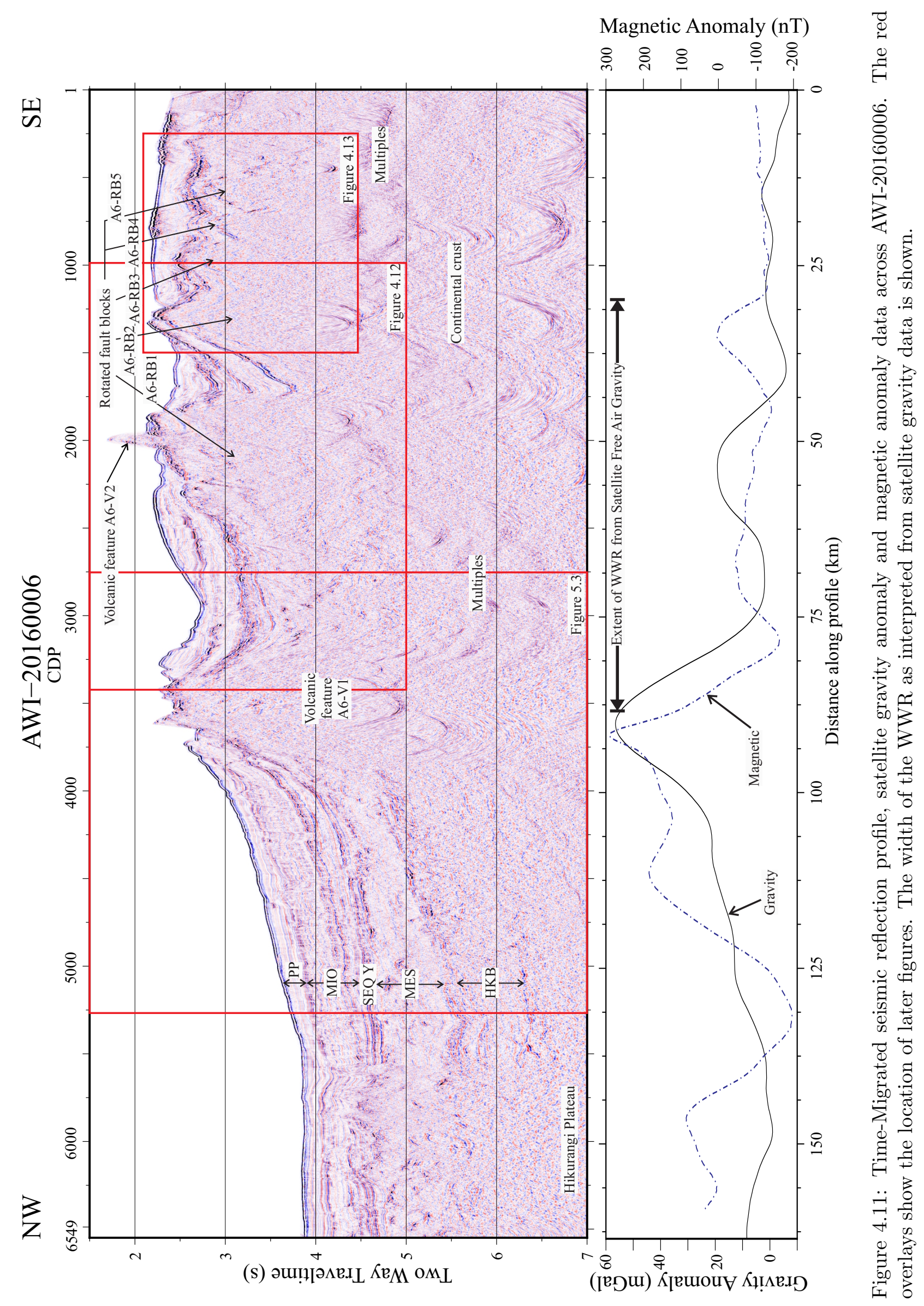


$\mathrm{Y}$ - Chapter 3.1.1). The region of high reflectivity imaged at 5.5 s TWTT at CDP 5500 (and shallowing to $4.8 \mathrm{~s}$ TWTT by CDP 4000, Figure 4.11) is interpreted to mark the interface between the Late Cretaceous/Paleocene (MES) sediments and the HKB layered volcaniclastic/limestone/chert sediments that overlie the basement of the Hikurangi Plateau (Chapter 3.1.4).

Between CDPs 4000 and 3750, the sedimentary units onlap onto the side of A6-V1 (Figure 4.11), a feature which is interpreted to be volcanic based on the variation in seafloor elevation between CDPs 3750 and 3350; the abrupt termination of the sedimentary horizons to the north-west upon meeting the edge of this feature; and the resulting conical shape. The location of A6-V1 coincides with paired positive gravity and magnetic anomalies (Figure 4.11). These will be examined and discussed at a later stage (Chapter 5.2).

The Late Cretaceous to Miocene sediments (MES, SEQ Y and the lower third of $\mathrm{MIO} / \mathrm{OLIG}$ ) which lie north-west of volcanic feature A6-V1 thin with proximity to A6-V1 (Figure 4.11). The slopes of A6-V1 dip at $\sim 25^{\circ}$ from horizontal (assuming an average sediment velocity of $3 \mathrm{~km} / \mathrm{s}$ ). Consequently, sediment that settles on the elevated volcanic slope will be prone to erosion by seafloor currents. This accounts for the observed thinning of the sedimentary units as they onlap onto the edge of A6-V1.

South-east of the volcanic structure A6-V1, a series of rotated fault blocks and half-grabens are imaged (Figure 4.11). The two largest rotated fault blocks A6-RB1 at CDP 2000, and A6-RB2 at CDP 1400, are $25 \mathrm{~km}$ and $12.5 \mathrm{~km}$ wide respectively (Figure 4.12). Basement outcrops at the south-eastern end of both these rotated blocks. The near-planar nature of the top of the crustal basement on the north-west edge of rotated block A6-RB2 is indicative of erosion prior to rotation (Figure 4.12).

The sediment which overlies rotated block A6-RB1 has been incised by a channel 


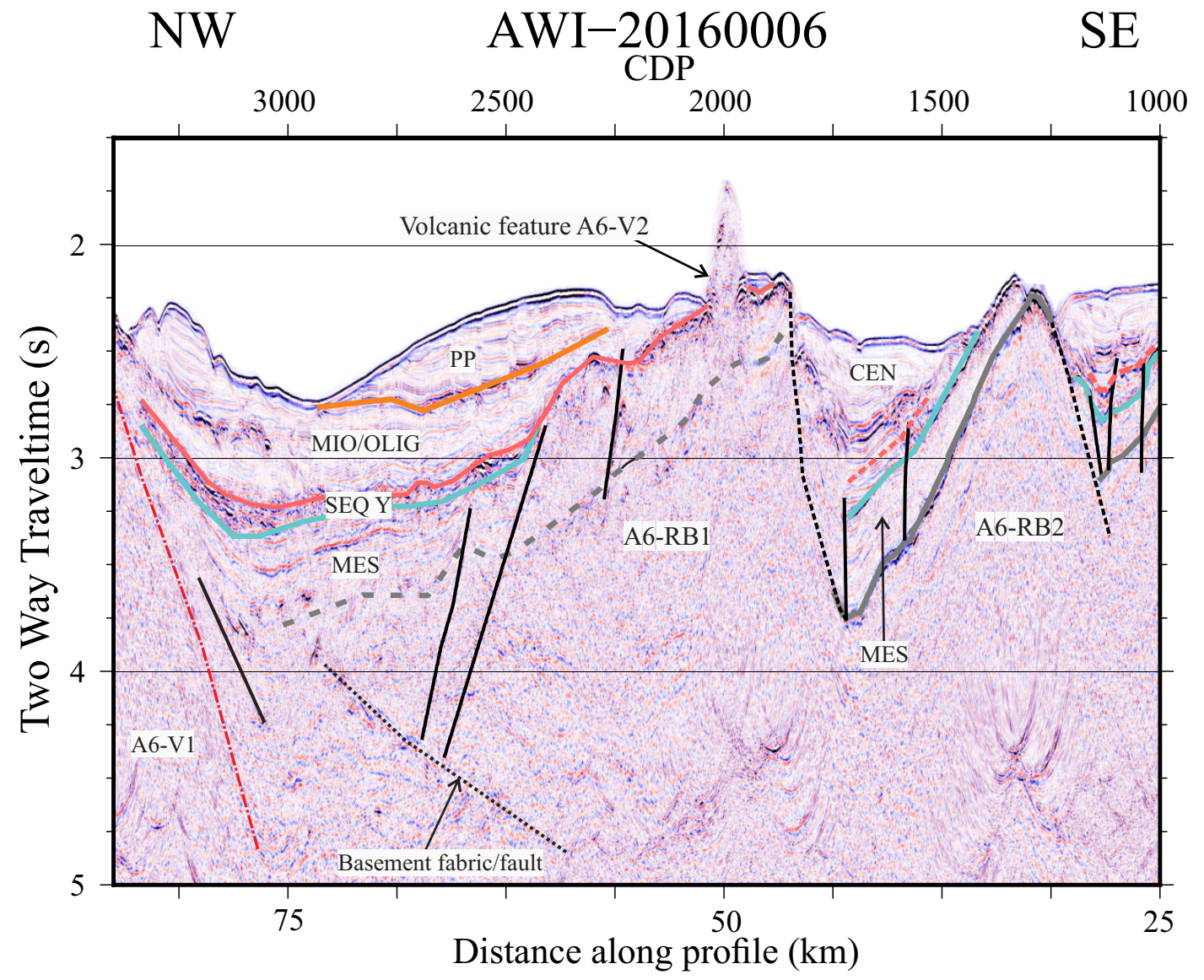

Figure 4.12: Portion of the time-migrated seismic profile AWI-20160006 showing showing rotated block faults A6-RB1 and A6-RB2. The lines are coloured as follows: orange $=$ base of PP (Plio-Pleistecene sediments); pink = base of MIO (Miocene sediments); turquoise = base of SEQ Y (Late Cretaceous to Paleogene sediments); grey = base of MES (Mesozoic sediments) where it overlies continental crust; dashed/dotted grey $=$ either base of MES or a basement reflector; solid black = faults; dotted black = rotated block edge faults; dashed red = edge of volcanic feature A6-V1. Rotated fault blocks A6-RB1 and A6-RB2 are indicated.

centred on CDP 3000 (Figure 4.12). At CDP 2000, an anomalous feature (A6-V2) is observed extending upwards from the basement and through the sedimentary cover. A6-V2 bears a strong resemblance to features observed further west on seismic reflection profile HKDC-1 (Figure 1.1), and interpreted as volcanic by Davy et al. (2008); although A6-V2 does not have a strong positive magnetic anomaly peak associated with it as might be expected for such a shallow volcanic feature (Figure 4.11).

The deeper sedimentary units of the half-graben that is south-east of rotated block 
A6-RB1 thicken towards the north-west (Figure 4.12). Based on its stratigraphic position within the sedimentary section, this unit is interpreted to be MES (Late Cretaceous to Paleogene - Chapter 3.1.1). The thickening of MES towards the fault on the south-east edge of rotated block A6-RB1 indicates that MES sediment deposition was synchronous with the rotation of block A6-RB1. Three smaller rotated fault blocks (A6-RB3, A6-RB4 and A6-RB5) are imaged south east of A6-RB2 (Figure 4.13). The overlying sedimentary units are draped over the top of these fault blocks, with no basement exposure. The planar nature of the seafloor above these rotated blocks indicates erosion by current activity or subareal exposure. Based on the interpreted age of the eroded sediments, this uplift and erosion occurred during the Miocene or more recently, and is post-dated by superficial volcanism which is observed on the seafloor at CDPs 250 and 750. An example of what this volcanism looks like at the seafloor in acoustic backscatter and multi-beam images is shown in Figure 4.14. On seismic reflection sections, such surface volcanism tends to be high in amplitude, attenuating seismic energy and reducing the amplitude of deeper reflectors. This is observed to be the case on this profile (Figure 4.11). Additional regions of possible volcanism are interpreted at a depth of $4.7 \mathrm{~s}$ TWTT between CDPs 6200 and 5500, and at $2.6 \mathrm{~s}$ TWTT between CDPs 750 and 400, based on the disturbance to reflective horizons and the attenuation of deeper horizons. 


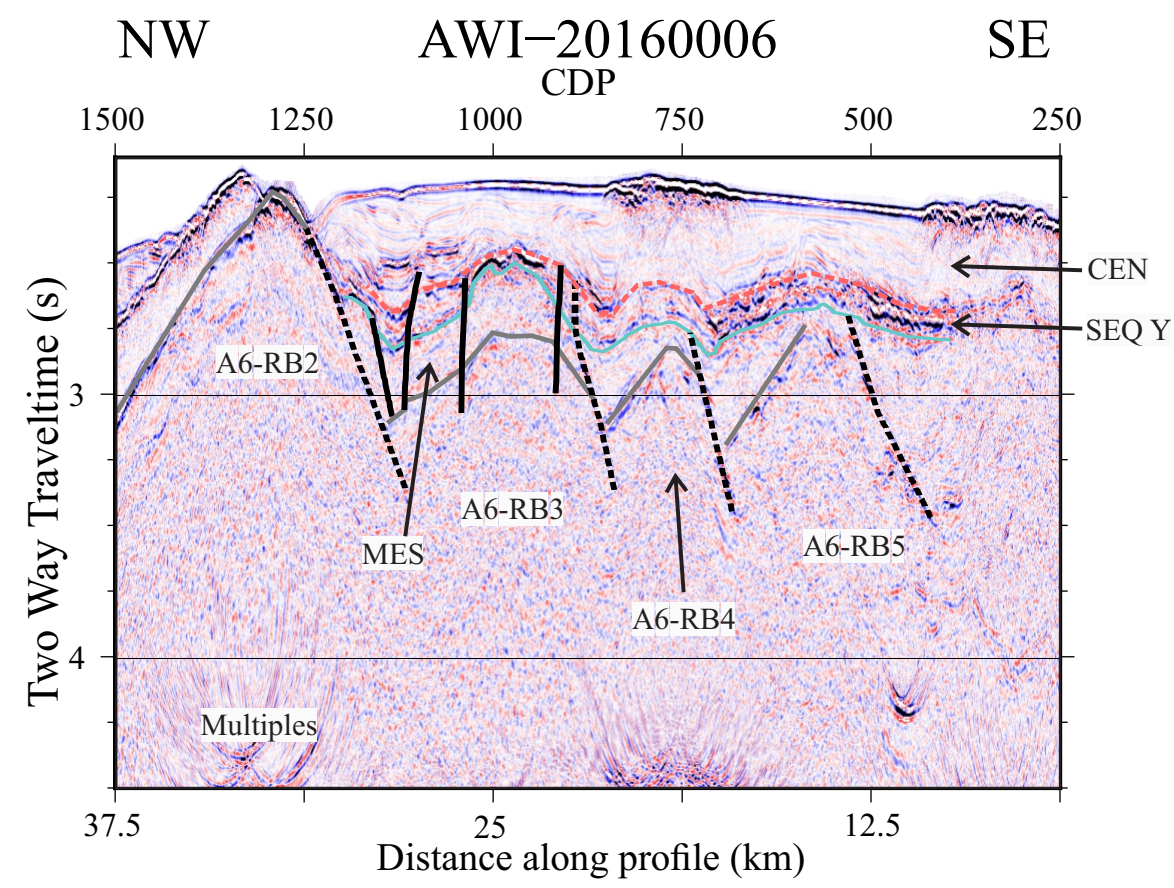

Figure 4.13: Portion of the time-migrated seismic profile AWI-20160006 showing the half-grabens on the south-east of this profile. The lines are coloured as follows: pink = base of CEN (Cenozoic sediments); turquoise = base of SEQ Y (Late Cretaceous to Paleogene sediments); grey = base of MES (Mesozoic sediments) where it overlies continental crust; solid black = faults; dotted black = rotated block edge faults. Rotated fault blocks A6-RB2, A6-RB3, A6-RB4 and A4-RB5 are indicated.
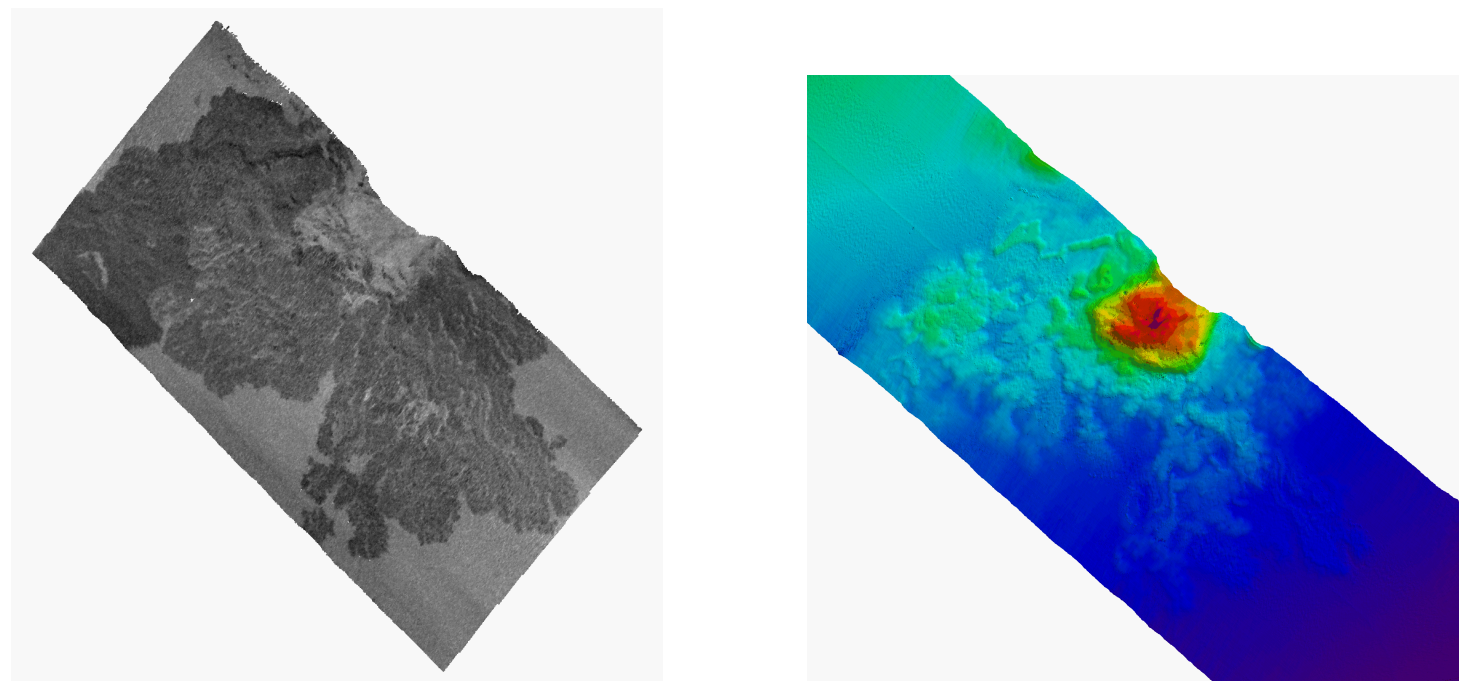

Figure 4.14: Acoustic backscatter (left) and multi-beam (right) images showing an example of a surface lava flow imaged on profile AWI-20160006 at CDP 750. 


\subsection{AWI-20160004}

AWI-20160004 is the southern-most of the profiles studied in this thesis, and lies predominantly over the Chatham Rise (Figure 4.1). Water depth over this profile varies between 1.3 and $2 \mathrm{~km}$, with a bathymetric high corresponding to the crest of the Chatham Rise margin (Figure 4.15).

Between CDPs 1 and 900, the sedimentary cover thins towards the south-east, onto the crest of the Chatham Rise (from $\sim 1$ s TWTT thick at CDP 250 to $<0.3$ s TWTT thick at CDP 900 - Figure 4.15). The sediments at the base of the sedimentary section are faulted, folded, and slumped - in short, heavily deformed (Figure 4.16). Within the sedimentary cover, a 0.1-0.2 s TWTT thick band of highly reflective horizons extends from $3.1 \mathrm{~s}$ TWTT at CDP 1 to $2.4 \mathrm{~s}$ TWTT at CDP 600, and is interpreted to be Sequence Y (early Oligocene to Late Cretaceous - Chapter 3.1.1) based on its stratigraphic position within the sedimentary section and strong reflective character.

Beneath these deformed, south-eastward-thinning sediments, a shallowly dipping region of high reflectivity extends from $3.25 \mathrm{~s}$ TWTT at CDP 200, to $4.6 \mathrm{~s}$ TWTT at CDP 800 (Figure 4.16). Based on the previous interpretation of Cretaceous subduction along the northern margin of the Chatham Rise (Wood and Davy, 1994), this reflective region is interpreted to represent paleo-subduction of the Hikurangi Plateau beneath the Chatham Rise on this profile. This interpretation is supported by a region of high reflectivity which underlies the shallowly-dipping reflection and extends vertically for $\sim 0.5 \mathrm{~s}$ TWTT, resembling HKB sediments which overlie the Hikurangi Plateau elsewhere along the margin (Figure 4.16) (Davy et al., 2008). However, an alternate explanation for this region of high reflectivity is that it is related to a volcanic feature. The single-channel data across this feature (Figure 2.5) reveals a dome-shaped structure extending to the north-west from CDP 250 (which corresponds with Shot $\sim 200$ ), and a maximum height at the approximate 


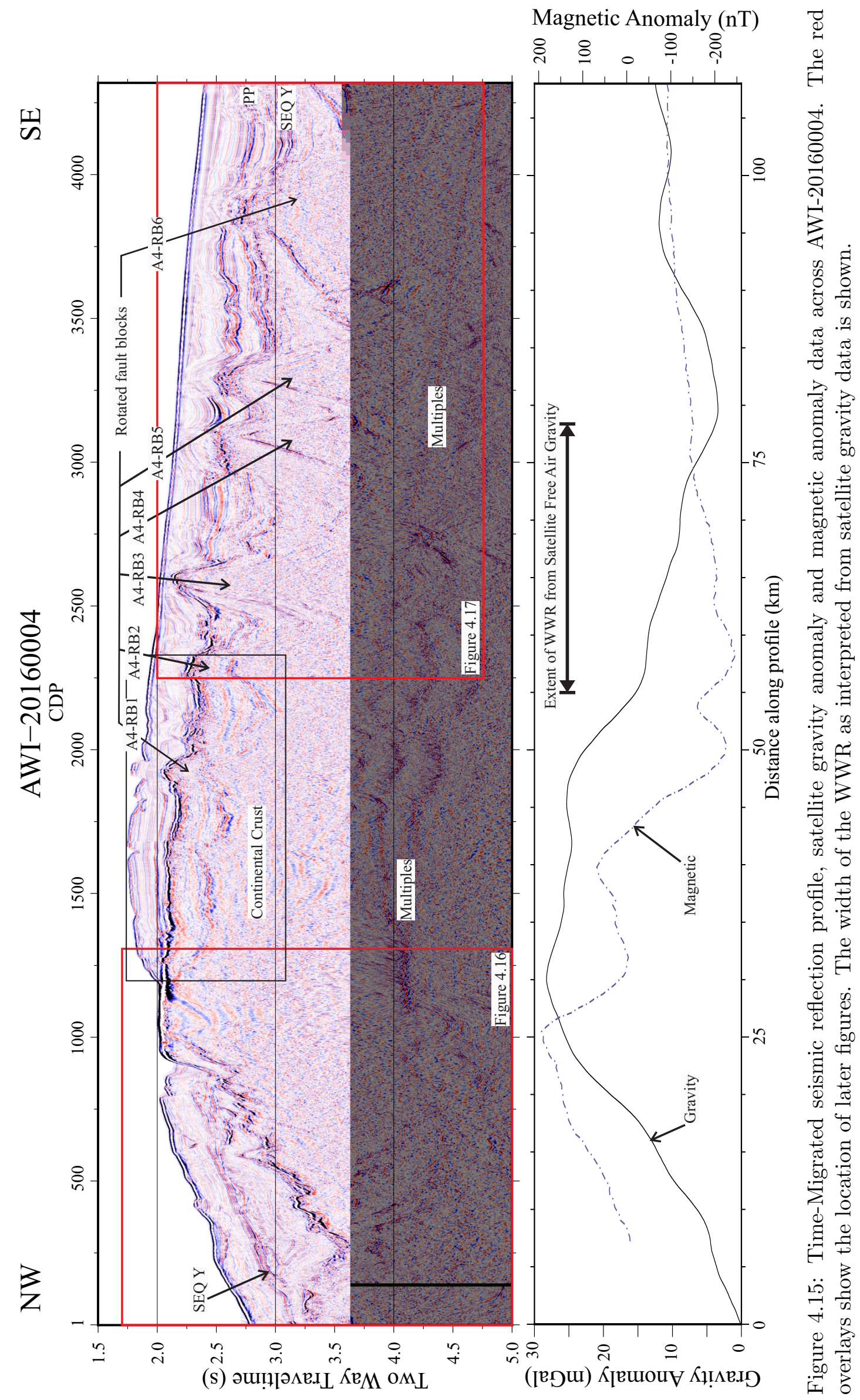




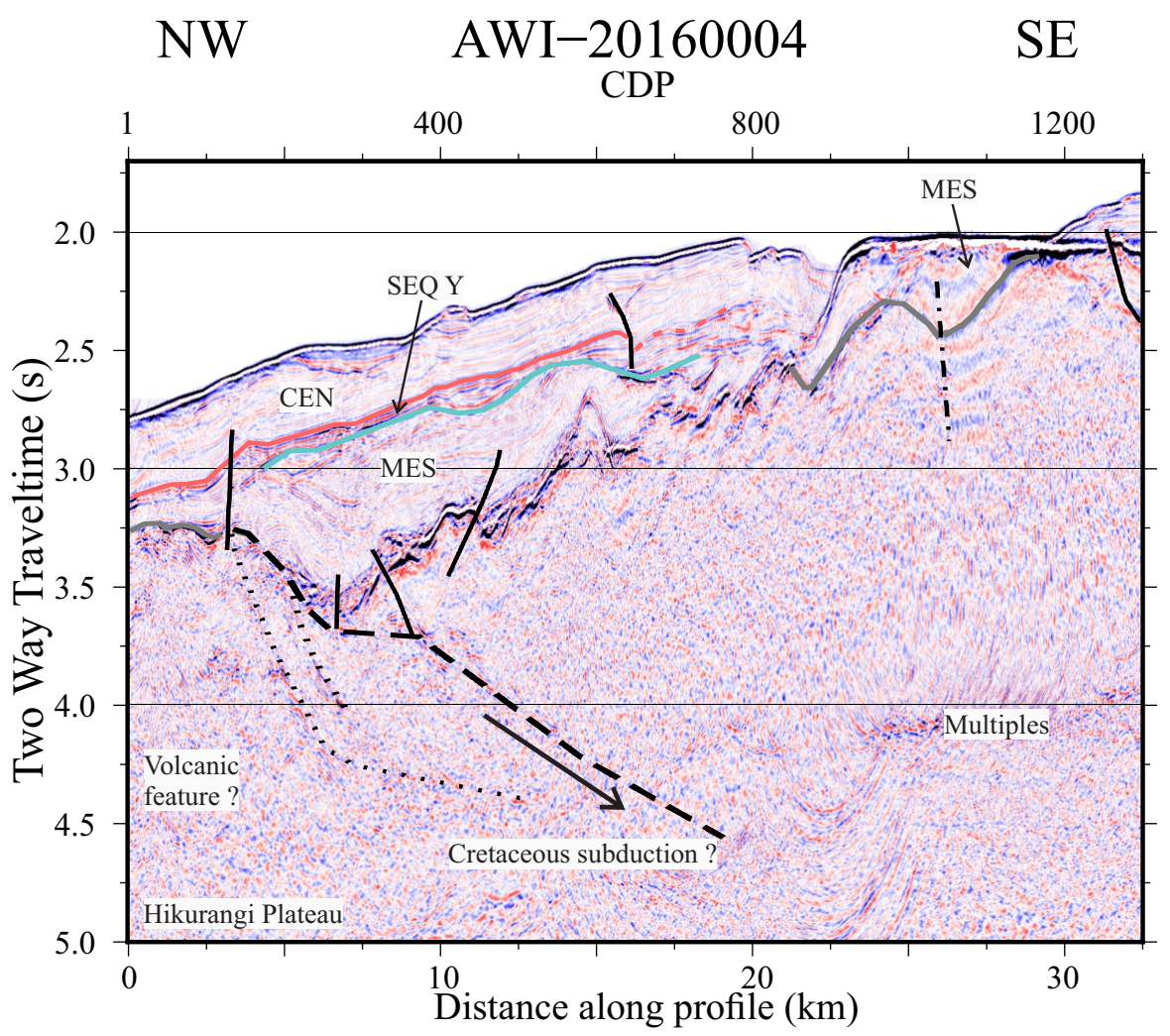

Figure 4.16: Portion of the time-migrated seismic profile AWI-20160004 highlighting the subduction margin and the strong seafloor reflector centred on CDP 1000. The lines are coloured as follows: pink = base of CEN (Cenozoic sediments); turquoise = base of SEQ Y (Late Cretaceous to Paleogene sediments); grey = base of MES (Mesozoic sediments); solid black $=$ faults; dotted black $=$ basement fabric; dashed black $=$ top of subduction margin.

location of CDP 1 (which corresponds with Shot 95) (Figure 4.16). This feature appears similar in shape to volcanic feature A6-V1, but is overlain by sediment. However, this part of the profile was cut during processing as the streamer geometry was not linear (Chapter 2.2), and magnetic data, which could help to determine the composition of this feature, are also unavailable. Consequently, the nature of this feature, and its relation to the subduction margin is uncertain.

South-east of the interpreted subduction margin and the overlying deformed material, a strong, planar reflection is exposed at the seafloor between CDPs 900 and 1200 (Figure 4.16). Its sharp, planar nature is consistent with uplift to sea level and subsequent erosion. The basement beneath this seafloor reflection is deformed in a manner that is indicative of either (a) faulting (as indicated by 
the black dashed/dotted line on Figure 4.16), (b) folding, or (c) current incision. There is not enough information to suggest which of these scenarios is most likely. Tracing this reflector further to the north-west indicates that it lies within unit MES (Figure 4.16), constraining the timing of the erosion to be more recent than Cretaceous.

Between CDPs 1200 and 4319, layered sediments overlie the continental crust of the Chatham Rise (Figure 4.15). Between CDPs 1200 and 2300, it is difficult to determine whether the horizons observed below the strong reflection (a continuation of that exposed at the seafloor between CDPs 900 and 1200) are primary reflections or peg-leg multiples. Consequently, these are left uninterpreted in this study. The sediments overlying this strong reflection, however, are slumped and folded. A series of six rotated fault blocks and corresponding half-grabens are identified between CDPs 1800 and the south-eastern end of the profile (Figure 4.15). The tops of rotated blocks A4-RB2 and A4-RB3 have been planed off and tilted (Figure 4.17). This suggests uplift to sea level and erosion prior to deposition of overlying sediment and rotation of the blocks. The period of uplift and erosion can be constrained to Mesozoic or older based on the interpreted age of the overlying sedimentary section. For the three southernmost identified half-grabens (south-east of each of A4-RB4, A4-RB5, and A4-RB6), the MES sedimentary unit (interpreted as such based on its stratigraphic position below the highly reflective SEQ Y) thickens towards the north-west (Figure 4.17). This indicates that MES sediment deposition was synchronous with the rotation of the fault blocks, as for the rotated fault blocks on AWI-20160006 (Section 4.3).

The seafloor between CDPs 2200 and the south-eastern end of the profile dips shallowly at $\sim 0.7^{\circ}$ towards the south-east (Figure 4.15 ). It has been planed off, suggesting either uplift to sea level and subsequent erosion prior to tilting, or erosion by current motion along the crest of the Chatham Rise. This erosion is constrained by the eroded sediments to have occurred within the Plio-Pleistocene. 


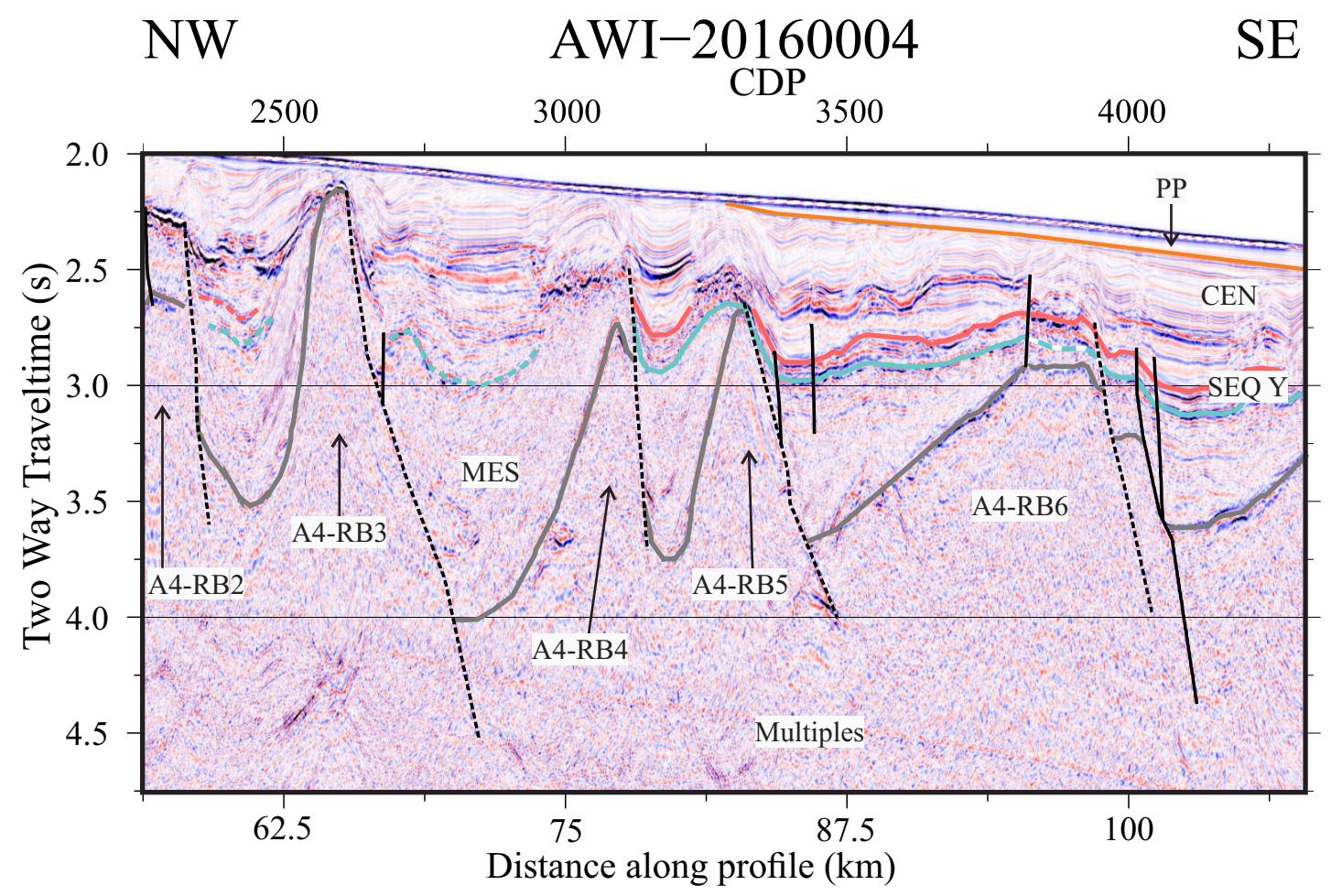

Figure 4.17: Portion of the time-migrated seismic profile AWI-20160004 showing a series of half-grabens and rotated fault blocks (A4-RB2, A4-RB3, A4-RB4, A4-RB5 and A4-RB6). The lines are coloured as follows: orange = base of PP (Plio-Pleistecene sediments); pink = base of MIO (Miocene sediments); turquoise = base of SEQ Y (Late Cretaceous to Paleogene sediments); grey = base of MES (Mesozoic sediments); black $=$ faults.

\subsection{The West Wishbone Ridge}

\section{On CHAT-4}

Examination of the Satellite Free Air Gravity data (Figure 4.1) reveals that the gravity low associated with the WWR extends between CDPs 500 and 8500 on CHAT-4 (approximately $100 \mathrm{~km}$, Figure 4.2). Consequently, the shear zone at the base of the crust between CDPs 5500 and 7000 is interpreted to mark the eastern boundary of the WWR (Figure 4.3). This shear zone dips at approximately $30^{\circ}$ when converted to depth assuming a crustal velocity of $6 \mathrm{~km} / \mathrm{s}$. However, if this shear zone is related to the WWR, then this is only an apparent dip because the profile is not orientated perpendicular to the strike of the WWR (Figure 4.1). For 
true dip to be observed, this profile would need to be rotated clockwise by $\sim 45^{\circ}$. Dobrin (1976) defines the following equation for converting apparent dip $(\alpha)$ to true $\operatorname{dip}(\phi)$ :

$$
\sin \alpha=\cos \theta \sin \phi
$$

where $\theta$ is the angle by which CHAT- 4 would need to be rotated so as to be perpendicular to the strike of the WWR. For $\alpha=30^{\circ}$ and $\theta=45^{\circ}$, the true dip of the shear zone, $\phi \approx 45^{\circ}$.

It is difficult to trace this shear zone with confidence above $10 \mathrm{~s}$ TWTT depth; however, significant deformation is observed in the upper crust (between 10 and 7 s TWTT) between CDPs 6500 and 7200 (Figure 4.3), suggesting that deformation associated with this margin may persist through the upper crust. This is bolstered by $\sim 1 \mathrm{~s}$ TWTT step in the elevation of the top of the crustal basement and a variation in the sedimentary thickness, as well as a change in the nature of the crust from east to west across this boundary (Figure 4.3, Section 4.1). Together, these features are indicative of transform faulting.

The two regions of compressional faulting centred on CDPs 4500 and 5400 (Figure 4.4) are within the WWR region of deformation, and thus are interpreted to be related to deformation along the WWR. The thrust fault observed on the western side of the profile (between CDPs 500 and 2500 - Figure 4.5) corresponds with the western edge of deformation associated with the WWR.

\section{On CHAT-3}

Tracing the WWR southwards on the Satellite Free Air Gravity data (Figure 4.1) indicates that south of $42^{\circ} \mathrm{S}$, the West Wishbone Ridge complex consists of three gravity highs, each separated by a gravity low. On CHAT-3, these gravity anomaly 
features extend between CDPs 3500 and 10000 (approximately $80 \mathrm{~km}$ ) (Figures 4.6, 4.8, 4.9), and include the rotated block C3-RB1, the half-graben south-east of C3-RB1, rotated block C3-RB2, the half-graben south-east of C3-RB2, the thrust fault at CDP 9600, and the region of uplifted crust between CDPs 9600 and 10500. Unlike on CHAT-4, where the WWR is associated with compressional faulting zones, on CHAT-3 the WWR is associated with extensional faulting.

\section{On AWI-20160006}

The gravity signature associated with the West Wishbone Ridge region of deformation on CHAT-3 (Figure 4.6) can be traced southwards on the Satellite Free-Air Gravity map (Figure 4.1) through AWI-20160006. On AWI-20160006, this corresponds to the region between CDPs 3500 and 1250, and includes volcanic feature A6-V1, rotated fault blocks A6-RB1 and A6-RB2, the half-grabens formed by the rotation of blocks A6-RB1 and A6-RB2, the sedimentary basin which overlies A6RB1, and volcanic feature A6-V2 (Figure 4.11) - a region approximately $55 \mathrm{~km}$ wide. Several steeply-dipping faults extend from the basement into the overlying sedimentary basins; however, these do not stem off a single central fault to resemble a flower structure as on CHAT-3 (Figure 4.9). It is unclear whether or not feature A6-V2 is related to deformation along the West Wishbone Ridge.

\section{On AWI-20160004}

The gravity high that corresponds with rotated block C3-RB2 on CHAT-3 (Figure 4.6) and A6-RB1 on AWI-20160006 (Figure 4.11) can be extended through rotated block A4-RB3 on AWI-20160004 using the Satellite Free Air Gravity data (Figure 4.1). Likewise, the two gravity lows that flank the gravity high on AWI-20160006 and CHAT-3 can be continued in map-view through AWI-20160004 (Figure 4.1), 
where they correspond with half-grabens, as on AWI-20160006 and CHAT-3. The region of deformation associated with the West Wishbone Ridge on AWI-20160004 is approximately $25 \mathrm{~km}$ wide (Figure 4.21 ). The gravity anomaly is dominated by a strong gravity high between 25 and $50 \mathrm{~km}$ along the profile (Figure 4.15). This high is probably a result of the shallow, uplifted crust in this region.

\subsection{Summary}

In this chapter, multi-channel seismic reflection data across four profiles that cross the WWR (CHAT-4, CHAT-3, AWI-20160006 and AWI-20160004 - Figure 1.1) were analysed and interpreted. The final migrated profiles, with interpretations discussed in this Chapter overlain, are shown in Figures 4.18, 4.19, 4.20, and 4.21. 


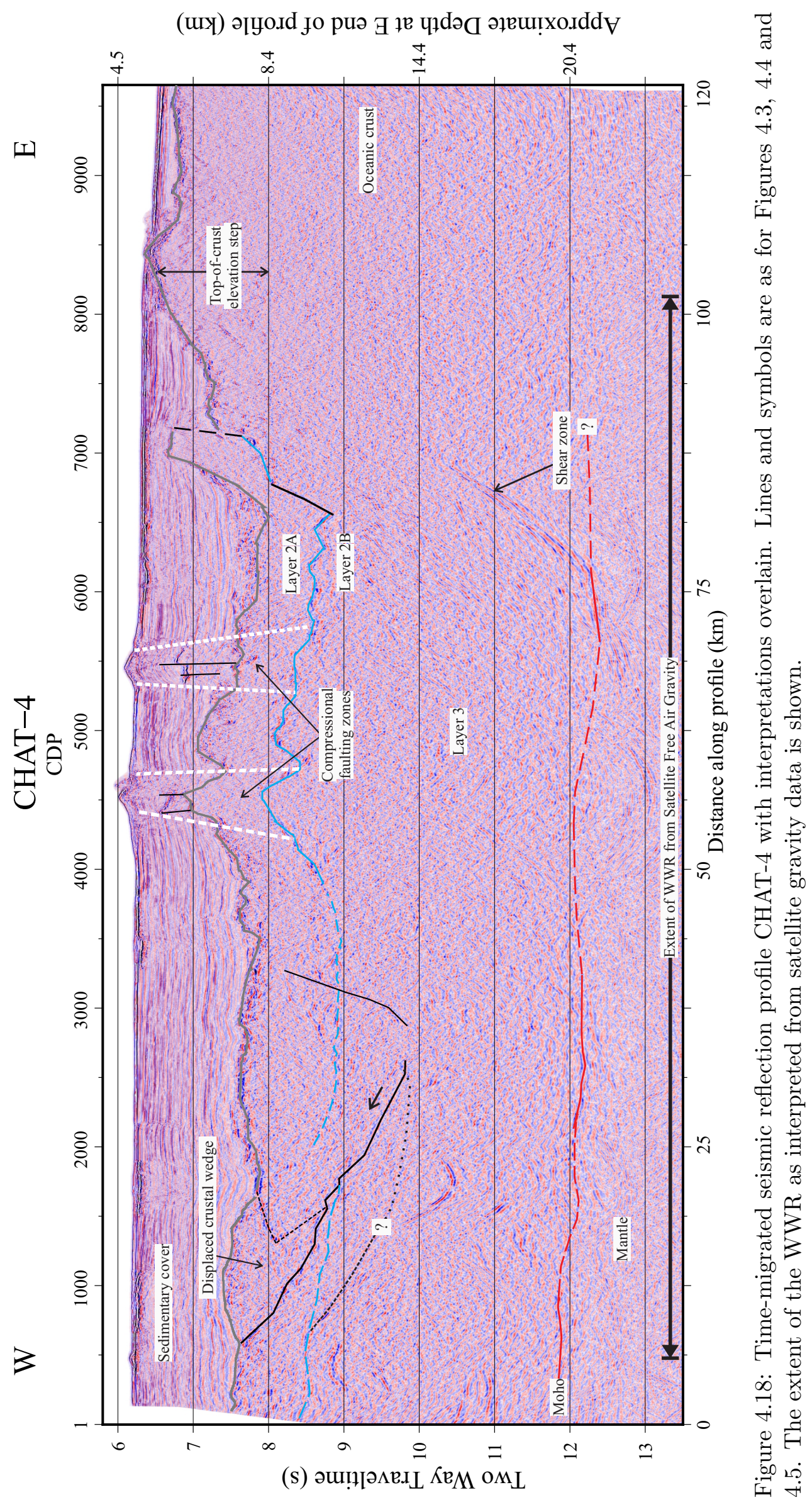




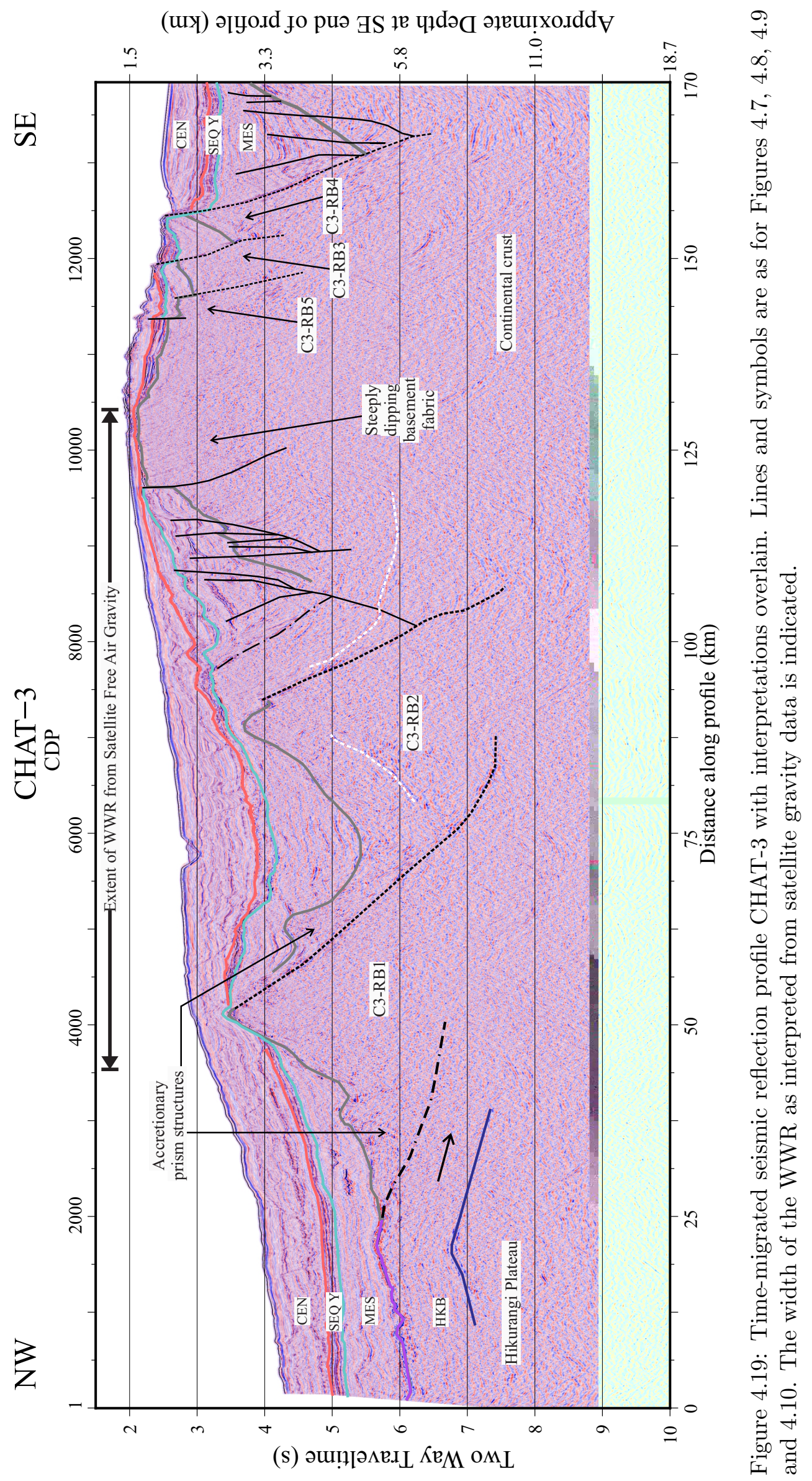




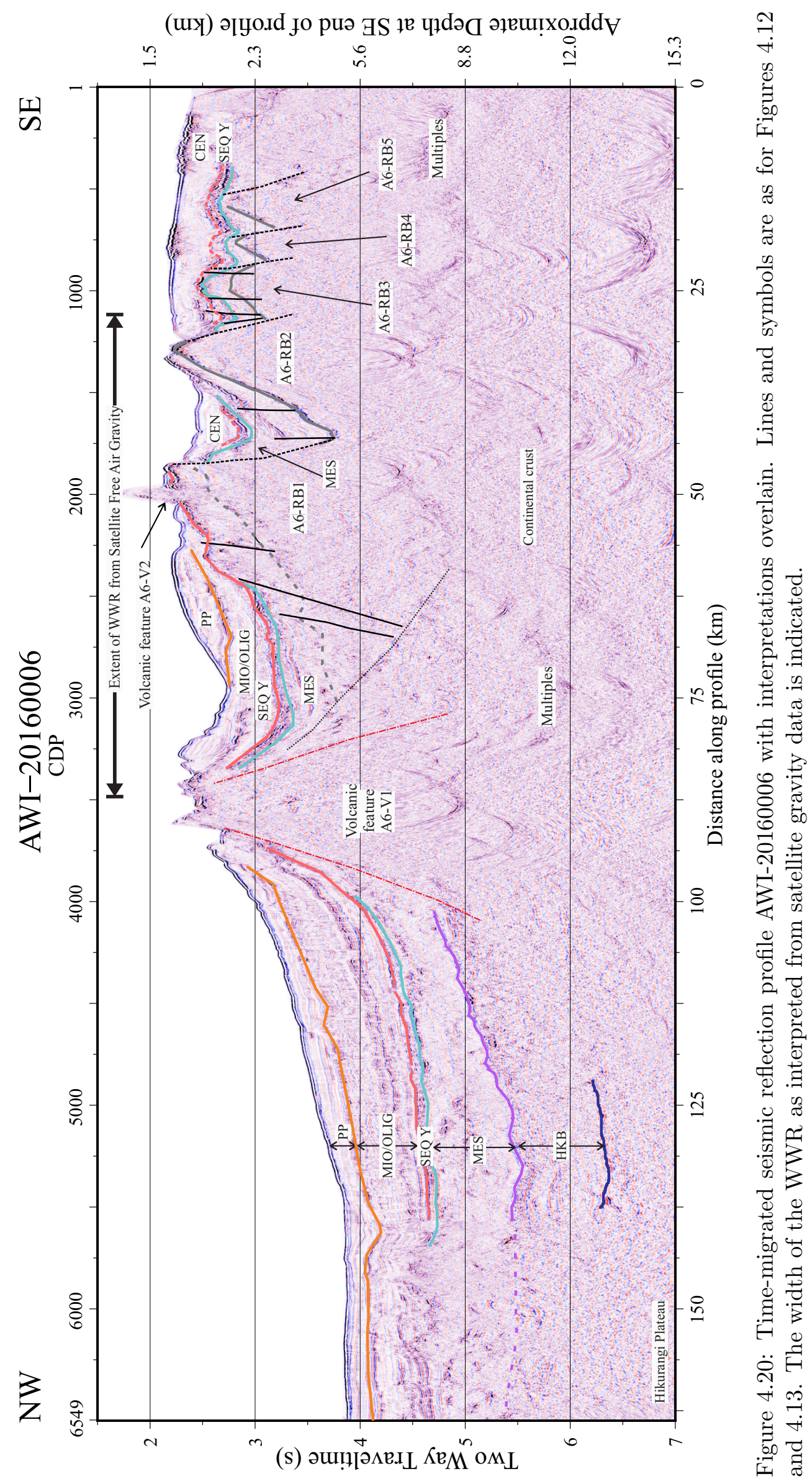




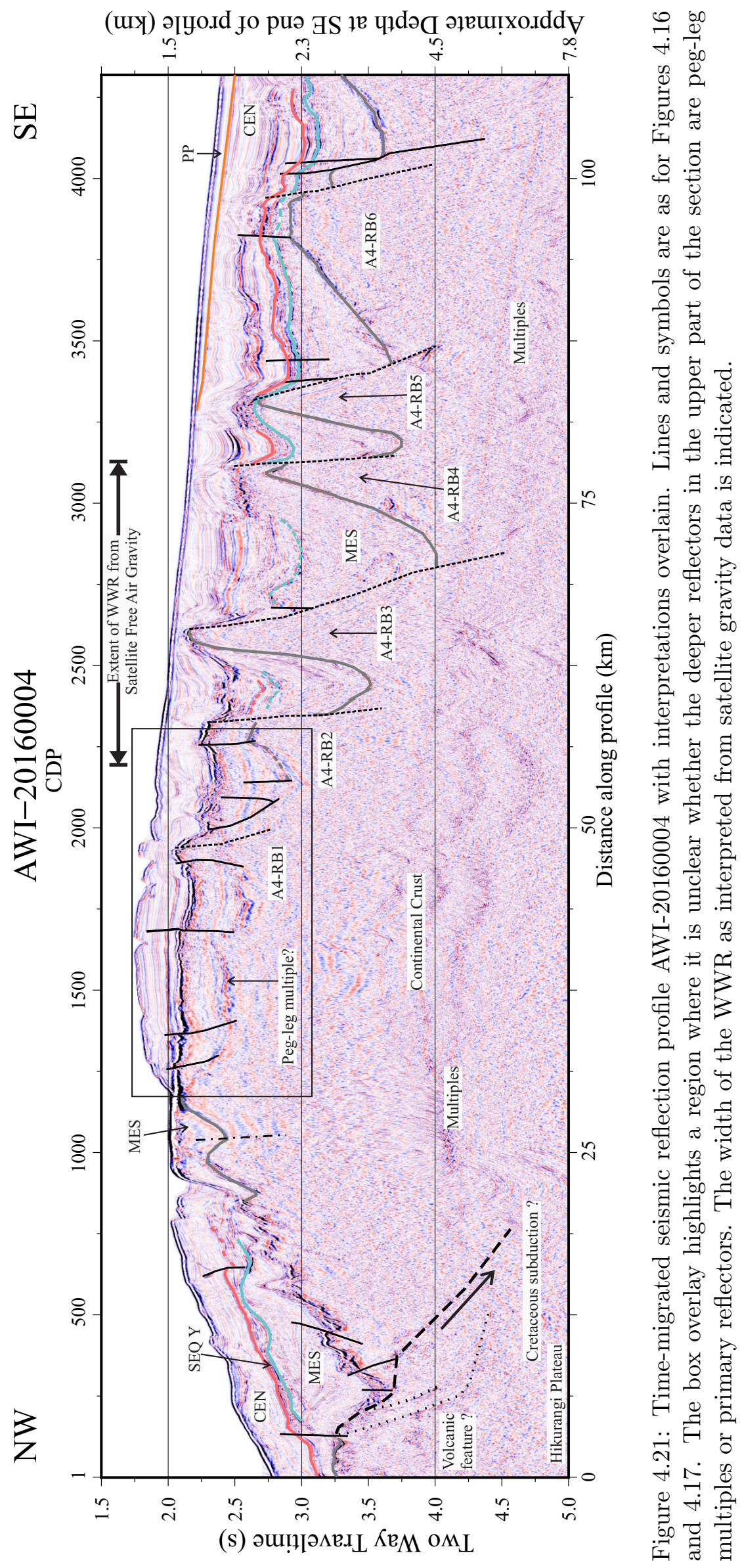




\section{Chapter 5}

\section{Discussion}

The primary motivation of this thesis is to learn about the nature of the West Wishbone Ridge (WWR), particularly at its southern end where it intersects the Chatham Rise. Analysis of seismic reflection data across profiles that cross the WWR (Chapter 4 - Results and Analysis) reveals variation in the character of the WWR along strike. These observations, together with pertinent results from previous studies and features discussed in this chapter, are summarised in Figure 5.1.

Analysis of the gravity and magnetic data across the profiles can also help to reveal more about the nature of the sub-surface. The wavelength of gravity and magnetic anomalies is a function of both the composition and the depth of an anomalous body: features located in the mantle or near the Moho are associated with long-wavelength anomalies, while variations in the upper crust result in shortwavelength anomalies (Reynolds, 1997).

This chapter is split into four sections:

1. 2-D Gravity modelling, and a discussion on the Moho and the nature of the crust on CHAT-4.

2. 2-D Gravity modelling, and a discussion on the three profiles which cross 


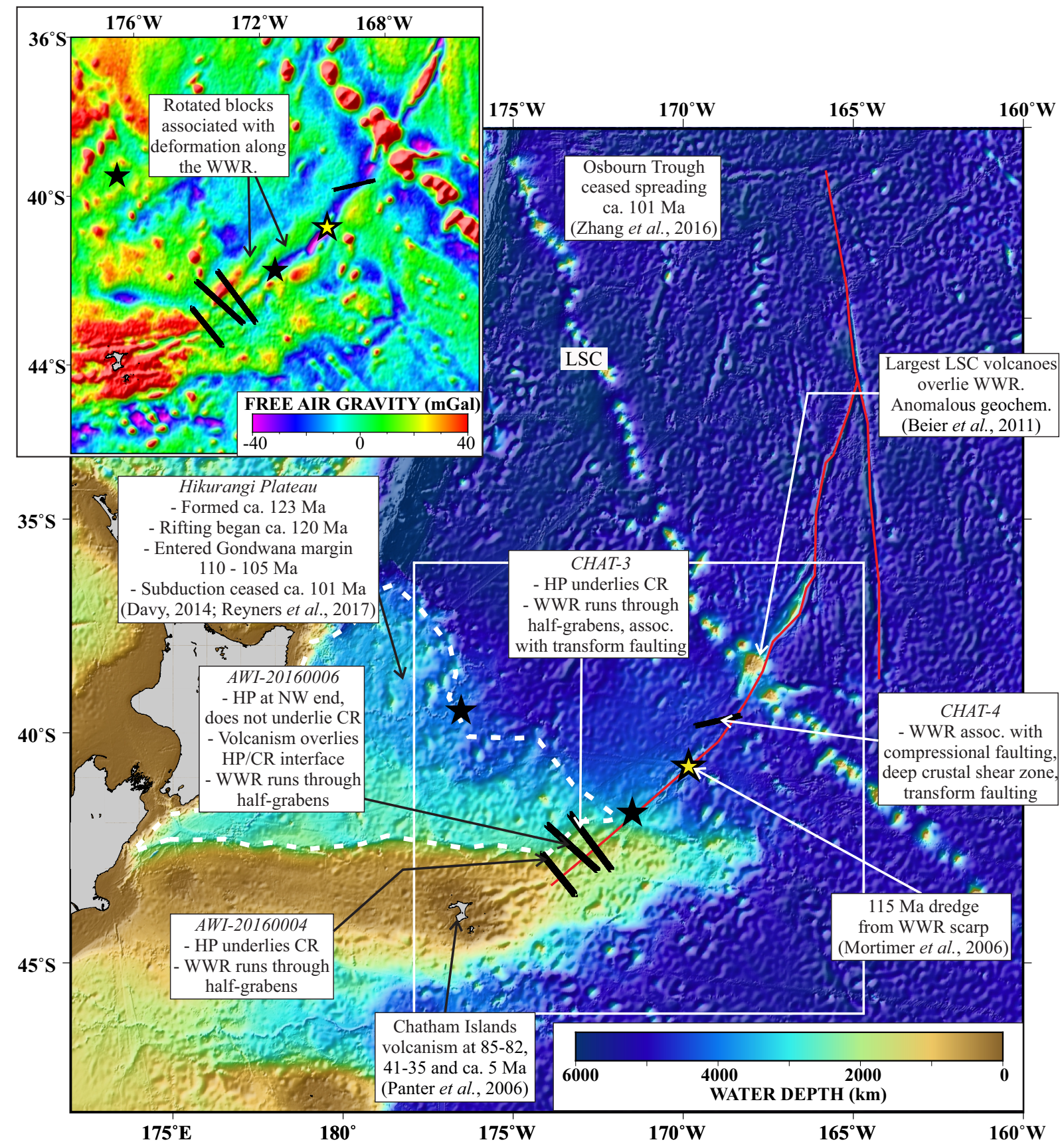

Figure 5.1: Bathymetric map of the broader Chatham Rise region with annotations highlighting key results from previous work as well as the characteristics of the four profiles studied here. Inset = Satellite Free Air Gravity (outlined in white box on the bathymetry map - Sandwell et al., 2014). The Wishbone Ridge is highlighted in red. Dotted white line outlines the surface exposure of the Hikurangi Plateau (HP). LSC $=$ Louisville Seamount Chain. $\mathrm{CR}=$ Chatham Rise. Black lines $=$ profiles of interest in this study. Black stars = ODP drill sites used to constrain the age of seismic horizons in this study. Bathymetry data are from GEBCO (2014). 
the WWR south of its intersection with the Chatham Rise (CHAT-3, AWI20160006 and AWI-20160004 - Figure 5.1). The nature of the interface between the Hikurangi Plateau and the continental crust of the Chatham Rise along these profiles is also discussed.

3. A discussion on the nature of the WWR as a transform fault.

4. A summary of the findings discussed in this chapter, and some conclusions from those.

\subsection{Moho and Oceanic crust on CHAT-4}

The Moho is interpreted at two locations in the seismic reflection data across CHAT-4 (Figure 4.18): the first is a region of high reflectivity that extends between 11.9 and $12.1 \mathrm{~s}$ TWTT, over CDPs 500 to 3000; and the second is at a depth of 12.3 s TWTT at CDP 5800, where the Moho is intersected by a lower crustal shear zone. This shear zone is interpreted to be associated with the West Wishbone Ridge, and transform motion along that feature (Chapter 4.5). Aside from these two regions where the Moho is identified, its depth is poorly constrained by the seismic reflection data.

Although gravity modelling can help to constrain the depth of the Moho along this profile, it is an inherently non-unique geophysical method involving a trade-off between density-distribution and depth (Fowler, 2005). Consequently, any a-priori knowledge about the sub-surface structure (from surface topography, wells and geophysical data such as seismic reflection) should be included in the modelling process. For gravity modelling across CHAT-4, seismic reflection horizons (the seafloor, the base of the sedimentary section, the interface between Layers $2 \mathrm{~A}$ and $\mathrm{B}$ on the western side of the profile, and the Moho reflectors) are converted to depths in kilometres using the velocities tabulated in Table 5.1. These horizons 
are imported as initial parameters and are not varied during the modelling process. As there is no constraint on the depth of the interface between Layers $2 \mathrm{~B}$ and 3 , these layers are modelled as a single layer. The densities of the layers modelled are based on the ranges suggested by Carlson and Herrick (1990) for Layers 2 and 3 (Table 5.1). Layer $2 \mathrm{~A}$ is modelled as having a density higher than average for $2 \mathrm{~A}$ to account for the absence of Layer $2 \mathrm{~B}$ in the model.

The principle of isostasy suggests that below a certain depth there is no density contrast between two adjacent columns, and that the weight of the columns above this compensation depth is equal (Angevine et al., 1990). The gravity models discussed in this chapter are isostatically balanced at a depth of $50 \mathrm{~km}$ (Appendix C). This standardisation of the modelled compensation depth allows for consistency across all of the gravity models included in this study.

In Section 4.1, an argument was made for the oceanic nature of the crust on the western side of CHAT-4 on the basis of its layered structure, reflectivity character, and the absence of extensional features which would be associated with continental crust thinned to a similar thickness. This crust being oceanic is in agreement with it having been formed at the Osbourn Trough (Billen and Stock, 2000). East of the West Wishbone Ridge, the layered structure associated with oceanic crust is not evident from the seismic reflection data (Figure 4.18), raising questions about the nature of this crust. However, gravity modelling across this profile (Figure 5.2) shows that the crust east of the WWR is likely oceanic. Layer $2 \mathrm{~A}$ is modelled as having a similar thickness across the length of the profile (Figure 5.2).

It should be noted that the gravity model across profile CHAT-4 is a 2-D model; consequently, an inherent assumption is that the geometry remains constant out of the plane of the model. The primary purpose of modelling the gravity anomaly along CHAT-4 is to constrain the nature of the crust on either side of the WWR. Variation in the nature of the WWR along strike is a source of uncertainty; however, because the length of the WWR is significantly longer than the length of the 
profile, and because the model incorporates seismic reflection data (Figure 4.18) and geologically reasonable densities based on previous studies (Table 5.1), a 2-D model is likely a good approximation for the actual density distribution.

Table 5.1: Velocities used to convert time horizons into depth horizons, and densities used for gravity modelling along CHAT-4. Bracketed velocity and density ranges are from Carlson and Herrick (1990).

\begin{tabular}{|l|l|l|}
\hline \multicolumn{2}{|c|}{ Geophysical characteristics of CHAT-4 layers } \\
\hline Layer & $\begin{array}{l}\text { Modelled Velocity } \\
\text { (Velocity range) } \\
(\mathrm{km} / \mathrm{s})\end{array}$ & $\begin{array}{l}\text { Modelled Density } \\
\text { (Density range) } \\
\left(\mathrm{kg} / \mathbf{m}^{3}\right)\end{array}$ \\
\hline \hline Water & 1.5 & 1000 \\
\hline Sediments & 2.4 & 2500 \\
\hline Layer 2A* & $4.6(<4.0->6.0)$ & $2650(2620-2690)$ \\
\hline Layer 3 & $6.7(6.5-7.0)$ & $2930(2920-2970)$ \\
\hline Mantle & 8.04 & 3300 \\
\hline
\end{tabular}

* Bracketed values are for net Layer 2 properties

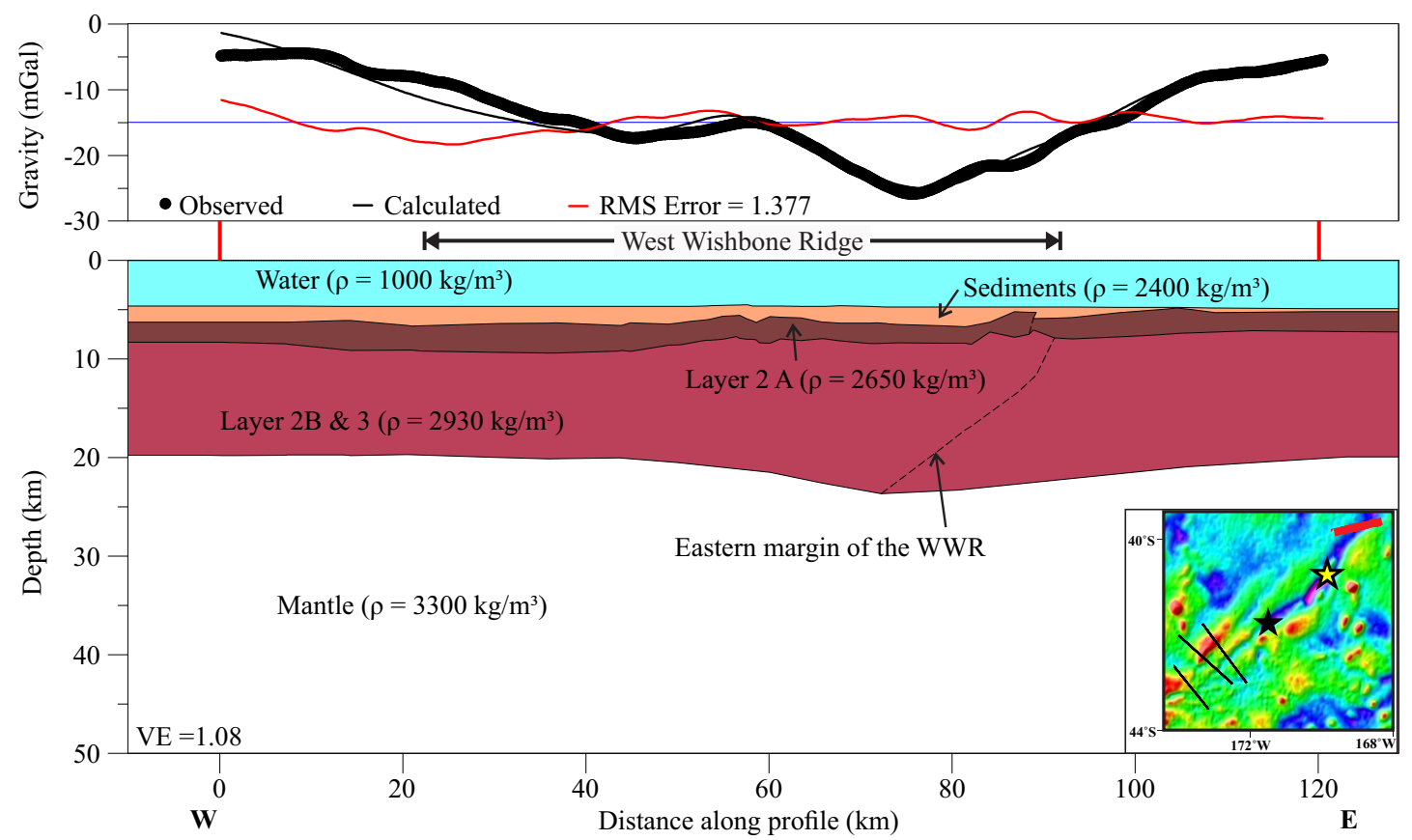

Figure 5.2: Gravity model across profile CHAT-4. This model is isostatically balanced at a depth of $50 \mathrm{~km}$ at the western and eastern ends of the profile (indicated by the red lines). VE = vertical exaggeration. Inset: Satellite Free Air gravity anomaly from Sandwell et al. (2014). Profile location is shown in red. 


\subsection{Hikurangi Plateau and the Chatham Rise}

The layered volcaniclastic/limestone/chert sediments (HKB) that overlie the crust of the Hikurangi Plateau (Chapter 3.1.4) are identified on the north-western end of seismic reflection profiles CHAT-3, AWI-20160006 and AWI-20160004 (Figures 4.19, 4.20 and 4.21). However, the base and the south-eastern boundary of the crust of this Large Igneous Province (LIP) are poorly resolved from these seismic profiles. On AWI-20160006, this interface is overlain by A6-V1, a volcanic feature which coincides with positive magnetic and gravity anomalies (Figure 5.3). Consequently, there are two features which could be the cause of the paired gravity and magnetic anomalies at this location: a steep interface between LIP and continental crust that would give rise to both gravity and magnetic edge-effect anomalies, or the volcanic feature A6-V1.

The magnetic anomaly has a half-width (half the width at half the maximum amplitude, $x_{1 / 2}$ ) of $3 \mathrm{~km}$ and is offset $5-10 \mathrm{~km}$ to the north from the gravity anomaly, which has $x_{1 / 2}=9 \mathrm{~km}$ (Figure 5.3). If the mass is assumed to be spherical, then the depth to the centre of that mass $\left(z_{c}\right)$ can be approximated by $z_{c}=1.305 x_{1 / 2}$, where $x_{1 / 2}$ is the half-width of the gravity anomaly (Reynolds, 1997). Thus, for $x_{1 / 2}=9 \mathrm{~km}, z_{c} \approx 11.7 \mathrm{~km}$.

To a rough first approximation, an intrusion can be modelled as a simple spherical body, and the edge-effect of a slab can be modelled as a vertical fault which juxtaposes unrelated crustal types adjacent to each other. While spherical bodies are realistically unlikely in geological settings, the anomaly produced by their modelling is similar to that produced by magnetic intrusions or salt domes (Nettleton, 1942). 


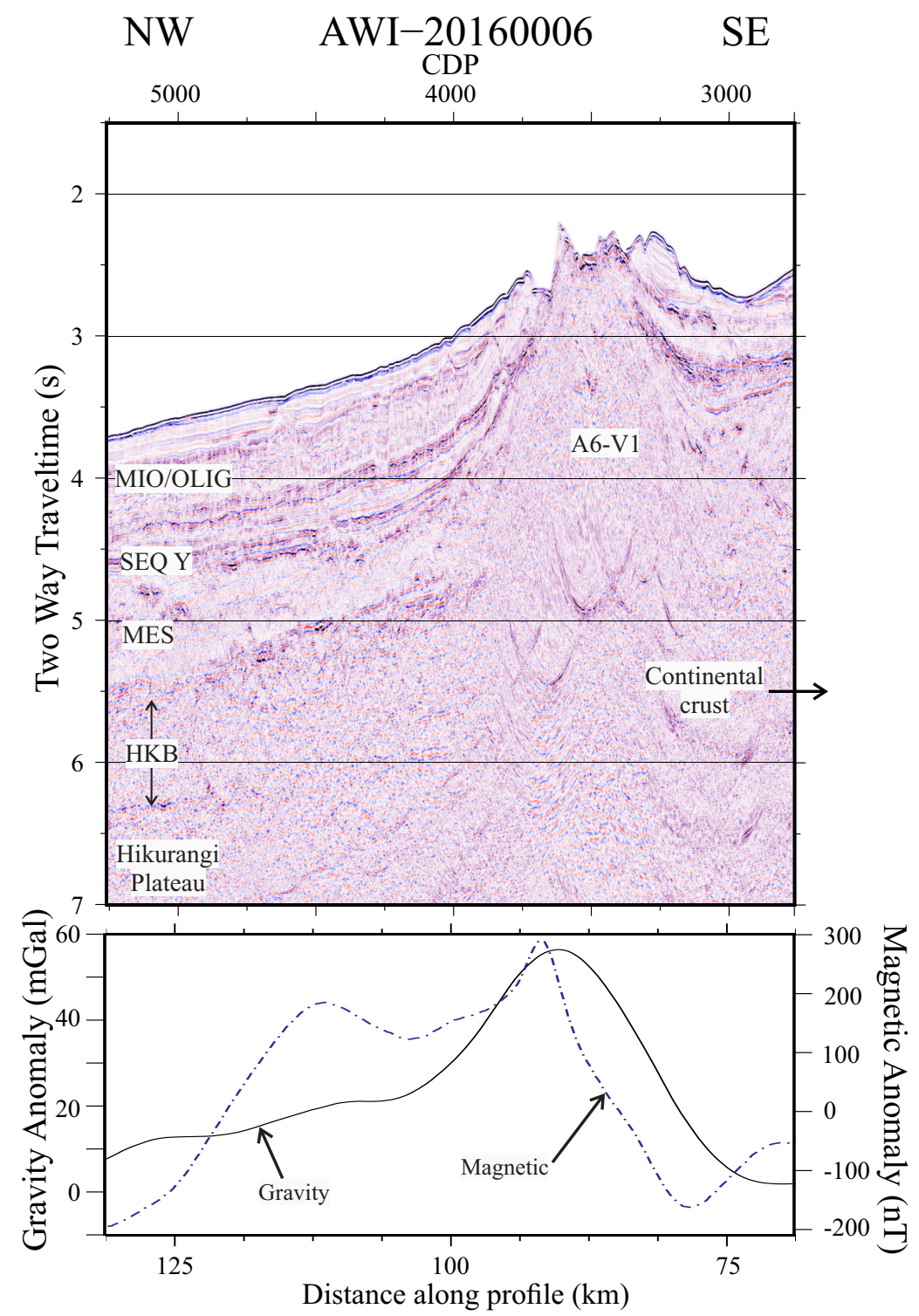

Figure 5.3: Portion of seismic reflection profile AWI-20160006 showing the volcanic feature A6-V1, and the magnetic and gravity anomalies at this location.

\subsubsection{Modelling a volcanic intrusion}

The gravity anomaly of a spherical body with radius $R$ and volume $V=(4 / 3) \pi R^{3}$ is defined by Nettleton (1942) as:

$$
g=\frac{G V \Delta \rho z_{c}}{\left(x^{2}+z_{c}^{2}\right)^{3 / 2}}
$$

where $G$ is the Universal Gravitational Constant $\left(=6.67 \times 10^{-11} \mathrm{Nm}^{2} \mathrm{~kg}^{-2}\right), \Delta \rho$ 
is the density contrast of the sphere compared to surrounding material, $z_{c}$ is the depth to the centre of the sphere, and $x$ is the horizontal distance away from the centre of the sphere (Table 5.2). The gravity anomaly which would result from a spherical body which has $\mathrm{R}=4 \mathrm{~km}, \Delta \rho=300 \mathrm{~kg} / \mathrm{m}^{3}$, and $z_{c}=9 \mathrm{~km}$ is shown in Figure 5.4.

The magnetic anomaly which would result from this same spherical body can be approximated using a single dipole whose poles are separated by the diameter of the sphere (Figure 5.4 - Kearey et al., 2002). Here, it is assumed that the dipole is magnetised in the direction of the present geomagnetic field (i.e. the direction of magnetisation, $\theta=30^{\circ}$ - Table 5.2). At each point, the magnetic anomaly can be divided into vertical $(\Delta Z)$ and horizontal $(\Delta H)$ components, defined by

$$
\begin{gathered}
\Delta Z=\frac{-\mu_{o} m z_{p}}{4 \pi\left(x^{2}+z_{p}^{2}\right)^{3 / 2}} \\
\Delta H=\frac{\mu_{o} m x}{4 \pi\left(x^{2}+z_{p}^{2}\right)^{3 / 2}}
\end{gathered}
$$

where $\mu_{o}$ is the permeability of a vacuum $\left(=4 \pi \times 10^{-7}\right.$ T.m/amp $), m$ is the magnetic pole strength, and $z_{p}$ is the depth of the pole (Table 5.2, Kearey et al., 2002). The total change in the strength of the magnetic field $(\Delta B)$ for that pole is calculated using

$$
\Delta B=\Delta Z \sin I+\Delta H \cos I \cos \alpha
$$

where $I$ is the angle of inclination of the geomagnetic field at that location, and $\alpha$ is the angle between the strike of the profile and magnetic north (Kearey et al., 2002) (Table 5.2). The total field anomaly is calculated by summing the individual effect of the two poles. For the modelled intrusion, the magnetic anomaly is shifted 
Table 5.2: Parameters used for modelling the gravitational and magnetic effects of a sphere, and of the edge-effect anomaly resulting from a slab which has contrasting density and magnetic susceptibility to an adjacent slab.

\begin{tabular}{|c|c|c|}
\hline \multicolumn{3}{|c|}{ Modelling Parameters } \\
\hline Parameter & Value & Description \\
\hline \multicolumn{3}{|c|}{ Fixed parameters } \\
\hline $\mathrm{G}$ & $6.67 \times 10^{-11} \mathrm{Nm}^{2} \mathrm{~kg}^{-2}$ & Universal Gravitational Constant \\
\hline$\mu_{o}$ & $4 \pi \times 10^{-7}$ T.m/amp & $\begin{array}{l}\text { Magnetic permeability of a vac- } \\
\text { uum }\end{array}$ \\
\hline $\mathrm{I}$ & $-60^{\circ}$ & $\begin{array}{l}\text { Inclination of the geomagnetic } \\
\text { field (in the NZ region) }\end{array}$ \\
\hline$\alpha$ & $-60^{\circ}$ & $\begin{array}{l}\text { Angle between the strike of the } \\
\text { profile and magnetic north }\end{array}$ \\
\hline$B$ & $55000 \mathrm{nT}$ & $\begin{array}{l}\text { Magnetic field strength in the } \\
\text { New Zealand region }\end{array}$ \\
\hline \multicolumn{3}{|c|}{ Model parameters } \\
\hline $\mathrm{R}$ & $4 \mathrm{~km}$ & Radius of sphere \\
\hline $\mathrm{x}$ & & $\begin{array}{l}\text { Horizontal distance away from } \\
\text { the centre of the sphere/edge of } \\
\text { the slab which has contrasting } \\
\text { characteristics }\end{array}$ \\
\hline$z_{p}$ & & Depth to pole \\
\hline$z_{p 1}$ & $12 \mathrm{~km}$ & Depth to first pole \\
\hline$\theta$ & $30^{\circ}$ & Angle of magnetisation \\
\hline$d$ & $8 \mathrm{~km}$ & Distance between poles \\
\hline$t$ & $15 \mathrm{~km}$ & Thickness of the slab \\
\hline$z_{c}$ & $9 \mathrm{~km}$ & Distance to centre of mass \\
\hline$m$ & $-3.5 \times 10^{8}$ Amp m & Magnetic pole strength \\
\hline$\Delta \rho$ & $300 \mathrm{~kg} / \mathrm{m}^{3}$ & Density contrast \\
\hline \multicolumn{3}{|c|}{ Additional terms/equations (discussed/derived in the text) } \\
\hline $\mathrm{V}$ & $(4 / 3) \pi R^{3}$ & Volume of sphere \\
\hline$M$ & $M=m d=J V\left(\mathrm{Amp} / \mathrm{m}^{2}\right)$ & Dipole moment \\
\hline$J$ & $J=k H(\mathrm{Amp} / \mathrm{m})$ & Induced magnetisation \\
\hline$k$ & $k=(m d) /(V H)(\mathrm{SI})$ & Magnetic susceptibility \\
\hline$H$ & $H=B / \mu_{o} \approx 44 \mathrm{Amp} / \mathrm{m}$ & Magnetising force \\
\hline
\end{tabular}




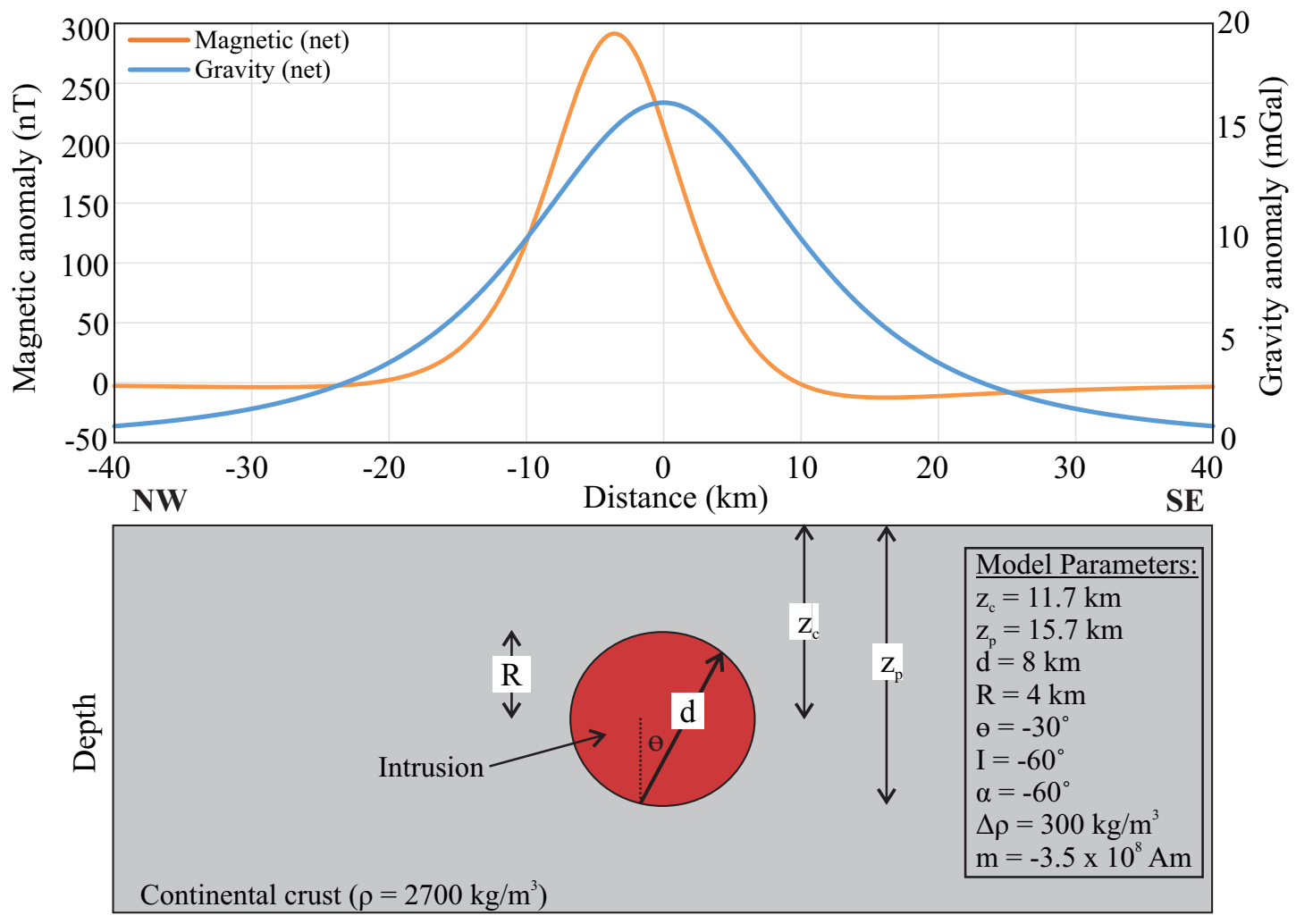

Figure 5.4: The gravity and magnetic anomalies which would result from an inclined dipole within a sphere. For details on the calculation of these anomalies, refer to the text. Abbreviations for model parameters are as shown in Table 5.2.

north-west of the gravity peak by $\sim 4 \mathrm{~km}$ (Figure 5.4 ). This corresponds with the direction and magnitude of offset in the observed paired magnetic and gravity anomalies over feature A6-V1 (Figure 5.3). For this modelled intrusion (Figure 5.4), the magnitude of the magnetic anomaly is similar to that of the observed anomaly (Figure 5.3). The magnitude of the modelled gravity anomaly, however, is three times smaller than the observed anomaly.

For a dipole with poles of strength $m$ a distance $d$ apart (Figure 5.4), the magnetic moment $(M)$ is defined by

$$
M=m d=J V
$$

where $J$ is the induced magnetisation and $V$ is the volume of the sphere (Kearey et al., 2002). $J$ is defined by the equation 


$$
J=k H
$$

where $k$ is the magnetic susceptibility, and $H$ is the magnetising force $\left(=B / \mu_{o}\right)$ (Kearey et al., 2002). In the New Zealand region, $B \approx 55000$ nT. Consequently, $H \approx 44 \mathrm{Amp} / \mathrm{m}$. Combining Equations 5.5 and 5.6 gives

$$
k=\frac{m d}{V H}
$$

Then, for a sphere with radius $R=4 \mathrm{~km}, d=8 \mathrm{~km}$ and $m=-3.5 \times 10^{8}$ A.m (Table 5.2), $k=-2.39 \times 10^{-1}(\mathrm{SI})$. This value of susceptibility correlates with that of a wide range of igneous rocks (Clark and Emerson, 1991). It should be noted, however, that the above calculation models only the effect of a single magnetised body. Any remanent magnetisation which may be present (and might have a different intensity and pole orientation to the modelled intrusion) is unconstrained, and is unaccounted for in this model.

\subsubsection{Modelling the edge-effect of a slab}

An alternative explanation for the paired magnetic and gravity anomalies is an edge-effect resulting from the juxtaposition of the LIP with the continental crust (Sibuet et al., 1974). The gravity anomaly associated with such an edge-effect can be modelled to a first approximation using an equation derived by Nettleton (1942) for a horizontal slab with a vertical edge:

$$
g=2 G \Delta \rho t\left(\frac{\pi}{2}+\tan ^{-1} \frac{x}{z_{c}}\right)
$$

where $\mathrm{G}, \Delta \rho, x$ and $z_{c}$ are as defined previously (Table 5.2), and $t$ describes the thickness of the slab. While a vertical edge to the slab does not necessarily reflect 
the actual interface between the LIP and the continental crust on the profiles of interest, it is appropriate for a first order approximation.

For the modelled slab edge-effect (Figure 5.5), the combined effect of sediments and deeper water on the north-west side of the margin is approximated as a $3 \mathrm{~km}$ thick slab, and the density contrast of that slab is set to $\Delta \rho=-700 \mathrm{~kg} / \mathrm{m}^{3}$ compared to the continental crust $\left(\rho=2700 \mathrm{~kg} / \mathrm{m}^{3}\right)$. The density contrast between the LIP and the continental crust is then calculated using a simple isostatic mass balance across the two columns, and is found to be $\Delta \rho=140 \mathrm{~kg} / \mathrm{m}^{3}$. The gravitational effect of each half-space layer is calculated and the results are summed to find the net gravitational anomaly resulting from the slab (Figure 5.5). In this model, the gravity anomaly is centred $10 \mathrm{~km}$ south-east of the slab-edge.

The vertical component of the magnetic anomaly associated with the edge-effect $(\Delta Z)$ is modelled using an equation derived by Nettleton (1942) for a single magnetised layer that terminates at a vertical edge:

$$
\Delta Z=\frac{2 J t x}{x^{2}+z_{c}^{2}}
$$

where $J, t, x$ and $z_{c}$ are as defined in Table 5.2.

The resulting magnetic anomaly (Figure 5.5) has a half-width of $\sim 25 \mathrm{~km}$, and is a maximum amplitude $\sim 15 \mathrm{~km}$ south of the interface between the Hikurangi Plateau and the continental crust of the Chatham Rise. As this model considers only the vertical component of the magnetic field, there is no anomaly above the Hikurangi Plateau (which has a higher magnetic susceptibility) (Figure 5.5).

In this vertical edge-effect model, the gravity anomaly is offset to the north relative to the magnetic anomaly (Figure 5.5). This differs from the observed anomalies where the magnetic anomaly is offset to the north by $5-10 \mathrm{~km}$ from the gravity anomaly peak (Figure 5.3). When considered in isolation, this variation in the 

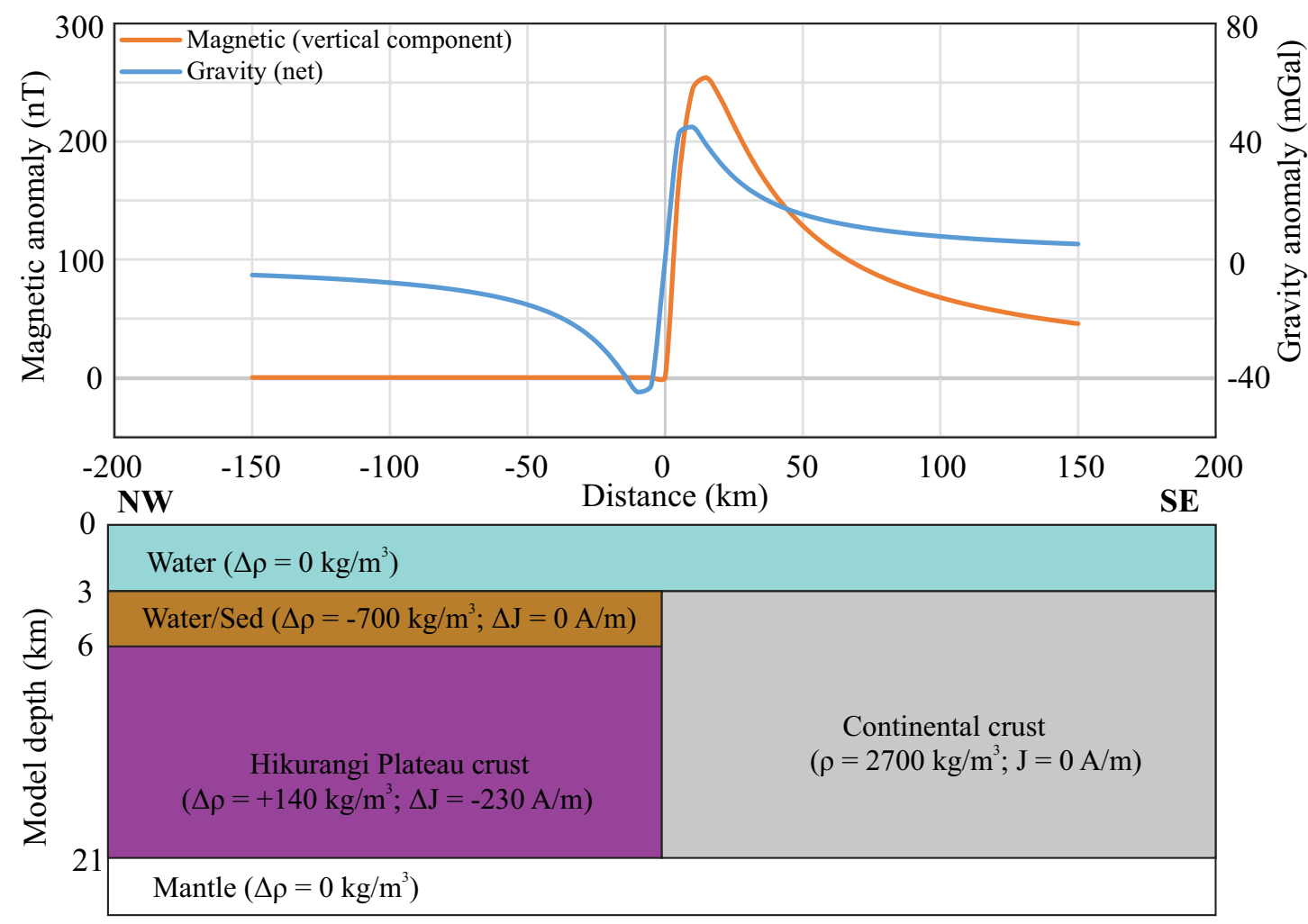

Figure 5.5: The net gravity anomaly and vertical-component of the magnetic anomaly which would result from the modelled slab-edge-effect. For details on the calculation of these anomalies, refer to the text.

offset of the anomalies favours the volcanic intrusion (Figure 5.4) as the source of the paired gravity and magnetic anomalies. However, several points should be noted:

- Firstly, the modelled magnetic anomaly for the slab edge-effect is only for the vertical component, rather than the net effect (Equation 5.9). This is likely an over-simplification, as in reality the magnetising field is seldom vertical (Nettleton, 1942).

- Secondly, the modelled intrusion has a gravity anomaly of about $17 \mathrm{mGal}$ (Figure 5.4), approximately three times less than the observed anomaly of $55 \mathrm{mGal}$ (Figure 5.3).

- Thirdly, for the edge-effect model (Figure 5.5), variations in the dip of the interface between the plateau and the continental crust will likely have an ef- 
fect on the offset of the anomalies. While this dip angle is poorly constrained

by the seismic reflection data (Figure 4.20), it is unlikely to be vertical.

Consequently, to model both the observed anomaly offset (the magnetic anomaly is shifted $5-10 \mathrm{~km}$ to the north of the gravity anomaly) and the magnitude of the gravity anomaly (poorly modelled by the intrusion) likely requires a combination of these two features (and possibly others such as lateral variations in sediment and/or mantle density). While these models are useful to a first approximation, it is unlikely that the actual sub-surface structure can be so simply represented.

\subsubsection{Gravity modelling across the interface between the Hikurangi Plateau and the continental crust of the Chatham Rise}

Gravity modelling across the whole profile can also help to better constrain the nature of the interface between the Hikurangi Plateau and the continental crust of the Chatham Rise. Gravity models are constructed across profiles CHAT-3, AWI20160006 and AWI-20160004 - three profiles which are orientated perpendicular to the strike of the WWR where it intersects the Chatham Rise margin (Figure 5.1). As discussed previously for gravity modelling across CHAT-4 (Section 5.1), incorporating a-priori information is essential for reducing uncertainties in the model. The horizons identified on the seismic reflection data (seafloor, base of the sedimentary section, and base of HKB sediments (where present) - Figures 4.19, 4.20 and 4.21) are input as initial parameters for gravity modelling, and are converted to depth sections using the velocities in Table 5.3. There are no constraints on variations in the geophysical properties of the lower crust and upper mantle, and so it is assumed that there is constant density within these layers. Consequently, short wavelength variation in crustal thickness and sediment accumulation is assumed to be the source of gravity variations along the profiles. 
Table 5.3: Velocities used to convert time horizons into depth horizons, and densities used for gravity modelling along CHAT-3, AWI-20160006 and AWI-20160004.

\begin{tabular}{|l|l|l|}
\hline \multicolumn{2}{|c|}{$\begin{array}{c}\text { Geophysical characteristics of layers associated with the Hikurangi } \\
\text { Plateau and the continental crust at the Chatham Rise margin }\end{array}$} \\
\hline \hline Layer & $\begin{array}{l}\text { Modelled Velocity } \\
\text { (km/s) }\end{array}$ & $\begin{array}{l}\text { Modelled Density } \\
\left(\mathrm{kg} / \mathbf{m}^{3}\right)\end{array}$ \\
\hline Water & 1.5 & 1000 \\
\hline Sediments & 2.4 & 2500 \\
\hline HKB layered sediments & 3.2 & 2700 \\
\hline Crust of the Hikurangi Plateau & 6.0 & 3000 \\
\hline $\begin{array}{l}\text { Averaged LIP crust and HKB } \\
\text { (AWI-20160004) }\end{array}$ & 6.0 & 2900 \\
\hline $\begin{array}{l}\text { Continental crust of the } \\
\text { Chatham Rise }\end{array}$ & 6.45 & 2700 \\
\hline Mantle & 8.04 & 3300 \\
\hline
\end{tabular}

Cenozoic shield volcanism beneath Otago, eastern Canterbury, and across the Campbell Plateau has been proposed to be a result of asthenospheric upwelling, as a result of slab and mantle lid detachment beneath the Chatham Rise (Hoernle et al., 2006). A zone of low relative velocity in the upper mantle beneath the eastern South Island and the inner Bounty Trough, and the identification of thinned crust beneath the Campbell Plateau supports this theory (Ball et al., 2016). Such asthenospheric upwelling across the wider region is long lived, having likely occurred over the last $\sim 100$ million years since subduction cessation at the Chatham Rise (Sutherland et al., 2010). This would result in variations of the density and velocity structure of the upper mantle which are not accounted for in the gravity models in this section, but could have significant consequences for the uncertainty of those models. However, as there are no constraints on the present-day density structure of the upper mantle, the approximation of constant mantle density is necessary.

The thickness of the crust of the Chatham Rise and of the Hikurangi Plateau 
is poorly constrained, both by the seismic reflection profiles studied here, and in previous work; with gravity models providing the best estimate of crustal thickness. Based on gravity modelling, Davy et al. (2008) suggested a total crustal thickness of 23 - $26 \mathrm{~km}$ at the central Chatham Rise (along HKDC1 - Figure 1.1) - a crustal thickness that includes both the continental crust of the Chatham Rise and the underlying, subducted crust of the Hikurangi Plateau. Older models by Wood and Anderson (1989) assumed a similar crustal thickness of $20 \mathrm{~km}$ proximal to the Chatham Islands. However, the variation in bathymetry and in the satellite gravity signature over the region (Figure 5.1) indicates that the Chatham Rise crust thins east of Chatham Islands, towards its eastern edge. Consequently it is considered reasonable for the continental crust of the Chatham Rise at the southeastern end of these profiles to be modelled as being $15 \mathrm{~km}$ thick. Similarly thinned continental crust $(15 \mathrm{~km}$, compared to the average crustal thickness of 25 to 70 $\mathrm{km}$ - Fowler, 2005) is observed in extensional regions elsewhere (e.g. Le Pichon et al., 1982, Thinon et al., 2003, Van Avendonk et al., 2009).

Given this adopted thickness of the continental crust at the south-east end of the profiles $(15 \mathrm{~km})$, the corresponding thickness of the Hikurangi Plateau at the northwest end of the profiles can be fixed by creating two columns that are required by isostasy to have the same mass at an adopted compensation depth of $50 \mathrm{~km}$. The locations of these mass-balanced columns are indicated on Figures 5.6, 5.7 and 5.8 for CHAT-3, AWI-20160006 and AWI-20160004, respectively. This isostatic mass balancing gives thicknesses of 16 to $22 \mathrm{~km}$ for the crust of the Hikurangi Plateau at the north-western end of profiles CHAT-3, AWI-20160006 and AWI-20160004 (Appendix C).

As for CHAT-4 (Section 5.1), it should be noted that gravity models across profiles CHAT-3, AWI-20160006 and AWI-20160004 are 2-D models. For these three profiles, the main purpose of gravity modelling is to better constrain the nature of the interface between the Hikurangi Plateau and the Chatham Rise at the east- 
ern margin of the Hikurangi Plateau. While the proximity of these profiles to the northern edge of both the Chatham Rise and the Hikurangi Plateau may be an additional source of uncertainty for these inherently non-unique 2-D models, the use of seismic and magnetic data as starting constraints, as well as the use of geologically reasonable densities based on previous studies (Table 5.3), means that these 2-D models are likely a good approximation to the actual density distribution.

\section{Gravity model across CHAT-3}

The gravity model (Figure 5.6) for CHAT-3 shows the following key features:

- The interface between the Hikurangi Plateau and the continental crust of the Chatham Rise,

- Variations in the Moho depth along the profile, and

- Shallowing of the upper crust and thinning of the sedimentary section between 120 and $155 \mathrm{~km}$ along the profile (which corresponds with the seismic reflection data - Figure 4.19).

At the north-west end of the profile, the Hikurangi Plateau under-thrusts the continental crust of the Chatham Rise (Figure 5.2). The dip of this interface is constrained by the seismic reflection data (Figure 4.18). Cretaceous subduction of the Hikurangi Plateau beneath the Chatham Rise margin was initially orientated towards the SSW (Davy et al., 2008). The plate convergence direction rotated to southward-orientated between 105 and $101 \mathrm{Ma}$, after which subduction of the Hikurangi Plateau at the margin ceased (Davy et al., 2008, Zhang and Li, 2016). These seismic profiles (CHAT3, AWI-20160006 and AWI-20160004) are perpendicular to the south-east margin of the Hikurangi Plateau (Figure 5.1). Consequently, the Hikurangi Plateau did not subduct beneath the Chatham Rise along profile CHAT-3. Instead, the under-thrusting of the Hikurangi Plateau on this profile 


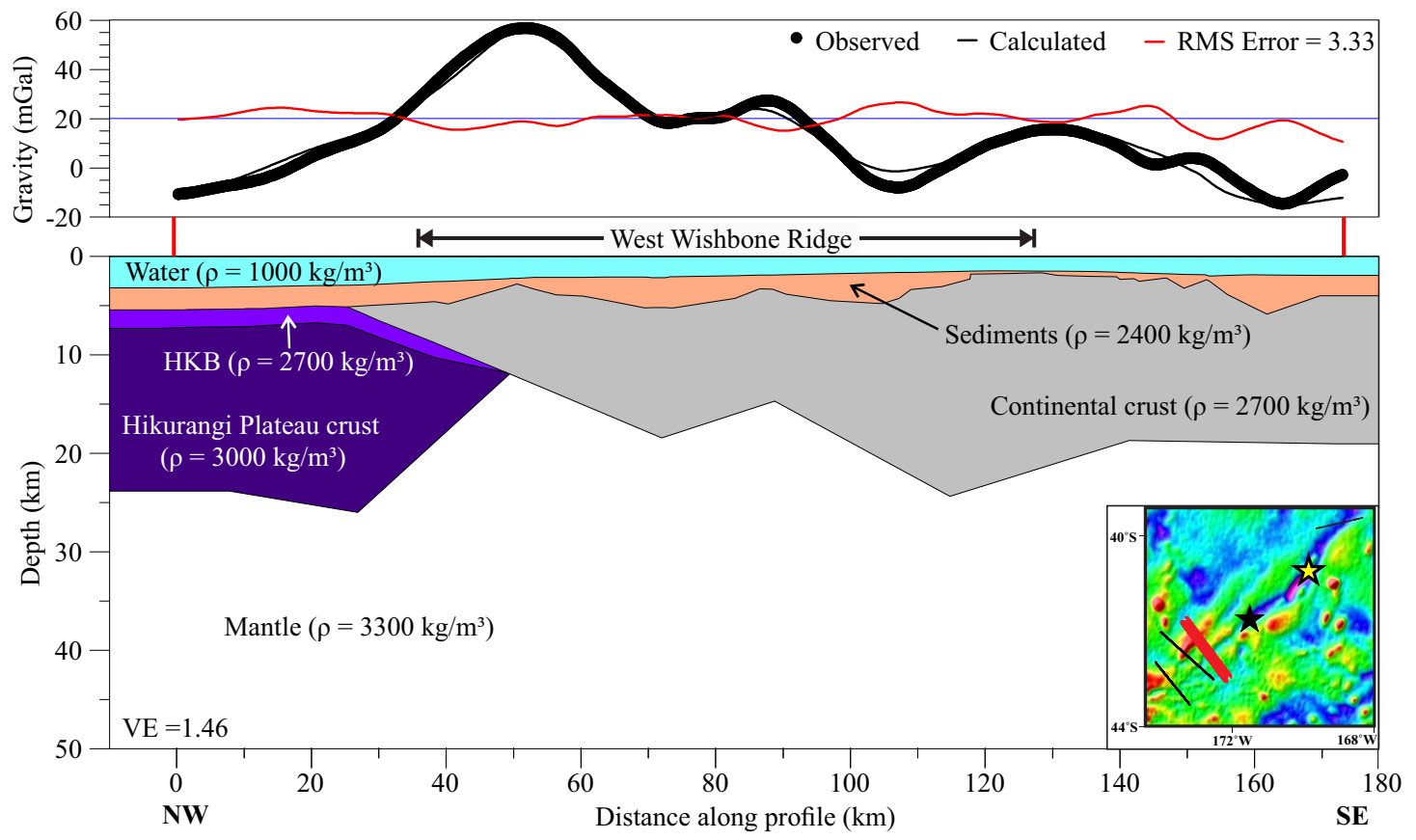

Figure 5.6: Gravity model across profile CHAT-3. This model is isostatically balanced at a depth of $50 \mathrm{~km}$ at the western and eastern ends of the profile (indicated by the red lines). VE = vertical exaggeration. Inset: Satellite Free Air gravity anomaly from Sandwell et al. (2014). Profile location is shown in red.

(Figure 5.6) may have been a result of N-S compression of the Chatham Rise margin in the period between 105 and $101 \mathrm{Ma}$ (Davy, 2014).

Results of gravity modelling indicate an abrupt south-eastern edge to the crust of the Hikurangi Plateau (Figure 5.6). Hochmuth and Gohl (2017) suggested that the Ontong-Java Nui super-LIP (consisting of Ontong-Java, Hikurangi and Manihiki Plateaux) may have extended further east than the Hikurangi Plateau, and identified a possible rifted fragment along the West Antarctic margin and another west of the South American Andes. These fragments may have rifted from the Hikurangi and Manihiki plateaux during the initial rifting phase of OntongJava Nui ca. 120 Ma (Hochmuth and Gohl, 2017). If these fragments were indeed once an extension of the Ontong-Java Nui super-LIP, their rifting could explain the abruptness of the eastern edge of the Hikurangi Plateau modelled here.

A secondary positive gravity anomaly centred on $90 \mathrm{~km}$ is well fit by varying the depth of the Moho in this region (between 70 and $120 \mathrm{~km}$ along the profile) (Figure 
5.6). Without some variation in the Moho depth in this region, it was not possible to fit the modelled gravity anomaly to that observed, given the constraints on the upper crust and sedimentary section from the seismic reflection data.

Another second-order, positive gravity anomaly, centred on $130 \mathrm{~km}$ along the profile (Figure 5.6), results from the shallow basement observed in the seismic data (Figure 4.19). This shallowing of the basement is accommodated by a variation in the depth of the Moho.

\section{Gravity model across AWI-20160006}

The following key features are identified in the gravity model for AWI-20160006 (Figure 5.7):

- The interface between the Hikurangi Plateau and the continental crust of the Chatham Rise,

- A basaltic intrusion (feature A6-V1) overlying that interface, and

- Variation in the crustal thickness between 30 and $60 \mathrm{~km}$ along the profile.

Similarly to on CHAT-3 (Figure 5.6), gravity modelling across AWI-20160006 indicates an abrupt south-eastern edge to the Hikurangi Plateau (Figure 5.7). However, the nature of this interface differs on these two profiles. On CHAT-3, the Hikurangi Plateau under-thrusts the continental crust of the Chatham Rise for about $20 \mathrm{~km}$ (Figure 5.6), while on AWI-20160006, the interface has characteristics of transform faulting - a steeply dipping interface which juxtaposes two varying crusts adjacent to each other (Figure 5.7). Additionally, the interface between the Hikurangi Plateau and the Chatham Rise is overlain by a basaltic volcanic intrusion (A6-V1 - Figures 5.3 and 5.7).

A second positive gravity anomaly is located $55 \mathrm{~km}$ along the profile (Figure 5.7). 


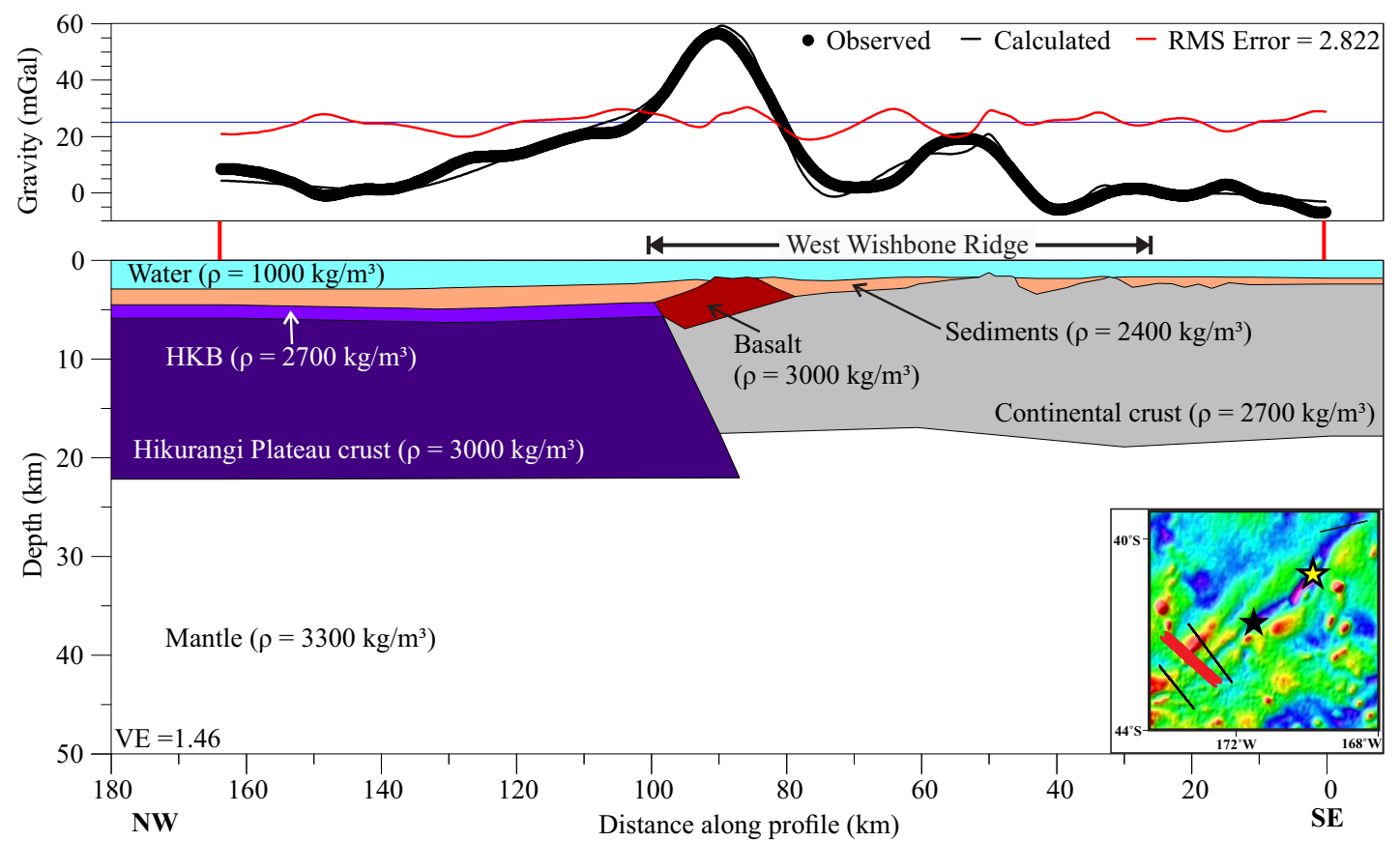

Figure 5.7: Gravity model across profile AWI-20160006. This model is isostatically balanced at a depth of $50 \mathrm{~km}$ at the western and eastern ends of the profile (indicated by the red lines). VE = vertical exaggeration. Inset: Satellite Free Air gravity anomaly from Sandwell et al. (2014). Profile location is shown in red.

This anomaly is predominantly the result of basement shallowing (as observed in the seismic reflection data - Figure 4.20). The gravity model indicates that the dense mantle also shallows beneath this feature (Figure 5.7).

The full-profile modelled gravity anomaly is offset $\sim 10 \mathrm{~km}$ to the south-east of the upper edge of the slab (Figure 5.7). This corresponds with the gravity anomaly which results from the modelled slab-edge effect (Figure 5.5). Such offset of the gravity anomaly from the source is not observed for the modelled volcanic intrusion (Figure 5.4), indicating that the slab edge-effect perhaps has a greater effect on the net observed gravity anomaly.

\section{Gravity model across AWI-20160004}

The observed gravity anomaly across AWI-20160004 is dominated by a single, broad positive anomaly with a half-width of $15 \mathrm{~km}$ (Figure 5.8). This anomaly is 
attributed to the interface between the contrasting crusts of the Hikurangi Plateau and the Chatham Rise, and to the shallowing of basement across the anomaly. As there is no constraint on the thickness of the HKB sediments from the seismic reflection data across this profile (Figure 4.21), the LIP crust and HKB sediments are modelled as a single, combined layer which has reduced density compared to that of the LIP crust alone (Table 5.3, Figure 5.8).

The location of AWI-20160004 coincides with the north-east offset of the Chatham Rise margin at $174^{\circ} \mathrm{W}$ (Figure 5.1), and also marks the eastern extent of previously interpreted Cretaceous subduction of the Hikurangi Plateau along the Chatham Rise. The gravity model across this profile (Figure 5.8) shows this subduction. As on AWI-20160006 and CHAT-3 (Figures 5.7 and 5.6), the south-eastern boundary of the Hikurangi Plateau on AWI-20160004 is abrupt and near-vertical (Figure $5.8)$.

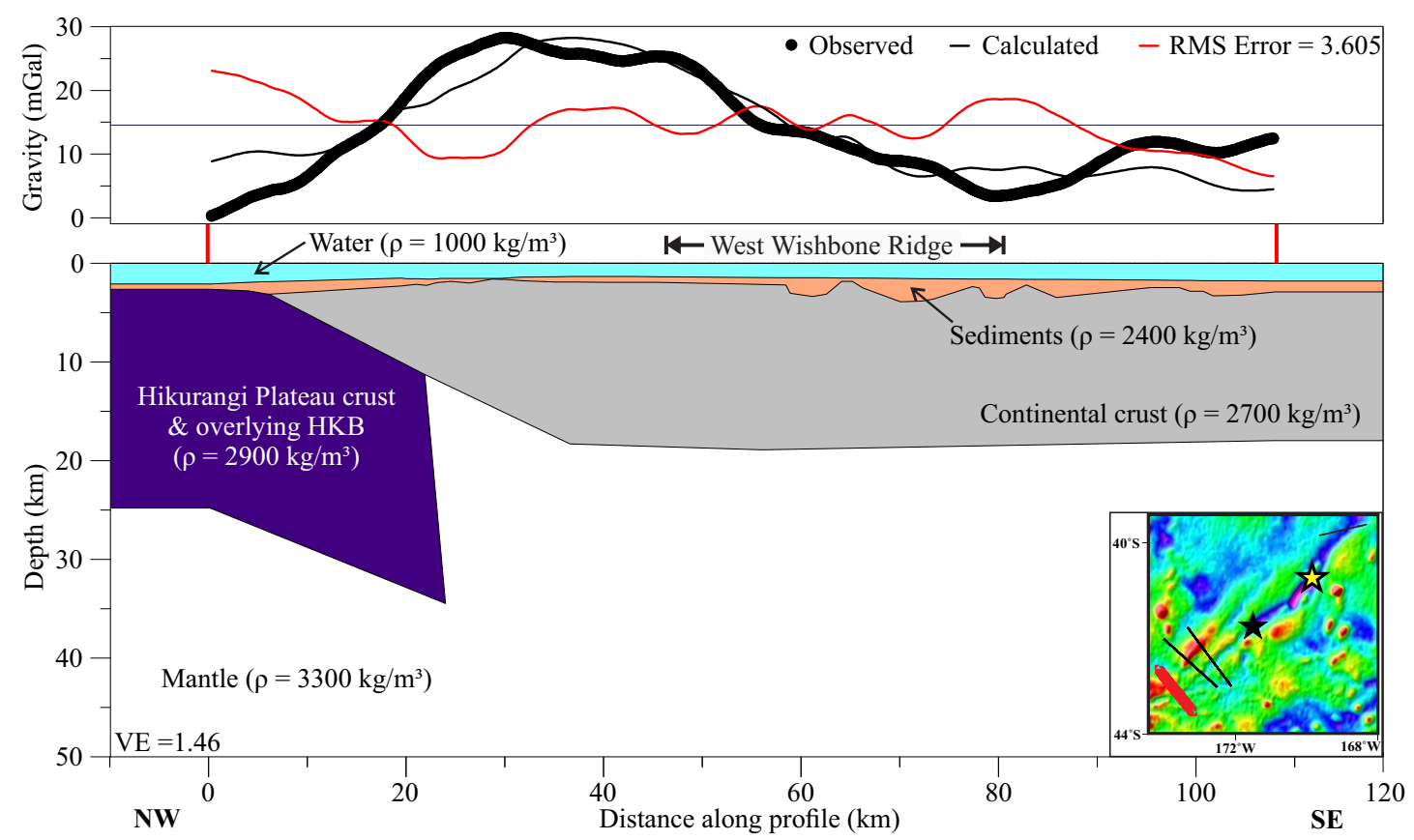

Figure 5.8: Gravity model across profile AWI-20160004. This model is isostatically balanced at a depth of $50 \mathrm{~km}$ at the western and eastern ends of the profile (indicated by the red lines). VE = vertical exaggeration. Inset: Satellite Free Air gravity anomaly from Sandwell et al. (2014). Profile location is shown in red. 


\subsection{The West Wishbone Ridge as a Transform Fault}

On seismic reflection profiles, transform faults can be identified by the presence of 'flower' structures, abrupt dip changes across faults, change in the vertical offset of horizons with depth, thickening or thinning of beds across faults or a change in the character of the seismic unit across a fault (D'Onfro and Glagola, 1983). Several of these characteristics are observed on profiles interpreted in this study, providing evidence for transform faulting along the WWR. These are discussed in the following paragraphs.

On CHAT-4, the eastern margin of the WWR coincides with an abrupt vertical step in the top of crust elevation and a crustal shear zone which intersects the Moho (Figure 4.18). The interface between oceanic crustal Layers 2A and B is present on both sides of this margin (constrained on the west by the seismic reflection data, and on the east by gravity modelling - Figures 4.18 and 5.2). However, the seismic reflection character of the crust varies from east to west across the eastern boundary of the WWR, with the Layer 2A/B interface identified on the western side, but not on the east (Figure 4.18). This change in the nature of the crust, which coincides with a vertical step in the crust and the lower-crustal shear zone, can be explained by transform motion having juxtaposed unrelated crust along the WWR at this latitude.

On CHAT-3, evidence of previous transform faulting is provided by flower structures that cut through a half-graben associated with the WWR-region of deformation, and which are proximal to a vertical step in the elevation of the top of crust (Figure 4.19). Evidence of transform motion is not observed along AWI-20160006 and AWI-20160004 (Figures 4.20 and 4.21). However, it should be noted that profiles AWI-20160006 and AWI-20160004 have a lower fold and were shot with a smaller source than the UNCLOS profiles (Tables 2.1, A.1). Consequently, that 
flower structures are not observed may be a result of the resolution of the data, rather than an indication that they are not present.

Alternatively, (a) motion along the WWR has been divided into different components at the intersection with the Chatham Rise (as suggested by Sutherland and Hollis, 2001, Davy et al., 2008), or (b) deformation was more dispersed in the deformed accretionary margin to the south-west (AWI-20160006 and AWI20160004) versus in the offset Chatham Rise fragment to the north (CHAT-3), i.e. deformation became more dispersed as the WWR propagated further into continental crust. This second option is consistent with well-documented global findings (Molnar, 1988) and is likely to have played a role in the differences observed. However, at this stage, and with these data, it is not possible to determine the role of (a) or (b) (or some combination of these factors) in the nature of the WWR.

\subsubsection{Sense of motion}

At CHAT-4, two regions of compressional faults are interpreted within the WWR region of deformation (Figure 5.1). Southwards along its strike, at CHAT-3, AWI20160006 and AWI-20160004, the WWR is associated with half-grabens and rotated fault blocks, features which are associated with extensional tectonic regimes (Figure 5.1).

The WWR can be separated into different segments according to their varying strike directions. Some of these segments probably correlate with pre-existing transform faults in oceanic crust, and other segments link those faults. When a transform fault steps across strike, compressional or extensional regimes will dominate in the region of this step (Cunningham and Mann, 2007). Which of these regimes dominates is dependent on whether the fault is sinistral or dextral, and whether it steps to the left or to the right of the direction of propagation (Figure 
5.9). Between $39^{\circ} \mathrm{S}$, where the WWR is overlain by the Louisville Seamount Chain (LSC), and $40.2^{\circ} \mathrm{S}$ the WWR steps to the left (eastwards), coinciding with the compressional faulting observed on CHAT-4 (Figure 5.10). This supports the previous interpretation of Cretaceous dextral motion along the WWR (Figure 5.9) (Sutherland and Hollis, 2001, Davy et al., 2008).

If this logic is applied further south, where CHAT-3, AWI-20160006 and AWI20160004 cross the WWR (Figure 5.1), the extensional regime associated with the WWR crustal structure suggests that the WWR steps to the right (westwards) through this region to follow the eastern edge of the Hikurangi Plateau (Figure 5.9). Distinguishing which features are related to the WWR and which are related to the Chatham Rise is challenging. The northward extension of the half-grabens and rotated fault blocks associated with the WWR-region of deformation on CHAT3, AWI-20160006, and AWI-20160006 (Figure 5.1) to $\sim 40.5^{\circ} \mathrm{S}$, well north of the Chatham Rise, indicates that these are WWR-related rather than related to the

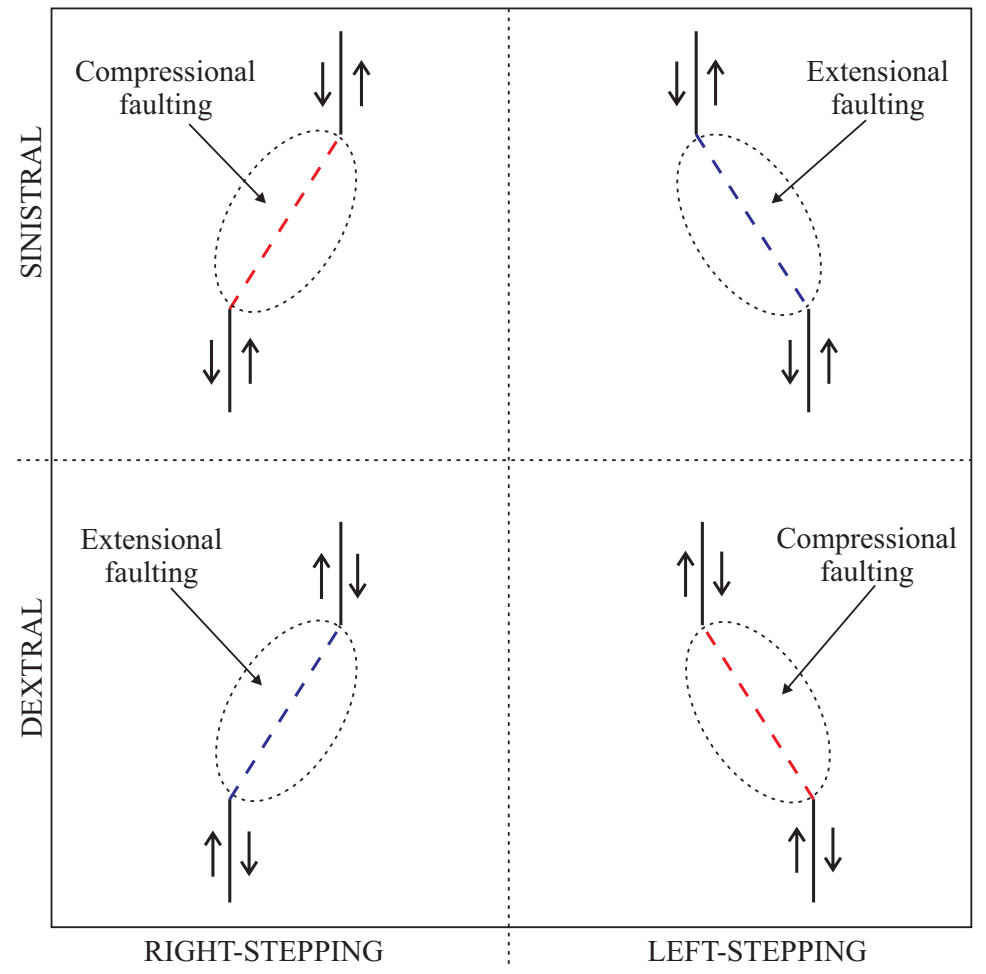

Figure 5.9: Schematic illustrating the compressional and extensional faulting regimes created when a fault steps laterally along strike. 


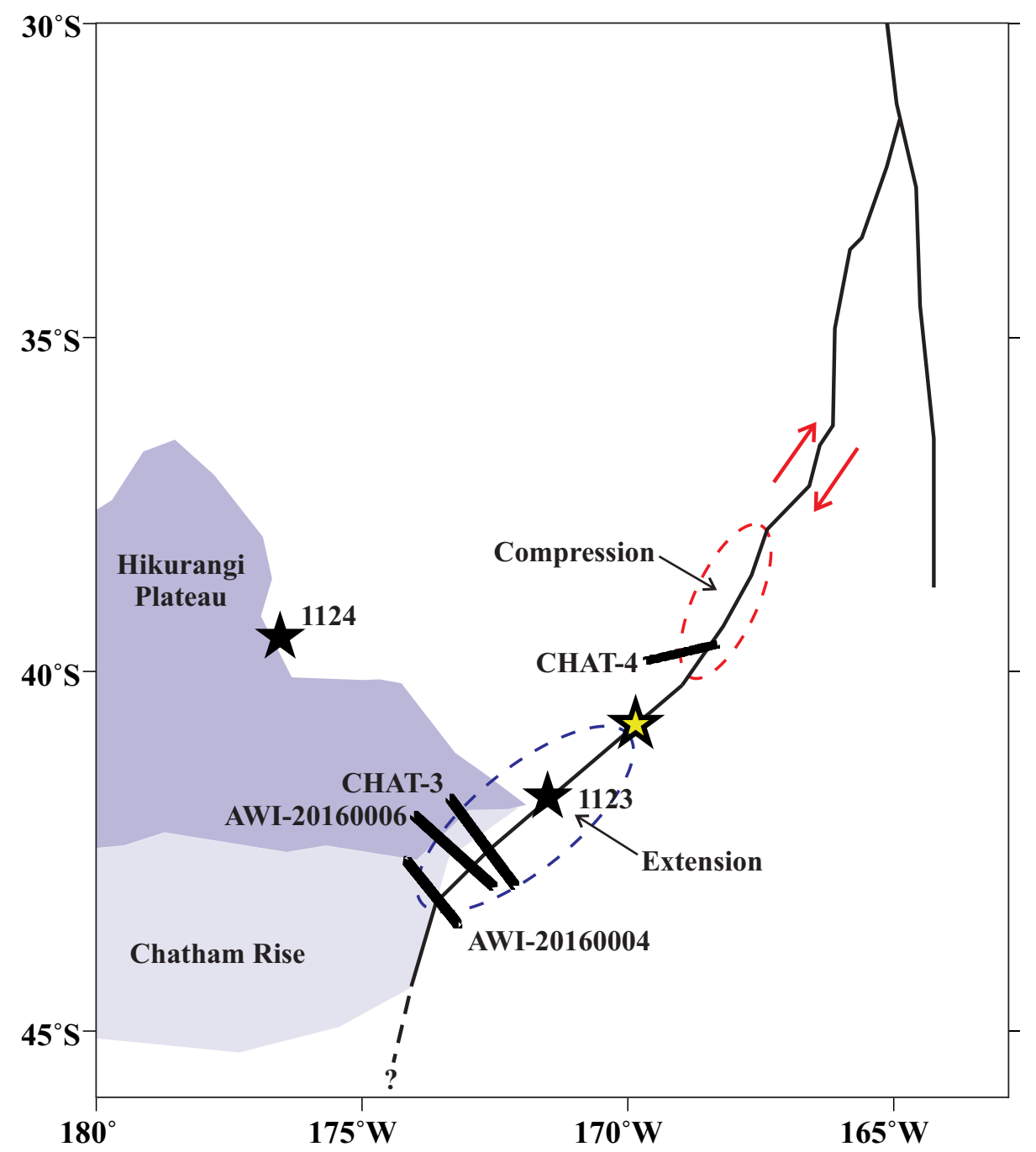

Figure 5.10: Line drawing of the Wishbone Ridge showing the location of compressional (red) and extensional (blue) regimes along the WWR. Those regimes, when correlated with the change in strike, indicate past dextral motion along the WWR (Figure 5.9). Yellow star shows the location of a dredge collected on the scarp of the WWR (Mortimer et al., 2006). Hikurangi Plateau is shaded in purple and where it underlies the Chatham Rise is light purple. Black stars show the locations of ODP Sites 1123 and 1124. Red arrows show direction of motion. WWR strike is averaged - in some regions, this may vary more frequently than shown in this schematic.

Chatham Rise. The southward continuation of the strike of the WWR through the half-graben south-east of C3-RB2 (and A4-RB3, and A6-RB1) enables the WWR to be confidently traced southwards to its intersection with AWI-20160004 (Figure 5.1). Its location south of this point is uncertain and is beyond the scope of this dataset. 


\subsubsection{A Leaky Transform Fault?}

Volcanic feature A6-V1 overlies the interface between the crust of the Hikurangi Plateau and the continental crust of the Chatham Rise and marks the northwestern edge of the WWR on profile AWI-20160006 (Figures 4.20 and 5.7). Two interpretations arise from the location of this basaltic feature above the crustal interface (modelled as basaltic based on gravity and magnetic modelling - Figures 5.4 and 5.7). The first is that $\mathrm{A} 6-\mathrm{V} 1$ is related to the transform motion along the WWR. 'Leaky' transforms such as this form when the transform fault is at an oblique angle to the direction of seafloor spreading, and are not uncommon in oceanic settings (Rothery, 2004). The WWR being a leaky transform is consistent with the composition of lavas erupted on seamounts in the vicinity of the WWR, which tends to be more variable than the composition of seamounts elsewhere along the LSC (Beier et al., 2011); and the size of those seamounts, which are larger than others along the LSC (Figure 5.1).

Based on satellite gravity data, Sutherland and Hollis (2001) suggested that the WWR extends through the Chatham Islands (Figure 5.1). Three main stages of volcanism have occurred at the Chathams - at 85-82, 41-35 and ca. 5 Ma (Panter et al., 2006), which could be related to magma upwelling along the leaky WWR. However, the location of the WWR south of AWI-20160004, and whether it extends through Chatham Islands cannot be constrained by these datasets.

A second interpretation of the basaltic feature A6-V1, and its location above the interface between continental and igneous crust, is that A6-V1 is related to the offset of the Chatham Rise margin at $174^{\circ} \mathrm{W}$. However, most horizons along the margin post-date the collision of the Hikurangi Plateau with the Chatham Rise, making it difficult to constrain the timing of activity of A6-V1. 


\subsection{Summary}

\subsubsection{The south-eastern edge of the Hikurangi Plateau}

On each of CHAT-3, AWI-20160006 and AWI-20160004, the south-eastern edge of the Hikurangi Plateau is abrupt (Figures 5.6, 5.7 and 5.8). The sharp nature of this margin could be due to rifting of fragments of Ontong-Java Nui (the super-LIP which combined Ontong Java, Manihiki and Hikurangi plateaux) from east of the Hikurangi and Manihiki plateaux during the initial rifting stage (ca. $120 \mathrm{Ma}$ ), as suggested by Hochmuth and Gohl (2017).

The interface between the continental crust of the Chatham Rise and the Hikurangi Plateau differs on each of those three profiles, and is described in the following paragraphs.

- AWI-20160004 overlies the southern point of the margin offset of the Chatham Rise at $174^{\circ} \mathrm{W}$ (Figure 5.1). Cretaceous subduction of the Hikurangi Plateau beneath the Chatham Rise has previously been interpreted to have extended to this point (Wood and Davy, 1994, Davy et al., 2008). Gravity modelling across this profile (Figure 5.8) shows the subducted edge of the Hikurangi Plateau underlying the continental crust of the Chatham Rise, as expected based on previous studies.

- Gravity modelling shows that the interface between the Hikurangi Plateau and the continental crust of the Chatham Rise on AWI-20160006 juxtaposes the two crusts adjacent to each other, resembling a fossil transform interface (Figure 5.7) instead of the subduction zone observed on AWI-20160004 to the south (Figure 5.8). The transform nature of this interface leads to the interpretation that margin offset of the Chatham Rise beneath these profiles is a result of the initial collision of the Hikurangi Plateau with the Chatham Rise (Figure 5.1). 
- On CHAT-3, gravity modelling and seismic reflection data show that the south-eastern edge of the Hikurangi Plateau has under-thrust the Chatham Rise for approximately $20 \mathrm{~km}$ (Figure 5.6). Cretaceous subduction of the Hikurangi Plateau beneath the Chatham Rise was orientated towards the SSW. Consequently, the Hikurangi Plateau cannot have subducted beneath the Chatham Rise along this profile during the initial collision and subsequent subduction 110 - 105 Ma (Davy et al., 2008, Davy, 2014, Reyners et al., 2017). However, it has been suggested that the Chatham Rise margin rotated in response to compressional forces related to the slowing and reorientation of subduction along the margin between 105 and 101 Ma (Davy, 2014, Zhang and Li, 2016). This margin compression and rotation provides a mechanism for the under-thrusting of the Chatham Rise observed on profile CHAT-3.

\subsubsection{The West Wishbone Ridge}

The WWR is identified as a dextral transform fault. This sense of motion is opposite to what would be expected if the WWR was a transform simply related to an offset of the Osbourn Trough, suggesting a more complicated mechanism. The sinistral offset of the Chatham Rise margin at $174^{\circ} \mathrm{W}$ is a result of the collision of the Hikurangi Plateau with the Chatham Rise, and provides a constraint on the timing of motion along the WWR - the southward propagation of the WWR along the eastern edge of the Hikurangi Plateau must post-date the initial collision of the Hikurangi Plateau with the Chatham Rise (ca. $110 \mathrm{Ma}$ ) that resulted in the sinistral offset of the Chatham Rise margin at $174^{\circ} \mathrm{W}$ (Figure 5.1).

Flower structures associated with transform motion along the WWR on CHAT-3 extend through the MES sediments (Mesozoic - Figure 4.19), raising the possibility that some component of motion along the WWR persisted through to at least the 
Late Cretaceous. However, significant motion after ca. 101 Ma would require a greater amount of dextral offset of the Chatham Rise at the WWR than that observed. This suggests that the extension of the WWR through MES is a result of minor reactivation or compaction, possibly due to regional Miocene compression related to the onset of eastwards-directed subduction of the Hikurangi Plateau beneath New Zealand. 


\section{Chapter 6}

\section{Tectonic Implications and Conclusions}

\subsection{Tectonic Implications}

The results of this study require several additions to the existing model of the interaction between the Hikurangi Plateau and the Chatham Rise during the Cretaceous (Table 1.1). In this section, these findings are integrated with the existing model (Figure 6.1).

The Hikurangi Plateau is a large igneous province (LIP) which formed simultaneously with the Ontong-Java and Manihiki Plateaux (as the Ontong-Java Nui super-LIP) ca. 123 Ma (Mortimer and Parkinson, 1996, Taylor, 2006, Neal et al., 1997). Shortly after this initial volcanic stage (ca. $120 \mathrm{Ma}$ ), Ontong-Java Nui began to rift apart, with Hikurangi and Manihiki Plateaux rifting at the Osbourn Trough (Billen and Stock, 2000) (Figure 6.1). The initiation of spreading at the Osbourn Trough continued southward-orientated subduction of oceanic crust at the northern Gondwana margin, which today corresponds with the Chatham Rise. At that time, the Chatham Rise margin extended east of the margin offset at $174^{\circ} \mathrm{W}$, 
(a) 110 - $105 \mathrm{Ma}$

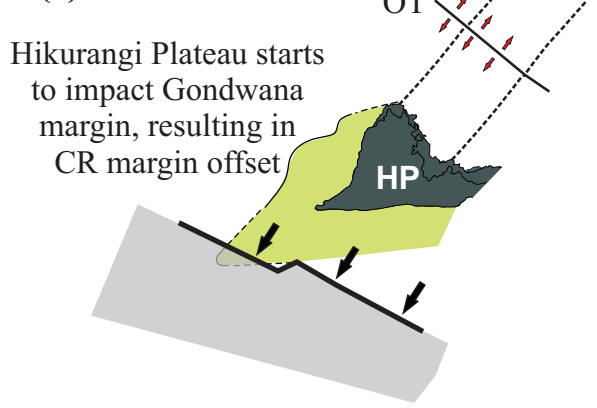

(c) 105 - $101 \mathrm{Ma}$

Slowing of subduction results in rotation of Chatham Rise segments

Accommodated by margin deformation and the westward widening of the WWR region of deformation

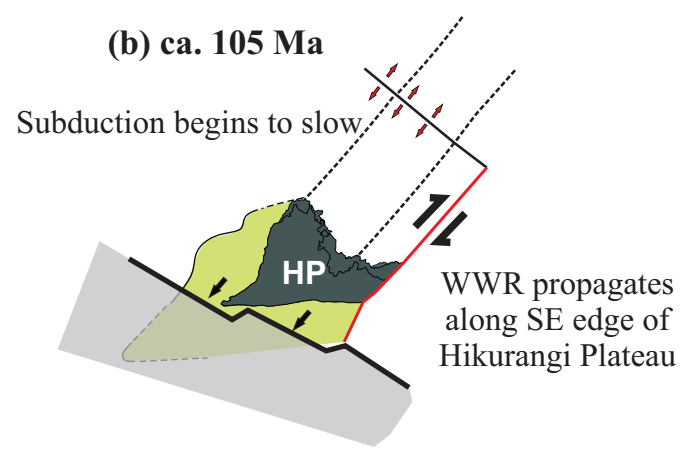

(d) ca.101 Ma

Spreading at the Osbourn Trough ceases

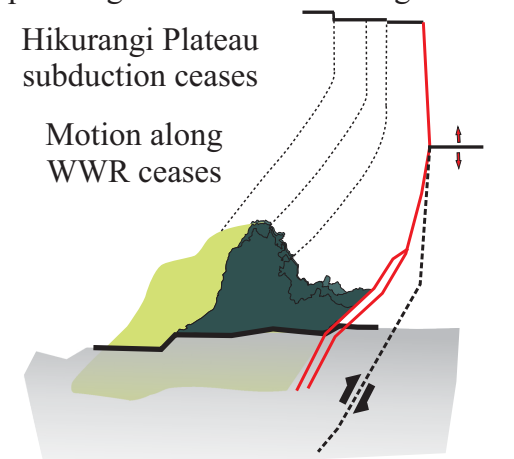

Figure 6.1: Tectonic schematic showing the revised sequence of Cretaceous motion at the intersection of the West Wishbone Ridge with the Chatham Rise. HP = Hikurangi Plateau. $\mathrm{CR}=$ Chatham Rise. OT $=$ Osbourn Trough. Sense of motion is shown by direction of arrows. Light green $=$ extension to HP proposed by Reyners et al. (2011), but still under investigation. Figure modified from Davy (2014).

likely to at least ca. $168^{\circ} \mathrm{W}$ (as discussed in Section 5.4) and probably further east along the margin now located in the Antarctic (Bradshaw, 1989, Larter et al., 2002).

Between 110 and $105 \mathrm{Ma}$, the Hikurangi Plateau entered the Gondwana margin (Davy et al., 2008, Davy, 2014, Reyners et al., 2017), resulting in uplift of the Chatham Rise and margin offset towards the south-west (Figure 5.1, Section 5.4). The eastern margin of the Hikurangi Plateau beneath the Chatham Rise is clearly delineated by variation in both the elevation of the Chatham Rise, and in the satellite gravity signature (Figure 5.1). Planing of the basement and sea floor in the seismic sections interpreted here (Figures 4.21, 4.19) indicates erosion of the uplifted Chatham Rise at sea level. The present elevation of the profiles (water depths greater than $1 \mathrm{~km}$ ) indicates that the margin has subsided. This can be 
attributed to the cooling and subsidence of the underlying Hikurangi Plateau.

At $105 \mathrm{Ma}$, subduction at the Gondwana margin began to stall, possibly as a result of the subduction of the buoyant Hikurangi Plateau (Davy et al., 2008) which was formed 15-20 million years prior (Neal et al., 1997). Sea floor spreading fabric in the vicinity of the Osbourn Trough indicates that the rate of spreading at the Osbourn Trough may have begun to slow at a similar time (Downey et al., 2007, Davy et al., 2008). East of the West Wishbone Ridge, however, sea floor spreading persisted, resulting in the southward extension of the WWR along the eastern margin of the Hikurangi Plateau. In propagating southwards, the WWR likely exploited zones of pre-existing weakness, including along the south-eastern edge of the Hikurangi Plateau where it is identified in seismic reflection data (Figures 4.19, 4.20 and $4.21)$.

From $105 \mathrm{Ma}$, subduction began to slow (rapidly onshore and more gradually offshore) (Davy, 2014). This resulted in an anticlockwise rotation of sectors of the offshore convergent margin which was accommodated by margin deformation and offshore extension zones (Davy et al., 2008), before subduction at the Gondwana margin and sea floor spreading at the Osbourn Trough ceased at ca. $101 \mathrm{Ma}$ (Zhang and Li, 2016).

Along the eastern edge of the Hikurangi Plateau, the West Wishbone Ridge was also affected by this rotation. Two sub-parallel half-grabens and the inter-linking rotated fault block can be extended northwards from the Chatham Rise to ca. $40.45^{\circ} \mathrm{S}$ (Figure 5.1). The extent of these extensional features such a distance away from the Chatham Rise margin suggests that they are WWR-related, rather than related to the Chatham Rise. The eastern of these two half-grabens has evidence of transform faulting on CHAT-3 (Figure 4.19), and is continuous with the main gravity low along the strike of the WWR. The western of the two halfgrabens can only be traced northward to ca. $40.45^{\circ} \mathrm{S}$ and does not show evidence of transform faulting in the seismic reflection profile (Figure 4.19). This indicates 
a lower level of deformation than for the eastern of the two half-grabens.

The accretionary prism structures observed on CHAT-3 are indicative of subduction along that profile. These accretionary prisms are separated by rotated block C3-RB1 (Figure 4.19). This anomalous juxtaposition of features can be explained by the westward broadening of the WWR zone of deformation to accommodate motion during the previously interpreted compression and rotation of the Chatham Rise margin between ca. 105 and 101 Ma (Davy, 2014), i.e. the rotation of faulted block C3-RB1 occurred after initial subduction along the Chatham Rise margin. From this, two interpretations are made: firstly, Cretaceous subduction along the northern Chatham Rise margin extended east of the eastern edge of the Hikurangi Plateau, and secondly, the zone of deformation associated with the WWR broadened towards the west in response to rotation of the Chatham Rise margin, resulting in the rotation of block $\mathrm{C} 3-\mathrm{RB} 1$ and its extension northwards from the Chatham Rise to $40.45^{\circ} \mathrm{S}$ (Figure 5.1).

The deformation observed in the vicinity of the intersection of the West Wishbone Ridge and the Chatham Rise (the margin offset of the Chatham Rise, the extensional half-grabens of the WWR, and the broadening of the deformation associated with the WWR near the Chatham Rise margin) is accounted for by the described sequence of motion. Consequently, it is unlikely that motion along the WWR persisted after ca. 101 Ma, when subduction of the Hikurangi Plateau beneath the Chatham Rise ceased; otherwise the far eastern Chatham Rise would have been offset further south than is observed. This implies that motion that led to the break-up of Gondwana was fed southwards through other faults east of the Chatham Rise, rather than through the WWR. 


\subsection{Conclusions}

The following is a summary of the key findings of this study:

- Seismic profiles orientated across the West Wishbone Ridge (WWR) reveal that transform motion was fed southwards along it. This is revealed through steps in the elevation of the top of the crustal basement, deep crustal shear, variation in the reflectivity of the crust on either side of a fault zone, and flower structures which offset sediments within half-grabens. Compressional faulting zones coincident with a leftward (eastward) step in the strike of the WWR at $40^{\circ} \mathrm{S}$ indicate that this motion was dextral, a finding which is consistent with previous suggestions.

- The WWR extends onto the continental crust of the Chatham Rise margin and is confidently located to $43^{\circ} \mathrm{S}$. South of this latitude, the WWR likely persists along the eastern margin of the Hikurangi Plateau, although its location is not obvious from this data.

- We suggest that the offset of the Chatham Rise margin at $174^{\circ} \mathrm{W}$ occurred as a result of the collision of the Hikurangi Plateau with the Chatham Rise between 110 and 105 Ma. Cretaceous subduction of oceanic crust beneath the Chatham Rise margin extended east of that margin offset.

- At the intersection of the WWR with the Chatham Rise, extensional tectonics dominate. We suggest that the zone of deformation associated with the WWR broadened towards the west to accommodate the previously suggested anti-clockwise rotation of the Chatham Rise, between ca. 105 and 101 Ma.

- The amount of offset of the Chatham Rise margin, and the deformation along the WWR indicates that significant motion along the WWR likely did not persist beyond ca. $101 \mathrm{Ma}$, when subduction along the Gondwana margin ceased. Consequently, motion along the WWR south of $\sim 40.5^{\circ}$ is unlikely 
to have contributed to the rifting of the Gondwana super-continent.

- Anomalously thick $(12.9 \mathrm{~km})$ oceanic crust is identified along the WWR, south of its intersection with the Louisville Seamount Chain. This is interpreted to be a result of proximity of the Osbourn Trough spreading centre to anomalously hot mantle adjacent to the mantle plume which is thought to have formed Ontong-Java Nui.

- We find that the Hikurangi Plateau has an abrupt south-eastern boundary. This corresponds with recent suggestion of additional fragments of the Ontong-Java Nui super-LIP extending east of the Hikurangi and Manihiki plateaux, which rifted during the initial rifting stage.

\subsection{Suggestions for future work}

Several existing seismic reflection profiles in the vicinity of the intersection of the WWR with the Chatham Rise may help to provide a greater constraint on the dispersal of Cretaceous motion along the WWR at the Chatham Rise margin. These include NIWA-2037 (which runs through ODP site 1123), HKDC-9 (which runs along the strike of the WWR), and AWI-20160003 (which runs parallel to AWI-20160004, south of that profile). AWI-20160003 was also shot as refraction profile AWI-20160200. That refraction profile (and others which were acquired during the SO-246 voyage of R/V Sonne) will better constrain the crustal thickness of the Chatham Rise. 


\section{Bibliography}

Angevine, C. L., Heller, P. L., and Paola, C. (1990). Quantitative Sedimentary Basin Modeling. Technical report, American Association of Petroleum Geologists.

Ball, J. S., Sheehan, A. F., Stachnik, J. C., Lin, F.-C., Yeck, W. L., and Collins, J. A. (2016). Lithospheric shear velocity structure of South Island, New Zealand, from amphibious Rayleigh wave tomography. Journal of Geophysical Research: Solid Earth, 121:3686-3702.

Beier, C., Vanderkluysen, L., Regelous, M., Mahoney, J. J., and Garbe-Schönberg, D. (2011). Lithospheric control on geochemical composition along the Louisville Seamount Chain. Geochemistry, Geophysics, Geosystems, 12(9):119.

Billen, M. I. and Stock, J. M. (2000). Morphology and origin of the Osbourn Trough. Journal of Geophysical Research, 105(B6):481-489.

Bland, K. J., Uruski, C. I., and Isaac, M. J. (2015). Pegasus Basin, eastern New Zealand: A stratigraphic record of subsidence and subduction, ancient and modern. New Zealand Journal of Geology and Geophysics, 58(4):319-343.

Bradshaw, J. D. (1989). Cretaceous Geotectonic Patterns in the New Zealand region. Tectonics, 8(4):803-820.

Carlson, R. L. and Herrick, C. N. (1990). Densities and porosities in the oceanic crust and their variations with depth and age. Journal of Geophysical Research, 95(B6):9153-9170.

Carter, L., Carter, R. M., and McCave, I. N. (2004). Evolution of the sedimentary system beneath the deep Pacific inflow off eastern New Zealand. Marine Geology, 205(1-4):9-27.

Carter, R. M., McCave, I. N., Richter, C., Carter, L., and Participants (1999a). Site 1123: North Chatham Drift - a 20-Ma record of the Pacific Deep West- 
ern Boundary Current. Proceedings of the Ocean Drilling Program, Initial Reports, Leg 181, 181:1-184.

Carter, R. M., McCave, I. N., Richter, C., Carter, L., and Participants (1999b). Site 1124: Rekohu Drift - from the K/T boundary to the Deep Western Boundary Current. Proceedings of the Ocean Drilling Program, Initial Reports, Leg 181, 181:1-137.

Chandler, M. T., Wessel, P., Taylor, B., Seton, M., Kim, S. S., and Hyeong, K. (2012). Reconstructing Ontong Java Nui: Implications for Pacific absolute plate motion, hotspot drift and true polar wander. Earth and Planetary Science Letters, 331-332:140-151.

Clark, D. and Emerson, D. (1991). Notes on Rock Magnetization Characteristics in Applied Geophysical Sciences. Exploration Geophysics, 22:547-555.

Cunningham, W. and Mann, P. (2007). Tectonics of strike-slip restraining and releasing bends. Geological Society, London, Special Publications, 290:1-12.

Davy, B. (2014). Rotation and offset of the Gondwana convergent margin in the New Zealand region following Cretaceous jamming of Hikurangi Plateau large igneous province subduction. Tectonics, 33:1-19.

Davy, B., Hoernle, K., and Werner, R. (2008). Hikurangi Plateau: Crustal structure, rifted formation, and Gondwana subduction history. Geochemistry, Geophysics, Geosystems, 9(7):1-31.

DeMets, C., Gordon, R., Argus, D., and Stein, S. (1994). Effect of recent revisions to the geomagnetic reversal time scale on estimates of current plate motions. Geophysical Research Letters, 21:2191-2194.

Detrick, R., Collins, J. A., Stephen, R., and Swift, S. (1994). In situ evidence for the nature of the seismic layer $2 / 3$ boundary in oceanic crust. Nature, 370(6487):288-290.

Dix, C. H. (1955). Seismic velocities from surface measurements. Geophysics, 20:68-86.

Dobrin, M. (1976). Introduction to geophysical prospecting. McGraw-Hill, New York, 3rd edition.

D'Onfro, P. and Glagola, P. (1983). Wrench Fault, Southeast Asia. Studies in Geology 15, Volume 3: Seismic Expression of Structural Styles: A Picture and Work Atlas. 
Downey, N. J., Stock, J. M., Clayton, R. W., and Cande, S. C. (2007). History of the Cretaceous Osbourn spreading center. Journal of Geophysical Research: Solid Earth, 112(4):1-18.

Fowler, C. M. R. (2005). The Solid Earth: An Introduction to Global Geophysics. Cambridge University Press, first edition.

Gladczenko, T. P., Coffin, M. F., and Eldholm, O. (1997). Crustal structure of the Ontong Java Plateau: Modeling of new gravity and existing seismic data. Journal of Geophysical Research, 102(B10):22711-22729.

Gohl, K., Werner, R., and Participants (2016). The Expedition SO246 of the Research Vessel SONNE to the Chatham Rise in 2016. Technical report, Alfred-Wegener-Institut, Bremerhaven, Germany.

Hampson, D. (1986). Inverse velocity stacking for multiple elimination. J.Can.Soc.Expl. Geophysics, 22(1):44-55.

Hochmuth, K. and Gohl, K. (2017). Collision of Manihiki Plateau fragments to accretional margins of northern Andes and Antarctic Peninsula. Tectonics, $36: 1-12$.

Hochmuth, K., Gohl, K., and Uenzelmann-Neben, G. (2015). Playing jigsaw with Large Igneous Provinces -A plate tectonic reconstruction of Ontong Java Nui, West Pacific. Geochemistry, Geophysics, Geosystems, 16:3789-3807.

Hoernle, K. and Participants (2003). Cruise Report SO168: Zealandia-Causes and effects of plume and rift-related Cretaceous and Cenozoic volcanism on Zealandia, GEOMAR Rep. 113. Technical report, Center for Marine Geoscience, GEOMAR, Kiel, Germany.

Hoernle, K., White, J. D. L., van den Bogaard, P., Hauff, F., Coombs, D. S., Werner, R., Timm, C., Garbe-Schönberg, D., Reay, A., and Cooper, A. F. (2006). Cenozoic intraplate volcanism on New Zealand: Upwelling induced by lithospheric removal. Earth and Planetary Science Letters, 248(1-2):335352 .

Houtz, R. and Ewing, J. (1976). Upper crustal structure as a function of plate age. Journal of Geophysical Research, 81(14):2490-2498.

Kearey, P., Brooks, M., and Hill, I. (2002). An Introduction to Geophysical Exploration. Blackwell Publishing, third edition.

Kodaira, S., Fujie, G., Yamashita, M., Sato, T., and Takahashi, T. (2014). Seis- 
mological evidence of mantle flow driving plate motions at a palaeo-spreading centre. Nature Geoscience, 7(5):371-375.

Laird, M. G. and Bradshaw, J. D. (2004). The Break-up of a Long-term Relationship: the Cretaceous Separation of New Zealand from Gondwana. Gondwana Research, 7(1):273-286.

Larter, R. D., Cunningham, A. P., Barker, P. F., Gohl, K., and Nitsche, F. O. (2002). Tectonic evolution of the Pacific margin of Antarctica 1. Late Cretaceous tectonic reconstructions. Journal of Geophysical Research, 107(B12):2345.

Le Pichon, X., Angelier, J., and Sibuet, J.-C. (1982). Plate Boundaries and Extensional Tectonics. Tectonophysics, pages 239-256.

Luyendyk, B. P. (1995). Hypothesis for Cretaceous rifting of east Gondwana caused by subducted slab capture. Geology, 23(4):373-376.

Mahoney, J. J., Storey, M., Duncan, R. A., Spencer, K., and Pringle, M. (1993). Geochemistry and Age of the Ontong Java Plateau. The Mesozoic Pacific: Geology, Tectonics, and Volcanism, Geophysica:223-261.

Mann, P. and Taira, A. (2004). Global tectonic significance of the Solomon Islands and Ontong Java Plateau convergent zone. Tectonophysics, 389(3-4 SPEC.ISS.):137-190.

Maslen, G. (2016). Personal Communication.

Miura, S., Suyehiro, K., Shinohara, M., Takahashi, N., Araki, E., and Taira, A. (2004). Seismological structure and implications of collision between the Ontong Java Plateau and Solomon Island Arc from ocean bottom seismometerairgun data. Tectonophysics, 389(3-4 SPEC.ISS.):191-220.

Molnar, P. (1988). Continental tectonics in the aftermath of plate tectonics. Nature, 335(6186):131-137.

Mortimer, N., Hoernle, K., Hauff, F., Palin, J. M., Dunlap, W. J., Werner, R., and Faure, K. (2006). New constraints on the age and evolution of the Wishbone Ridge, southwest Pacific Cretaceous microplates, and Zealandia - West Antarctica breakup. Geology, 34(3):185-188.

Mortimer, N. and Parkinson, D. (1996). Hikurangi Plateau: A Cretaceous large igneous province in the southwest Pacific Ocean. Journal of Geophysical Research, 101(B1):687. 
Müller, R. D., Sdrolias, M., Gaina, C., and Roest, W. R. (2008). Age, spreading rates, and spreading asymmetry of the world's ocean crust. Geochemistry, Geophysics, Geosystems, 9(4):1-19.

Neal, C. R., Mahoney, J. J., Kroenke, L. W., Duncan, R. A., and Petterson, M. G. (1997). The Ontong Java Plateau. Large Igenous Provinces: Continental, Oceanic, and Planetary Floord Volcanism, Geophysical Monograph, 100:183216.

Nettleton, L. L. (1942). Gravity and Magnetic Calculations. Geophysics, 7(3):293310.

Onajite, E. (2014). Seismic Data Analysis Techniques in Hydrocarbon Exploration. Elsevier, Oxford, UK.

Panter, K. S., Blusztajn, J., Hart, S. R., Kyle, P. R., Esser, R., and McIntosh, W. C. (2006). The origin of HIMU in the SW Pacific: Evidence from intraplate volcanism in Southern New Zealand and Subantarctic Islands. Journal of Petrology, 47(9):1673-1704.

Peacock, K. L. and Treitel, S. (1969). Predictive Deconvolution: Theory and Practice. Geophysics, 34:155-169.

Pietsch, R. and Uenzelmann-Neben, G. (2015). The Manihiki Plateau - A multistage volcanic emplacement history. Geochemistry Geophysics Geosystems, $16: 2480-2498$.

Ravens, J. M. (1995). Globe Claritas: seismic processing software manual. Technical report, Institute of Geological and Nuclear Sciences science report 95/43, Wellington.

Reyners, M., Eberhart-Phillips, D., and Bannister, S. (2011). Tracking repeated subduction of the Hikurangi Plateau beneath New Zealand. Earth and Planetary Science Letters, 311(1-2):165-171.

Reyners, M., Eberhart-Phillips, D., Upton, P., and Gubbins, D. (2017). Threedimensional imaging of impact of a large igneous province with a subduction zone. Earth and Planetary Science Letters, 460:143-151.

Reynolds, J. M. (1997). An Introduction to Applied and Environmental Geophysics. John Wiley \& Sons, West Sussex, England, first edition.

Robertson Reseach (2002). UNCLOS Deep MCS Processing Report for Institute 
of Geological and Nuclear Sciences Limited. Technical report, Robertson Research, Perth, Australia.

Rothery, D. (2004). The Ocean Basins: Their Structure and Evolution. The Open University, Walton Hall, Milton Keynes, 2nd edition.

Sandwell, D. T., Müller, R. D., Smith, W. H. F., Garcia, E., and Francis, R. (2014). New global marine gravity model from CryoSat-2 and Jason-1 reveals buried tectonic structure. Science (New York, N.Y.), 346(6205):65-7.

Sandwell, D. T. and Smith, W. H. F. (1992). Global marine gravity from ERS-1, GEOSAT, and SEASAT reveals new tectonic fabric [abs.]: Eos (Transactions, American Geophysical Union), v. 73.

Sauter, D., Unternehr, P., Manatschal, G., Tugend, J., Cannat, M., Quellec, P. L., Kusznir, N., Munschy, M., Leroy, S., de Lepinay, J. M., Granath, J. W., Horn, B. W., and Ridge, D. (2016). Evidence for magma entrapment below oceanic crust from deep seismic reflections in the Western Somali Basin. Geology, 44(6):407-410.

Seher, T., Crawford, W. C., Singh, S. C., and Cannat, M. (2010). Seismic layer 2A variations in the Lucky Strike segment at the Mid-Atlantic Ridge from reflection measurements. Journal of Geophysical Research: Solid Earth, 115(7):120 .

Sibuet, J.-C., Le Pichon, X., and Goslin, J. (1974). Thickness of lithosphere deduced from gravity edge effects across the Mendocino fault. Nature, 252(5485):676-679.

Stewart, P. G., Jones, I. F., and Hardy, P. B. (2007). Solutions for Deep Water Imaging. Technology.

Sutherland, R. (1999). Basement geology and tectonic development of the greater New Zealand region: An interpretation from regional magnetic data. Tectonophysics, 308(3):341-362.

Sutherland, R. and Hollis, C. (2001). Cretaceous demise of the Moa plate and strike-slip motion at the Gondwana margin. Geology, 29(3):279-282.

Sutherland, R., Spasojevic, S., and Gurnis, M. (2010). Mantle upwelling after Gondwana subduction death explains anomalous topography and subsidence histories of eastern New Zealand and west Antarctica. Geology, 38(2):155158. 
Taylor, B. (2006). The single largest oceanic plateau: Ontong Java-ManihikiHikurangi. Earth and Planetary Science Letters, 241(3-4):372-380.

Thinon, I., Matias, L., Rehault, J., Hirn, A., Fidalgo-Gonzalez, L., and Avedik, F. (2003). Deep structure of the Armorican Basin (Bay of Biscay): a review of Norgasis seismic reflection and refraction data. Journal of the Geological Society, 160(1):99-116.

Van Avendonk, H. J. A., Lavier, L. L., Shillington, D. J., and Manatschal, G. (2009). Extension of continental crust at the margin of the eastern Grand Banks, Newfoundland. Tectonophysics, 468(1-4):131-148.

Verschuur, D. J., Berkhout, A. J., and Wapenaar, C. P. A. (1992). Adaptive surface-related multiple elimination. Geophysics, 57(09):1166-1177.

Wang, Y. (2003). Multiple subtraction using an expanded multichannel matching filter. Geophysics, 68(1):346-354.

Wessel, P., Smith, W. H. F., Scharroo, R., Luis, J. F., and Wobbe, F. (2013). Generic Mapping Tools: Improved version released. EOS Trans. AGU, 94:409410.

White, R. S., McKenzie, D., and O'Nions, R. K. (1992). Oceanic Crustal Thickness From Seismic Measurements and Rare Earth Element Inversions. Journal of Geophysical Research, 97(B13):19,683-19,715.

Wood, R. A. and Anderson, H. J. (1989). Basement structure at the Chatham Islands. Journal of the Royal Society of New Zealand, 19(3):269-282.

Wood, R. A., Andrews, P., Herzer, R. H., and Others (1989). Cretaceous and Cenozoic geology of the Chatham Rise region, South Island, New Zealand. New Zealand Geological Survey Basin Studies 3.

Wood, R. A. and Davy, B. (1994). The Hikurangi Plateau. Marine Geology, 118(1-2):153-173.

Worthington, T. J., Hekinian, R., Stoffers, P., Kuhn, T., and Hauff, F. (2006). Osbourn Trough: Structure, geochemistry and implications of a mid-Cretaceous paleospreading ridge in the South Pacific. Earth and Planetary Science Letters, 245(3-4):685-701.

Yilmaz, O. (2001). Seismic Data Analysis: Processing, Inversion and Interpretation of Seismic data. Society of Exploration Geophysicists, Tulsa, USA, second edition. 
Zhang, G.-L. and Li, C. (2016). Interactions of the Greater Ontong Java mantle plume component with the Osbourn Trough. Scientific Reports, 6:37561. 


\section{Appendix A}

\section{Seismic reflection processing sequence for CHAT-3 and CHAT-4}

Seismic reflection profiles CHAT-3 and CHAT-4 were collected on behalf of GNS Science by MV Geco Resolution in 2001. These profiles were processed by Robertson Research (Perth, Australia). A full description of the processing parameters applied to these profiles is available in their processing report (Robertson Reseach, 2002). Summaries of the acquisition and processing parameters are shown in Table A.1 and Figure A.1, respectively. 
Table A.1: Seismic acquisition parameters for profiles CHAT-3 and CHAT-4 collected by M/V Geco Resolution during the New Zealand stage of the UNCLOS project in 2001.

\begin{tabular}{|c|c|}
\hline Source & $\begin{array}{l}\text { Airgun array with a total volume of } 8204 \mathrm{in}^{3} / 134.4 \\
\text { litres }\end{array}$ \\
\hline Average source depth & $7 \mathrm{~m}$ \\
\hline Shot interval & $50 \mathrm{~m}$ \\
\hline Nominal operating pressure & 2000 psi/138 bars \\
\hline Seismic streamer & $6000 \mathrm{~m}$ active length \\
\hline Hydrophones & 480 at $12.5 \mathrm{~m}$ spacings \\
\hline Streamer depth & $10-16 \mathrm{~m}$ \\
\hline Near group number & 1 \\
\hline $\begin{array}{l}\text { First hydrophone offset } \\
\text { from source }\end{array}$ & $210-229 \mathrm{~m}$ \\
\hline Initial sampling rate & $2 \mathrm{~ms}$, resulting in $250 \mathrm{~Hz}$ Nyquist frequency \\
\hline Record length & $16.384 \mathrm{~s}$ \\
\hline Filters & $\begin{array}{l}\text { Low: } 3 \mathrm{~Hz} \text { at } 18 \mathrm{~dB} / \text { Oct } \\
\text { High: } 200 \mathrm{~Hz} \text { at } 406 \mathrm{~dB} / \mathrm{Oc}\end{array}$ \\
\hline Recording system & Triacq $1.6 \mathrm{c}$ \\
\hline Storage format & SEG-D 8015 \\
\hline Average shooting direction & $\begin{array}{l}\text { CHAT-4: } 77^{\circ} \\
\text { CHAT-3: } 143^{\circ}\end{array}$ \\
\hline Total Profile length & $\begin{array}{l}\text { CHAT-4: } 117.70 \mathrm{~km} \\
\text { CHAT-3: } 170.05 \mathrm{~km}\end{array}$ \\
\hline
\end{tabular}




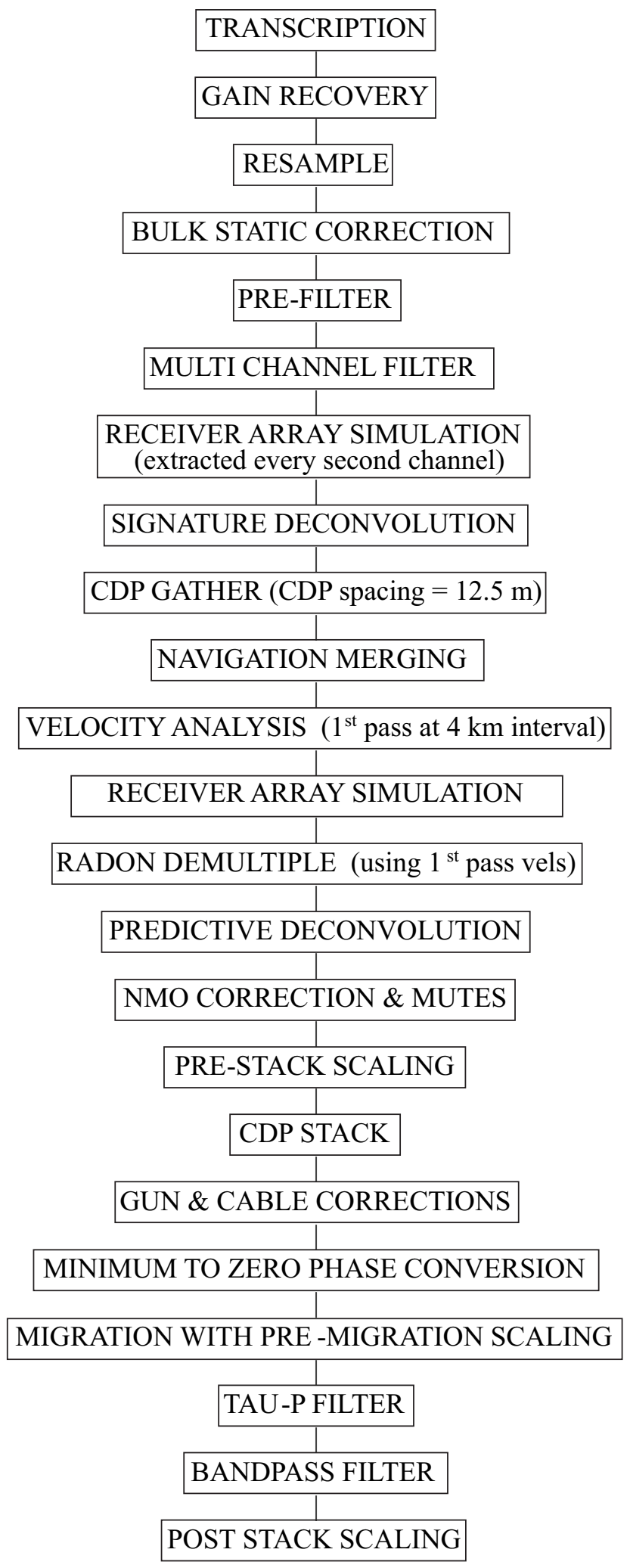

Figure A.1: Generalised production processing sequence for UNCLOS Deep MCS seismic reflection processing (including profiles CHAT-3 and CHAT-4) developed and applied by Robertson Reseach (2002). 
130APPENDIX A. SEISMIC REFLECTION PROCESSING SEQUENCE FOR CHAT-3 AND CHAT-4 


\section{Appendix B}

\section{Magnetic data}

A Seaspy Overhauser marine magnetometer was deployed while seismic reflection lines AWI-20160004 and AWI-20160006 were collected during voyage SO-246. The data were recorded at $0.5 \mathrm{~s}$ intervals and then decimated to a $10 \mathrm{~s}$ interval to coincide with GPS records of location. The total magnetic anomaly was calculated by subtracting the International Geomagnetic Reference Field from this decimated dataset (Gohl et al., 2016).

Thanks to Bryan Davy for processing this data. 


\section{Appendix C}

\section{Isostatic mass balancing for gravity modelling}

The principle of isostasy indicates that below a certain compensation depth, the weight of adjacent columns of rock should be equal to each other (Angevine et al., 1990). In order for gravity models to be geologically feasible, it is important that they are balanced. In this study, a compensation depth of $50 \mathrm{~km}$ was assumed. Isostatic mass balancing columns were constructed at the end-points of each modelled profile. For the profiles which cross from the Hikurangi Plateau onto the continental crust of the Chatham Rise, these calculations were used to find the thickness of the Hikurangi Plateau when the continental crust of the Chatham Rise at the SE end of the profile was set to be $15 \mathrm{~km}$. The following figures show the isostatic mass balancing columns constructed for each of the profiles studied here. 


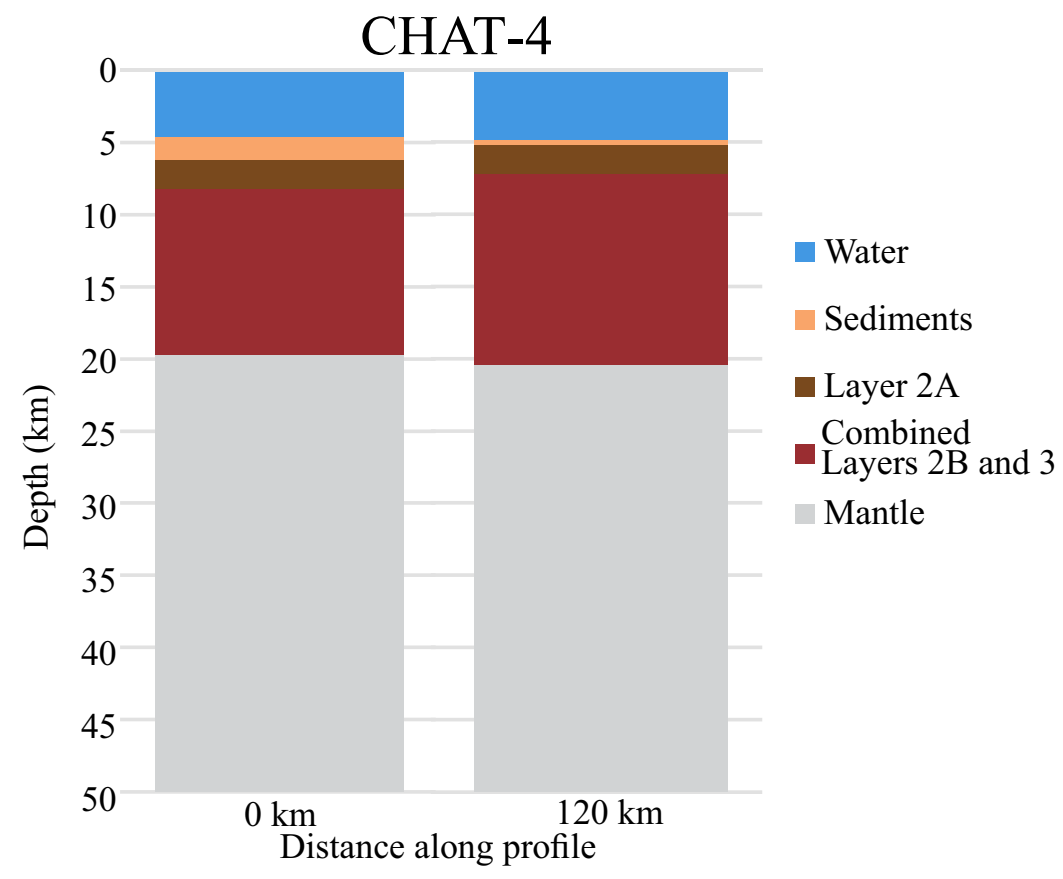

Figure C.1: Isostatic mass balancing columns constructed for the $\mathrm{E}$ and $\mathrm{W}$ ends of CHAT-4.

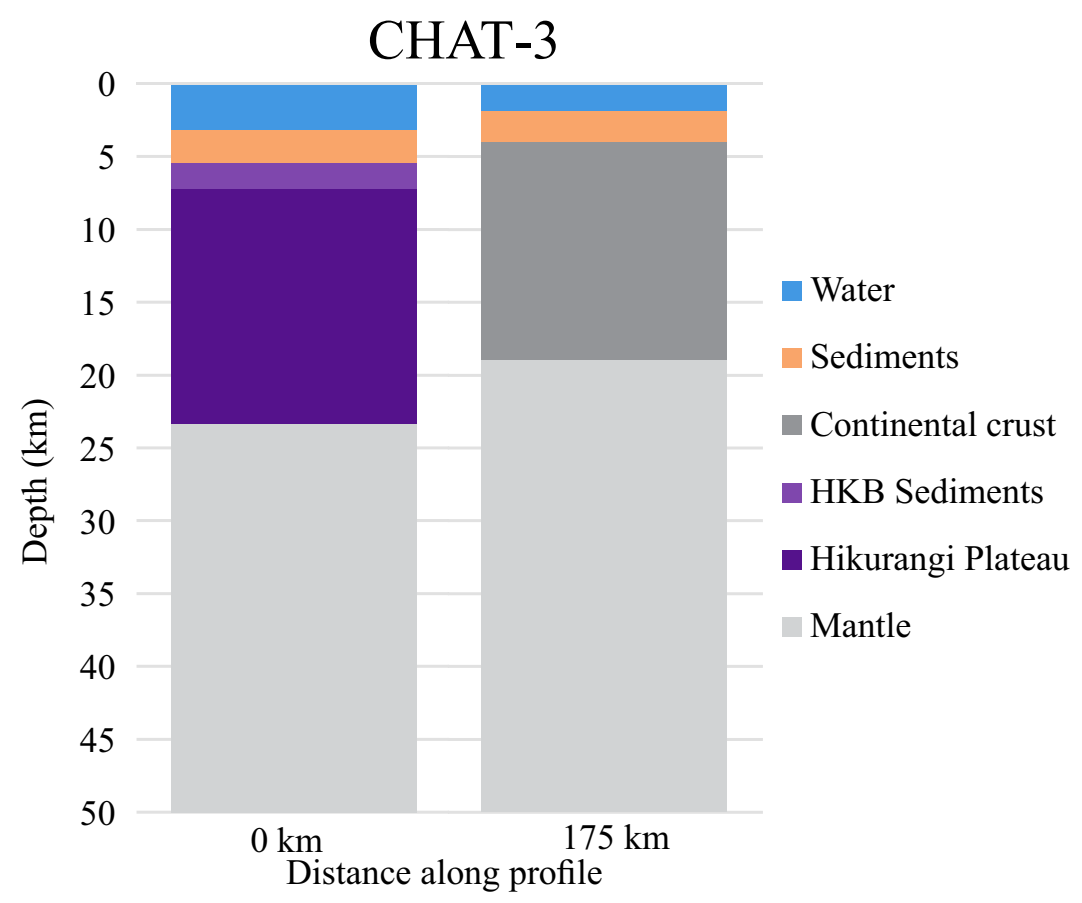

Figure C.2: Isostatic mass balancing columns constructed for the SE and NW ends of CHAT-3. 


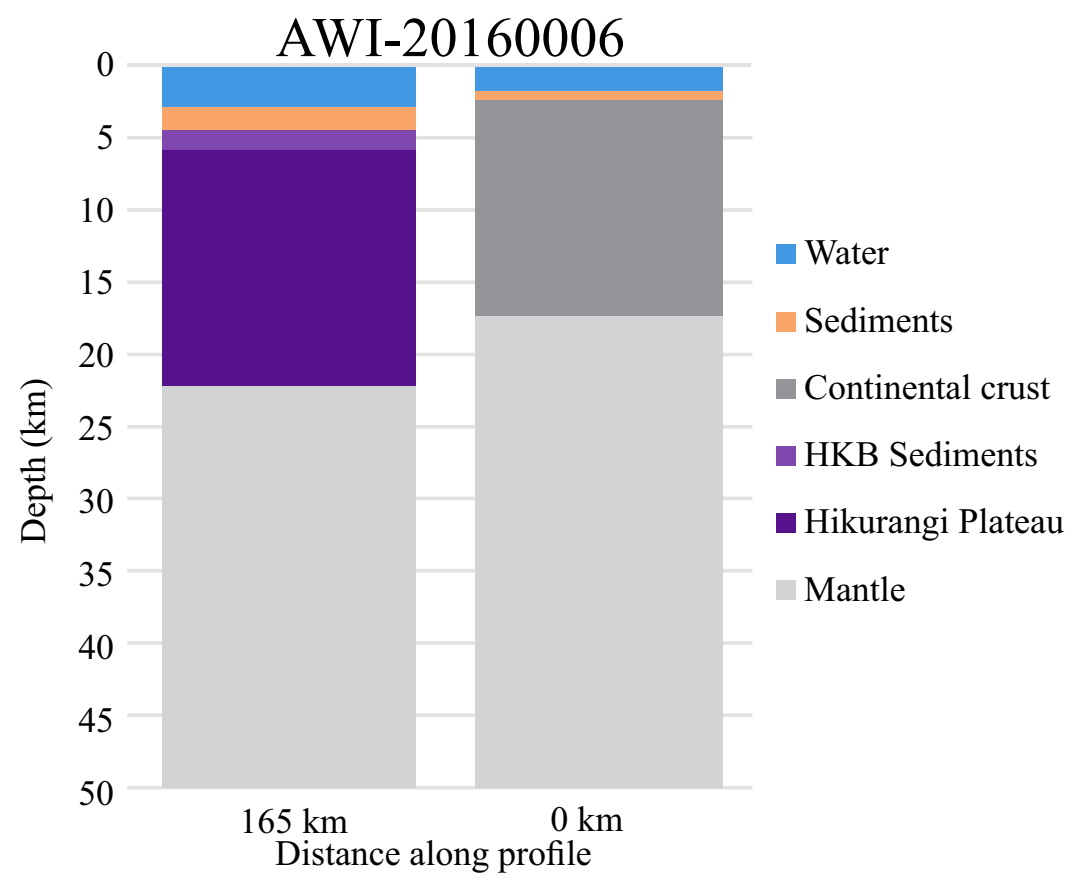

Figure C.3: Isostatic mass balancing columns constructed for the SE and NW ends of AWI-20160006.

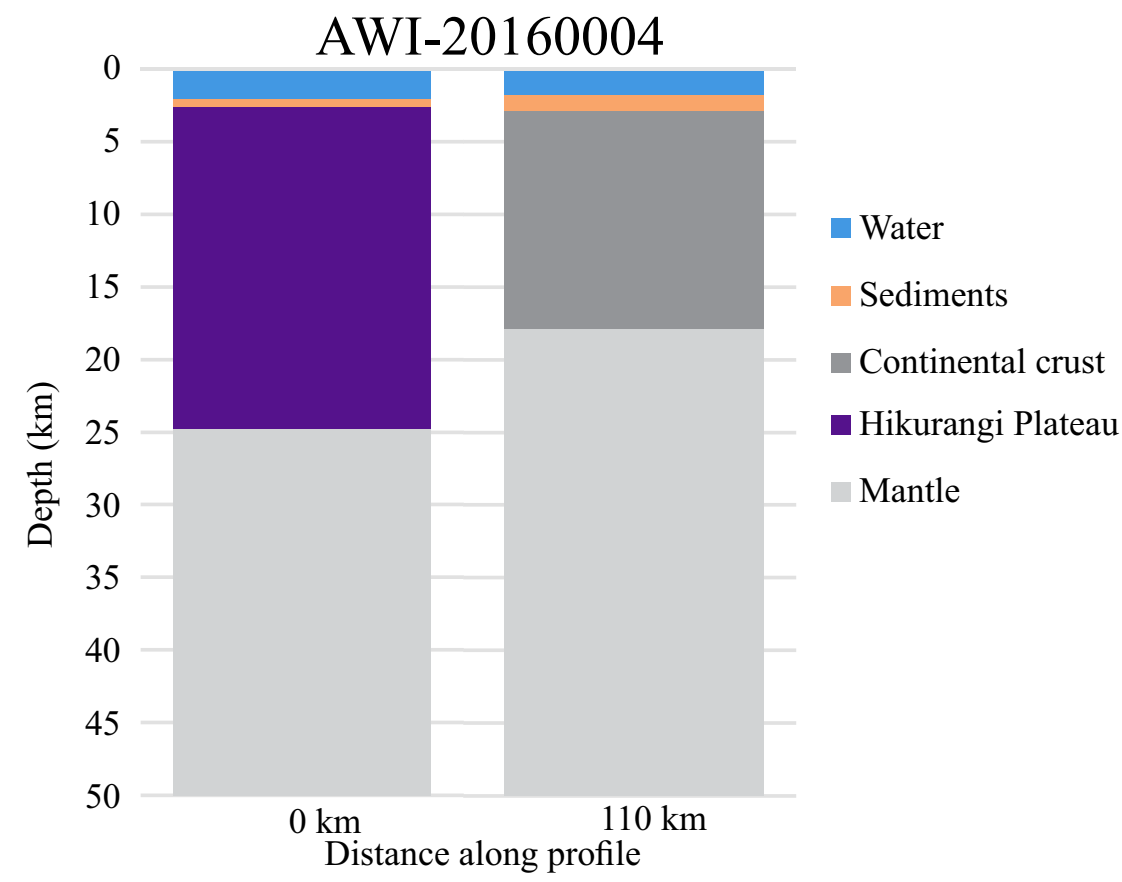

Figure C.4: Isostatic mass balancing columns constructed for the SE and NW ends of AWI-20160004. 
136APPENDIX C. ISOSTATIC MASS BALANCING FOR GRAVITY MODELLING 
Appendix D

Final migrated seismic reflection profiles 